\title{
PROCESSAMENTO PARALELO NA SIMULAÇÃO DE CAMPOS ELETROMAGNÉTICOS PELO MÉTODO DAS DIFERENÇAS FINITAS NO DOMINIO DO TEMPO - FDTD
}

Dissertação apresentada à Escola Politécnica da Universidade de São Paulo para obtenção do título de Mestre em Engenharia 


\section{PROCESSAMENTO PARALELO NA SIMULAÇÃO DE CAMPOS ELETROMAGNÉTICOS PELO MÉTODO DAS DIFERENÇAS FINITAS NO DOMÍNIO DO TEMPO - FDTD}

Dissertação apresentada à Escola Politécnica da Universidade de São Paulo para obtenção do título de Mestre em Engenharia

Área de concentração:

Sistemas Eletrônicos

Orientador:

Jorge Mieczyslaw Janiszewski 
AUTORIZO A REPRODUÇÃO E DIVULGAÇÃO TOTAL OU PARCIAL DESTE TRABALHO, POR QUALQUER MEIO CONVENCIONAL OU ELETRÔNICO, PARA FINS DE ESTUDO E PESQUISA, DESDE QUE CITADA A FONTE.

Este exemplar foi revisado e alterado em relação à versão original, sob responsabilidade única do autor $\mathrm{e}$ com a anuência de seu orientador.

São Paulo, 06 de fevereiro de 2007.

Assinatura do autor

Assinatura do orientador

FICHA CATALOGRÁFICA

Trevizan, Marcelo Porto

Processamento paralelo na simulação de campos eletromagnéticos pelo método das diferenças finitas no domínio do tempo - FDTD / M.P. Trevizan. --- ed.rev. -- São Paulo, 2007.

p.

Dissertação (Mestrado) - Escola Politécnica da Universidade de São Paulo. Departamento de Engenharia de Telecomunicações e Controle.

1.Campo eletromagnético (Simulação) 2.Diferenças finitas I.Universidade de São Paulo. Escola Politécnica. Departamento de Engenharia de Telecomunicações e Controle II.t. 


\section{FOLHA DE APROVAÇÃO}

Marcelo Porto Trevizan

Processamento paralelo na simulação de campos eletromagnéticos pelo método das diferenças finitas no domínio do tempo - FDTD

Dissertação apresentada à Escola Politécnica da Universidade de São Paulo para obtenção do título de Mestre em Engenharia

Área de concentração:

Sistemas Eletrônicos

Aprovado em: 08 de janeiro de 2007

\section{Banca Examinadora}

Prof. Dr. Jorge Mieczyslaw Janiszewski

Instituição: Universidade de São Paulo Assinatura:

Prof. Dr. Plínio Francisco dos Santos Rodrigues

Instituição: Universidade de São Paulo Assinatura:

Prof. Dr. Eduardo Víctor dos Santos Pouzada

Instituição: Escola de Engenharia Mauá Assinatura: 
Aos familiares e amigos. 


\section{AGRADECIMENTOS}

A todos que, direta ou indiretamente, contribuíram para a realização do presente trabalho.

Em especial, ao orientador Prof. Dr. Jorge Mieczyslaw Janiszewski por todo seu apoio, compreensão e empenho.

Aos amigos da Escola de Engenharia Mauá e, entre eles, o Prof. Dr. Augusto Carlos Pavão, ao Prof. Dr. Márcio Mathias, ao Prof. Mestre Everson Dênis e ao Prof. Dr. Eduardo V. S. Pouzada, pelos apoios e pelas colaborações oferecidas.

Ao Instituto Mauá de Tecnologia pela disponibilização dos recursos para a realização do trabalho.

E aos demais amigos e familiares, que em muito contribuem no dia-a-dia. 


\section{Sumário}

Lista de Figuras $\quad$ iv

Lista de Tabelas $\quad$ ix

Lista de Siglas $\quad$ xi

Lista de Símbolos $\quad$ xiv

Resumo $\quad$ xvii

"Abstract" xviii

1 INTRODUÇÃO 1

1.1 Revisão Bibliográfica ................... 5

2 BASES DO ESTUDO 17

2.1 Formulação Matemática . . . . . . . . . . . . . . . . . . 17

2.1.1 Diferenças Finitas . . . . . . . . . . . . . . . 18

2.1.2 O Método das Diferenças Finitas no Domínio do Tempo . . 18

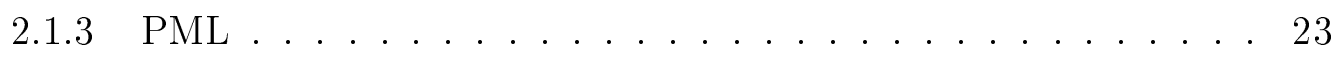

2.2 Tecnologia e Recursos: Panoramas Gerais . . . . . . . . . . . . . . 26

2.2.1 Breve Histórico dos Recursos Tecnológicos Atuais e do Processamento Paralelo . . . . . . . . . . . . . 27

2.2.2 Arquiteturas de Computador e Sistemas de Processamento . . 29 
2.2 .3 Periféricos de Rede . . . . . . . . . . . . . . . . . . . . . 30

2.2 .4 Topologias de Redes . . . . . . . . . . . . . . . . . . . . 32

2.2.5 Topologias de Processamento Paralelo . . . . . . . . . . . . 32

2.2.6 Recursos Computacionais . . . . . . . . . . . . . . 33

2.3 Técnicas de Programação _ . . . . . . . . . . . . . . . . . . . 33

2.3 .1 Apresentação . . . . . . . . . . . . . . . . . . . 33

2.3.2 Boas Práticas de Programação . . . . . . . . . . . . . . 36

2.3.3 Nota sobre a Programação Orientada a Objeto . . . . . . . . . 39

3 "PARADIGMAS" E SOLUÇÕES 40

3.1 Vantagens e Desvantagens do FDTD . . . . . . . . . . . . . . 40

3.2 Processamento Paralelo . . . . . . . . . . . . . . . . . . . . . . . . . . 42

3.3 Implementação do Programa . . . . . . . . . . . . . . . . . . . . 43

3.4 O Uso de Outros Métodos Numéricos . . . . . . . . . . . . . . . . . 44

3.5 Considerações para o Uso do FDTD . . . . . . . . . . . . . . . . 45

3.6 Problemas de Eletromagnetismo que Justificam o Paralelismo . . . . 47

4 DESENVOLVIMENTOS $\quad 49$

4.1 Proposta . . . . . . . . . . . . . . . . . . . . . . . . . . 49

4.2 Metodologia . . . . . . . . . . . . . . . . . . 50

4.3 Ambiente e Ferramentas . . . . . . . . . . . . . . . . . . . . 51

4.4 Processamento Paralelo . . . . . . . . . . . . . . . . . . . 53

4.4 .1 Características . . . . . . . . . . . . . 53

4.4.2 Uso da Biblioteca de Comunicação LAM/MPI . . . . . . . . . 54

4.5 Recursos do Programa . . . . . . . . . . . . . . . . . . 61

4.6 Uso do Programa . . . . . . . . . . . . . . . . . . . . . . . . . . 66

4.7 O Método FDTD Paralelizado: Algoritmos do Programa . . . . . . . 68

4.7.1 Algoritmo Global . . . . . . . . . . . . . . . . . . . 68

4.7.2 Algoritmo do Programa Principal . . . . . . . . . . . . . . . 69 
4.7.3 Algoritmo do Carregamento e Distribuição do Meio Físico . 72

4.7.4 Algoritmo do Laço do Método FDTD . . . . . . . . . . . . . . 74

4.7.5 Algoritmo da Implementação da PML . . . . . . . . . . . . . 78

4.7.6 Algoritmo da Transferência dos Dados . . . . . . . . . . . . . 83

4.7.7 Algoritmo da Aplicação da Fonte . . . . . . . . . . . . . . 86

4.7.8 Algoritmo do Agrupamento dos Dados dos Resultados . . . . 93

4.8 Estimativas Matemáticas . . . . . . . . . . . . . . . . 95

4.8.1 Equacionamento dos Tempos Envolvidos . . . . . . . . . . . 95

4.8.2 Análises da Influência das Topologias nos Tempos . . . . . . . 101

4.8.3 Ganho e Eficiência . . . . . . . . . . . . . . . 107

4.8.4 Memória Requisitada . . . . . . . . . . . . . . . . . . . 109

5 APLICAÇÕES

5.1 Validação do Código . . . . . . . . . . . . . . . . . . . 111

5.2 Validação das Estimativas Matemáticas e Análises de Desempenho do Sistema Paralelizado . . . . . . . . . . . . . . . . . 112

5.3 Nota sobre a Funcionalidade do Paralelismo . . . . . . . . . . . . 125

5.4 Ensaio para o Estudo de uma Aplicação Prática - Descargas Atmosféricas em Regiões com Edifícios . . . . . . . . . . . . . . . . 126

6 CONCLUSÕES

134

$\begin{array}{ll}\text { Referências Bibliográficas } & 137\end{array}$ 


\section{Lista de Figuras}

2.1 Exemplo de um diagrama de Nassi-Schneidermann. Percebe-se que a lógica é representada de forma bastante estruturada e, por isso, este diagrama torna-se uma ferramenta útil para a programação estruturada. 34

2.2 Exemplo de um fluxograma. A lógica apresentada é a mesma que a do diagrama de Nassi-Schneidermann, na Figura 2.1. Percebe-se que o desenho ocupa uma área maior, sendo mais volumoso, visualmente, que o diagrama de Nassi-Schneidermann. . . . . . . . . . . . . . 35

4.1 Algoritmo global do programa, salientando-se, resumidamente, as etapas principais do seu comportamento. . . . . . . . . . . . . 69

4.2 Algoritmo do programa principal, definindo-se as etapas de evolução

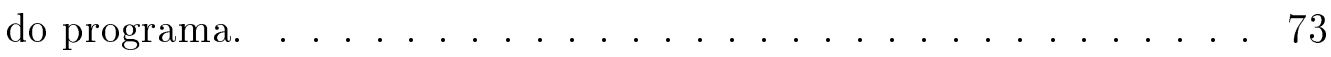

4.3 Algoritmo para o carregamento das propriedades do meio físico e sua distribuição aos demais nós. . . . . . . . . . . . . . . . . . . . 75

4.4 Implementação do método FDTD paralelizado, podendo-se observar as trocas de dados para o prosseguimento dos cálculos. . . . . . . . . 76

4.5 Regiões da PML nas faces do problema. Para a implementação da PML, em cada uma destas regiões, há uma matriz tridimensional de integração para o campo elétrico e outra para o magnético. . . . . . 79

4.6 Diagrama com a lógica para o cálculo da componente $D_{z}$ utilizando uma técnica de implementação padrão. . . . . . . . . . . . . . . . . 80 
4.7 Diagrama com a lógica para o cálculo da componente $D_{z}$ utilizando uma técnica de implementação otimizada. . . . . . . . . . . . . . . . 81

4.8 Matriz única de integração da PML e seus índices, para a implementação da técnica otimizada. . . . . . . . . . . . . . . . . . . . 81

4.9 Dependências para o cálculo de cada componente dos campos. . . . . 83

4.10 Região do problema com as subdivisões e as referências adotadas. . 84

4.11 Fluxo de troca de dados entre os nós. Aqui, têm-se os seguintes significados: $\operatorname{lin}(n o)$ e $\operatorname{col}(n o)$ representam a linha e a coluna, respectivamente, do nó corrente, isto é, aquele que está executando este código, de acordo com sua coordenada cartesiana na topologia de subdivisão; prm_lin e ult_lin referem-se à primeira e última linha da grade formada pelos nós, conforme com a topologia de subdivisão; prm_col e ult_col é semelhante, mas para a coluna; $T$ indica transmissão e $R$, recepção; @ indica onde está o destino, para a transmissão, e onde está a origem, para a recepção. . . . . . . . . . . . . . . . . . . 85

4.12 Sub-região do problema. Cada nó irá trabalhar com uma região como esta. Sua parte central é a parte que contém os dados propriamente ditos, com significado físico. As margens externas são utilizadas apenas como buffer de recepção durante a troca de dados entre os nós. 86

4.13 Exemplo de uma fonte, conforme as descrições. Percebe-se sua geometria quadrada e seu perfil senoidal, com máximo ao centro do quadrado. A variação das amplitudes mostradas ao longo do tempo poderão se dar segundo qualquer função; por exemplo, poderá ser uma variação senoidal ou tipo pulso gaussiano. . . . . . . . . . . . . . 87

4.14 Algoritmo para a aplicação da fonte, no qual são salientadas as múltiplas escolhas de geometria e de perfil espacial, ocasionando trechos redundantes. . . . . . . . . . . . . . . . . . . 90 
4.15 Algoritmo para a aplicação da fonte com o auxílio de uma variável do tipo ponteiro para função, resultando num código otimizado. . . . . . 90

4.16 Algoritmo para o agrupamento dos resultados gravados por cada nó. O agrupamento e a gravação final serão realizados pelo nó gerenciador. 94

4.17 Gráfico com as curvas do comportamento dos tempos de cálculo, comunicação e total. Nota-se, neste gráfico, claramente, um ponto de mínimo para o tempo total. . . . . . . . . . . . . . . . 102

4.18 Gráfico com os tempos de cálculo, de comunicação e total correspondentes ao exemplo descrito no texto. . . . . . . . . . . . . 106

5.1 Modos resultantes numa cavidade, para a freqüência de ressonância. . 112

5.2 Tempos medidos e estimados relativos à tabela 5.1. As linhas "cheias" indicam os tempos medidos e as "pontilhadas", os estimados. . . . . . 114

5.3 Razão entre tempos de comunicação e cálculo $(f)$, eficiência $\left(E_{f}\right)$ e ganho de velocidade $\left(G_{v}\right)$ do caso simulado e das estimativas matemáticas, conforme a tabela 5.2. As linhas "cheias" indicam os valores do caso simulado e as "pontilhadas", das estimativas matemáticas. . . 117

5.4 Geometria do problema para a simulação de uma situação próxima a um caso real de descarga atmosférica em regiões com edifícios. Nela, tem-se indicado o plano de aplicação da fonte, o solo e os prédios. O espaço aberto será considerado pela presença da PML, não desenhada nesta figura. . . . . . . . . . . . . . . . . . . . . . 128

5.5 Distribuição do campo elétrico vertical no instante de tempo 1,67 $\mu$ s a $10 \mathrm{~m}$ acima do solo. A barra de cores indica as intensidades relativas do campo elétrico. . . . . . . . . . . . . . . . . . . 129 
5.6 Distribuição do campo elétrico vertical no instante de tempo 2,00 $\mu \mathrm{s}$ a $10 \mathrm{~m}$ acima do solo. Nota-se a presença de campos mais intensos nos arredores da região dos edifícios e a de campos menos intensos na região entre eles. A barra de cores indica as intensidades relativas do campo elétrico. ....................... 130

5.7 Distribuição do campo elétrico vertical no instante de tempo 2,51 $\mu$ s a $10 \mathrm{~m}$ acima do solo. Nota-se que a presença de campos mais intensos aos arredores da região dos edifícios permanece, assim como a de campos menos intensos na região entre eles. A barra de cores indica as intensidades relativas do campo elétrico. . . . . . . . . . . . . 130

5.8 Variação ao longo do espaço do campo elétrico. O campo elétrico traçado corresponde a uma linha horizontal que passa entre os prédios, na direção de maior dimensão. A notação nEy indica que a intensidade do campo elétrico mostrada está normalizada em relação à máxima intensidade aplicada pela fonte.A distância $d$ é medida a partir da borda plana esquerda do volume. Cada traço representa $10 \mathrm{~m}$ no eixo $d . \ldots \ldots \ldots \ldots 131$

5.9 Variação do campo elétrico ao longo do tempo em quatro pontos distintos, num plano a $10 \mathrm{~m}$ de altura. Na legenda, a distância de $0 \mathrm{~m}$ corresponde à posição da fonte e as distâncias maiores, a posições mais afastadas da fonte. Assim, tem-se, respectivamente, pontos que se situam em frente aos edifícios, entre eles e atrás deles. A notação nEy indica que a intensidade do campo elétrico mostrada está normalizada em relação à máxima intensidade aplicada pela fonte. . . . . . . . . . 132 
5.10 Variação do campo elétrico ao longo do tempo em quatro pontos distintos, num plano a $30 \mathrm{~m}$ de altura. Na legenda, a distância de $0 \mathrm{~m}$ corresponde à posição da fonte e as distâncias maiores, a posições mais afastadas da fonte. Assim, tem-se, respectivamente, pontos que se situam em frente aos edifícios, entre eles e atrás deles. A notação nEy indica que a intensidade do campo elétrico mostrada está normalizada em relação à máxima intensidade aplicada pela fonte. . . . . . . . . . 133 


\section{Lista de Tabelas}

2.1 Influência dos parâmetros de discretização sobre o número de onda na simulação. . . . . . . . . . . . . . . . . . . . 22

4.1 Valores padrão das opções da linha de comando. . . . . . . . . . . . . 67

5.1 Tempos de cálculo, comunicação e total reais medidos por meio da simulação de um problema com tamanho fixo e com quantidade de nós variáveis, segundo a topologia $n_{x} \times 1$. São mostrados, também, os tempos correspondentes obtidos pelas estimativas matemáticas e o erro percentual (em módulo) entre estes e os reais. Os tempos para a topologia com $n_{x}=1$ foram obtidos por extrapolação de dados, conforme descreve o texto. . . . . . . . . . . . . . . . . . 114

5.2 Razão entre tempos de comunicação e cálculo, eficiência e ganho de velocidade do caso simulado e das estimativas matemáticas. . . . . . 117

5.3 Dois exemplos, utilizando-se a topologia $n_{x} \times 1$, de casos extremos, mostrando valores das estimativas matemáticas incoerentes frente aos medidos. Foram realizados 1001 passos no tempo. . . . . . . . . . . . 119

5.4 Os mesmos exemplos da tabela 5.3, mas agora com os tempos de comunicação corrigidos conforme o descritivo. . . . . . . . . . . . . 120 
5.5 Tempos de cálculo, comunicação e total reais medidos por meio da simulação de um problema com tamanho fixo e com quantidade de nós variáveis, segundo a topologia $n_{x} \mathrm{x} n_{y}$. São mostrados também os tempos correspondentes obtidos pelas estimativas matemáticas e o erro percentual entre estes e os reais. . . . . . . . . . . . . . . 122

5.6 Tempos medidos, estimados e os erros percentuais correspondentes para a simulação de um problema num sistema paralelizado utilizando-se dois computadores interconectados por $h u b$ de baixa velocidade. 123

5.7 Comparativos entre várias situações para a simulação de um problema com quantidade de dados que não pode ser alocada totalmente na memória física de um único computador. O computador utilizado possui 256 Mbytes de memória física e o volume considerado é de 100 x 100 x 160 células, necessitando de 254 Mbytes de memória. As situações são: (a) ideal, caso houvesse memória física suficiente para um único nó alocar o problema; (b) real, para um passo no tempo, nas condições atuais, para um nó; (c) real, idem a (b), mas para 1001 passos no tempo - resultado obtido por extrapolação; (d) real, com uso de hub com baixa taxa de transferência; (e) real, com uso de chaveador com média taxa de transferência. . . . . . . . . . . . . . . 124 


\section{Lista de Siglas}

\begin{tabular}{ll}
\hline Sigla & Descrição \\
\hline ADI-FDTD & Alternating-Direction Implicit Finite-Difference Time-Domain \\
BEM & Boundary Element Method \\
CM-2 & Connection Machine - 2 \\
Cpar & C paralelo \\
daa & Dynamic Array Allocator \\
DDD & The Data Display Debugger \\
DD-FDTD & Domain Decomposition Finite-Difference Time-Domain \\
D-FDTD & Diaz Frits Gerald Finite-Difference Time-Domain \\
EMC & Electromagnetic Compatibility \\
EMI & Electromagnetic Interference \\
FDFD & Finite-Difference Frequency-Domain \\
FDTD-3D & FDTD em Três Dimensões \\
FDTD & Finite-Difference Time-Domain \\
FE-FDTD & Finite-Element Finite-Difference Time-Domain \\
FETD & Finite-Element Time-Domain \\
FSF & GNee Software Foundation \\
GCC & \\
\hline & GDB
\end{tabular}

Continua... 


\begin{tabular}{|c|c|}
\hline Sigla & Descrição \\
\hline GLUT & OpenGL Utility Tool \\
\hline GNU & GNU's Not UNIX \\
\hline GPL & General Public License \\
\hline $\mathrm{HPF}$ & High Performance Fortran \\
\hline LAM & Local Area Multicomputing \\
\hline LOD-FDTD & Locally One-Dimensional Finite-Difference Time-Domain \\
\hline MoM & Method of Moments \\
\hline MPI & Message Passing Interface \\
\hline MTW & Moving Time Window \\
\hline NASA & National Aeronautics and Space Administration \\
\hline OOMPI & Object-Oriented MPI \\
\hline ParaView & Parallel Visualization Application \\
\hline PML ABC & Perfecty Matched Layer Absorbing Boundary Condition \\
\hline PML & Perfecty Matched Layer \\
\hline PVM & Parallel Virtual Machine \\
\hline PWB & Printed Wiring Board \\
\hline SCI & Scalable Coherent Interface \\
\hline SIMD & Single-Instruction Multiple-Data \\
\hline SPMD & Multiple-Instruction Multiple-Data \\
\hline SPMD & Single-Program Multiple-Data \\
\hline $\mathrm{Tcl} / \mathrm{Tk}$ & Tool Command Language/Tool Kit \\
\hline $\mathrm{TCP} / \mathrm{IP}$ & Transfer Control Protocol/Internet Protocol \\
\hline $\mathrm{TCP}$ & Transfer Control Protocol \\
\hline TLM & Trasmission-Line Matrix \\
\hline
\end{tabular}

Continua... 


\begin{tabular}{ll}
\hline Sigla & Descrição \\
\hline TW & Time Warp \\
UDP & User Datagram Protocol \\
VIM & Vi Improved \\
VTK & Visualization Tool Kit \\
\hline
\end{tabular}




\section{Lista de Símbolos}

\begin{tabular}{|c|c|}
\hline Símbolo & Significado \\
\hline$\beta$ & número de onda \\
\hline$\widehat{\beta}$ & número de onda computacional \\
\hline$c_{0}$ & velocidade da luz \\
\hline$D$ & densidade de fluxo elétrico \\
\hline$\delta$ & passo no espaço (aresta das células - cúbicas) \\
\hline$\Delta t$ & passo no tempo \\
\hline$\Delta x, \Delta y, \Delta z$ & tamanho da célula em $x, y, z$. \\
\hline$E$ & campo elétrico \\
\hline$E_{f}$ & eficiência \\
\hline$\epsilon_{0}$ & permissividade elétrica do vácuo \\
\hline$\epsilon_{F}^{*}$ & "permissividade" fictícia \\
\hline$\epsilon_{r}$ & permissividade elétrica relativa de um meio \\
\hline$\eta_{0}$ & impedância intrínseca do vácuo \\
\hline$\eta$ & impedância intrínseca \\
\hline$f_{d x}, f_{d y}$ & fator, relativo ao periférico, em $x, y$ \\
\hline$f$ & freqüência \\
\hline$f, g$ & matrizes unidimensionais com coeficientes para a PML \\
\hline$f_{r}$ & fator de relação entre $t_{c a l c}$ e $t_{c o m}$ \\
\hline
\end{tabular}

Continua... 


\begin{tabular}{|c|c|}
\hline Símbolo & Significado \\
\hline$G_{v}$ & ganho de velocidade \\
\hline$H$ & campo magnético \\
\hline$I_{D}$ & matriz de integração para a PML (campo $D)$ \\
\hline$i, j, k$ & número do passo no espaço em $x, y, z$ \\
\hline$K$ & constante auxiliar \\
\hline$\lambda$ & comprimento de onda \\
\hline mem $_{P M L}$ & quantidade de memória para a PML \\
\hline mem $_{\text {princ }}$ & quantidade de memória principal \\
\hline mem $_{\text {tot }}$ & quantidade de memória total \\
\hline$\mu_{0}$ & permeabilidade magnética do vácuo \\
\hline$\mu_{F}^{*}$ & "permeabilidade" fictícia \\
\hline$M_{x}, M_{y}$ & quantidade de células da margem em $x, y$, dos subvolumes \\
\hline$n_{c c x}, n_{c c y}$ & número de células envolvidas na comunicação em $x, y$ \\
\hline NCELPML & número de células da PML \\
\hline$n_{c x}, n_{c y}$ & número de comunicações em $x, y$ \\
\hline$n_{d}$ & número de dimensões de um problema \\
\hline$n_{e x}, n_{e y}$ & número de elementos que serão transferidos em $x, y$ \\
\hline$N_{I}$ & número de iterações no tempo \\
\hline$n$ & nas equações de diferenças: número do passo no tempo \\
\hline$n$ & nas estimativas matemáticas: quantidade de nós computacionais \\
\hline$n_{\text {pmin }}$ & número de subdivisões para o ponto de mínimo em $t_{t o t}$ \\
\hline$N_{P M L}$ & número de células para a PML (espessura da PML) \\
\hline$N_{T}$ & número total de células num volume \\
\hline$n_{x}, n_{y}$ & número de subdivisões em $x, y$ \\
\hline
\end{tabular}

Continua... 


\begin{tabular}{ll}
\hline Símbolo & Significado \\
\hline$N_{x}, N_{y}, N_{z}$ & número de células em $x, y, z$ \\
$n_{x p m i n}, n_{y p m i n}$ & número de subdivisões em $x, y$, para o ponto de mínimo em $t_{\text {tot }}$ \\
$\omega$ & freqüência angular \\
$p$ & parâmetro que relaciona $v$ e $\Delta t$ com $\delta$ \\
$r o t_{h}$ & relaciona-se ao rotacional de $H$ \\
$R_{T}$ & taxa de transferência \\
$\sigma$ & condutividade \\
$\sigma_{D}$ & condutividade associada a $D$ para a consideração de perdas \\
$\sigma_{H}$ & condutividade associada a $H$ para a consideração de perdas \\
$t$ & tempo \\
$t_{c a l c}$ & tempo de cálculo \\
$t_{c o m}$ & tempo de comunicação \\
$T_{e}$ & tamanho do elemento, em $b y t e s$ \\
$T_{\text {tot }}$ & tempo equivalente de cálculo por célula \\
$x_{0}$ & telocidadade de propagação \\
&
\end{tabular}




\section{RESUMO}

São crescentes as pesquisas e os projetos envolvendo o eletromagnetismo. Tanto para as pesquisas quanto para os projetos, tem-se o recurso de realizar simulações computacionais dos problemas envolvidos, a fim de investigar o comportamento dos fenômenos eletromagnéticos diante da situação na qual encontram-se.

Há casos, contudo, em que o problema pode ficar computacionalmente grande, requisitando maior quantidade de memória e maior tempo de processamento, devido às geometrias envolvidas ou à acuracidade desejada.

Com o objetivo de contornar estas questões, tem-se o desenvolvimento da computação paralela. Uma das implementações possíveis de sistema paralelizado é por meio de uma rede de computadores e, empregando-se programas gratuitos, tem-se sua realização a custo praticamente nulo.

O presente trabalho, utilizando o método FDTD, visa a implementação de tal sistema paralelizado. Entretanto, na etapa de desenvolvimento, uma especial atenção foi dada às boas práticas de programação, com o objetivo de garantir ao programa flexibilidade, modularidade e expansibilidade.

Adicionalmente, desenvolveu-se uma ferramenta matemática para estimar o tempo de processamento total de uma simulação paralelizada, além de fornecer indicativos de ajustes de parâmetros para que este tempo seja o menor possível.

Validam-se o código, o sistema paralelizado e a ferramenta matemática com alguns exemplos. Finalmente, realiza-se um estudo para uma aplicação prática de interesse com a ferramenta desenvolvida. 


\section{"ABSTRACT"}

Researches and projects involving electromagnetic problems are continuously increasing. As much for researches as for projects, there is a resource of achieving computer simulations for the involved problems aiming to investigate the electromagnetic phenomenons behavior, in the situation they are.

There are cases, however, the problem results in high computational size, requesting more memories sizes and high processing times, because of the given geometries or high accuracy wanted.

With the intent of solving these questions, the parallel computation developing becomes interesting. One of the possible implementations of this parallel system is the use of a computer network. Besides, using free programms, the implementation has almost any costs.

The present work, using the FDTD method, aims at the implementation of this parallel system. However, during the development stage, a special attention was given to the programming practices, with the intent of guaranteeing the flexibility, modularity and expansibility of the program.

In addition, a mathematic tool was developed to estimate the total processing time of the parallel simulation and to predict indications for adjustments of parameters to reach the minimum time possible.

The code, the parallel system and the mathematic tool are validated with some examples. Finally, a study for a practical aplication of interest is done with the developed tool. 


\section{Capítulo 1}

\section{INTRODUÇÃO}

A resolução de problemas de eletromagnetismo, em geral, não apresenta solução analítica. Nestes casos, a solução pode ser encontrada por meio de simulações numéricas.

Dentre os diversos métodos numéricos existentes, encontra-se o Método das Diferenças Finitas no Domínio do Tempo - Finite-Difference Time-Domain (FDTD), que é largamente utilizado em diversas aplicações.

Contudo, se, por um lado, a simulação numérica permite a resolução de problemas antes insolúveis, por outro ele também apresenta restrições. Uma delas é a necessidade de discretização dos objetos envolvidos num certo problema e do fenômeno físico em interesse de estudo. Assim, não se poderá trabalhar sobre variáveis contínuas, mas sim amostras destas. Tal fato é intrínseco a todo método numérico. Outras duas restrições que se destacam são as relacionadas ao tempo total de processamento e a quantidade de memória computacional requerida para a simulação. Quanto mais detalhes um problema possuir e quanto mais acuracidade for desejada, mais refinada deverá ser a discretização e, conseqüentemente, mais memória será utilizada e mais tempo de processamento será requerido. Isto, conseqüentemente, limita as possibilidades de resolução de problemas por um único computador, uma vez que o problema deve ser compatível com as características do computador. 
Para contornar tais limitações e ampliar a aplicabilidade dos métodos numéricos - como um todo e não só do FDTD-, utiliza-se a técnica do processamento paralelo, permitindo, em um primeiro momento, a redução do tempo de processamento e, considerando-se uma arquitetura com memória distribuída, uma maior quantidade disponível de memória.

O presente trabalho realizará uma implementação numa arquitetura com memória distribuída, utilizando uma rede já existente de computadores, a fim de dispensar investimentos adicionais para aquisição de equipamentos.

Ainda, serão empregadas ferramentas e ambientes Linux gratuitos, visando-se manter nulo o custo de desenvolvimento e também facilitar e possibilitar o seu uso em qualquer computador, por não ser necessária a aquisição de licença específica.

Já quanto ao desempenho final do programa, ele terá influências de diversos fatores. Um primeiro fator é a escrita do código, que pode ser feita de forma mais ou menos otimizada. Um segundo, deve-se às topologias de comunicação entre os computadores, sob o contexto do sistema paralelizado. Um terceiro, é relacionado à taxa de transferência dos periféricos de rede utilizados. Portanto, um estudo destas influências será também realizado.

À escrita do código, tarefa da programação, faz-se necessária uma atenção especial. Visando dar características importantes ao programa, determinadas técnicas e conceitos deverão ser observados. Entre estas características, encontram-se a flexibilidade, a consistência, a redução de código, a facilidade de depuração, as otimizações - quanto ao tempo de execução e uso de memória -, a facilidade de manutenção futura, a expansibilidade e a aplicabilidade. A implementação do programa, então, procurou considerar essas proposições.

Percebendo-se a possibilidade de se equacionar o tempo total de processamento paralelo, um modelo matemático foi desenvolvido, sob o contexto do programa implementado. Com tal modelo, pode-se estimar o tempo total do processamento para uma determinada simulação e, também, prever qual o menor tempo total de proces- 
samento possível de se obter. Além disto, ter-se-á um indicativo de quais ajustes de configuração de comunicação deverão ser realizados para se atingir o tempo mínimo. Aqui, "configuração de comunicação" refere-se à forma como o volume de um problema será subdividido e como se dará a atribuição de cada subvolume resultante aos computadores.

Por último, como o processamento paralelo torna-se viável para problemas eletricamente grandes, a aplicabilidade do trabalho será validada por meio de um ensaio para o estudo de um caso prático, de bastante interesse, no qual um razoável refinamento se faz necessário: a análise dos efeitos de uma descarga atmosférica próxima a regiões com edifícios.

Assim, conforme o que foi exposto, o seguinte objetivo geral foi definido:

"Realizar um estudo das características do processamento paralelo aplicado ao Método das Diferenças Finitas no Dominio do Tempo em três dimensões para simulação de problemas de eletromagnetismo e mostrar a aplicabilidade da ferramenta desenvolvida para o estudo de um caso real."

E, decorrentes deste objetivo geral, têm-se os objetivos parciais abaixo:

- desenvolvimento do código que implementa o método FDTD em Três Dimensões (FDTD-3D) paralelizado, com flexibilidade de ajustes dos parâmetros do problema;

- validação das principais vantagens esperadas com o emprego do processamento paralelo: redução do tempo total de processamento e aumento da memória disponível em arquiteturas distribuídas;

- desenvolvimento e operação utilizando ferramentas e ambientes Linux gratuitos; 
- desenvolvimento do processamento paralelo empregando uma rede de computadores previamente existente;

- validação dos resultados numéricos;

- verificação da influência no tempo de comunicação de diferentes periféricos de rede;

- elaboração de modelo matemático para estimar o tempo total de um processamento paralelizado e sua configuração ótima, para o menor tempo de processamento possível;

- aplicação da ferramenta desenvolvida para obtenção da distribuição de campo eletromagnético em problemas reais que necessitem de grande detalhamento, como por exemplo, num problema de descargas atmosféricas ocorrendo nas vizinhanças de edificações.

O conteúdo deste documento segue dividido da seguinte forma:

Ainda neste capítulo, na seção seguinte, é apresentada a revisão bibliográfica de trabalhos correlacionados com o assunto em estudo.

No Capítulo 2, são reunidas (de forma resumida) todas as informações e conceitos necessários ou complementares para o desenvolvimento do trabalho.

No Capítulo 3, relatam-se as opções de solução dados os objetivos a serem alcançados pelo trabalho.

No Capítulo 4, é apresentado, com razoável detalhamento, todo o desenvolvimento realizado.

No Capítulo 5, por fim, realizam-se as validações necessárias e apresenta-se o ensaio do estudo da aplicação prática proposta. 


\subsection{Revisão Bibliográfica}

No trabalho [1], foi apresentada uma topologia de célula computacional que permitiu, adequadamente, a aplicação do método numérico das diferenças finitas no domínio do tempo - FDTD em problemas de eletromagnetismo. A proposta fundamentava-se em escolher, na célula computacional, pontos distintos nos quais estaria presente cada uma das componentes dos campos $\vec{E}$ (intensidade de campo elétrico) e $\vec{H}$ (intensidade de campo magnético) e de forma a respeitarem as equações de Maxwell, ao calcularem-se os valores de umas componentes com base nos das outras. Esta topologia tornou-se a base de diversos outros trabalhos conseguintes neste ramo e a célula computacional ficou conhecida como célula de Yee.

Em [2], há resumos dos desenvolvimentos da formulação matemática, conforme apresentado por Yee, para problemas em uma, duas e três dimensões (1D, 2D e 3D). Nele, a formulação matemática faz uso do vetor $\vec{D}$ (densidade de fluxo elétrico), permitindo caracterizar meios dielétricos com ou sem perdas. Aborda-se também a questão das reflexões intrínsecas que surgem nas bordas da região do problema e a respectiva solução, ao utilizar-se uma camada absorvedora perfeitamente casada Perfecty Matched Layer (PML). São expostas, em seguida, técnicas para a geração de onda plana em 2D e 3D e para o cálculo da transformada de Fourier. Citam-se, ainda, o uso da transformada Z como ferramenta auxiliar na formulação matemática, a aplicação do método em situações reais e a adaptação do método para outros tipos de problemas, como os acústicos. Para compatibilizar as magnitudes dos vetores $\vec{E}$, $\vec{D}$ e $\vec{H}$ a fim de evitar acúmulo de erros numéricos, os vetores $\vec{E}$ e $\vec{D}$ são normalizados. Por fim, após os desenvolvimentos, as equações resultantes são reescritas na forma computacional e listam-se programas completos em linguagem C.

O trabalho [3], num primeiro momento, retoma os conceitos fundamentais do eletromagnetismo e apresenta métodos analíticos para a solução de problemas. Em seguida, descreve diversos métodos numéricos: o método das diferenças finitas, o 
variacional, o dos momentos, o dos elementos finitos, o da matriz de linha de transmissão, o Monte Carlo, e o das linhas. Quanto ao método das diferenças finitas - FDTD, a abordagem trata, de forma generalizada e com mais detalhes que em [2], seus aspectos básicos e questões essenciais, como o critério de estabilidade e os erros intrínsecos de arredondamento e discretização. Em aplicações práticas, foca o uso do método para solucionar problemas eletromagnéticos, inclusive em 3D, confrontando os resultados numéricos com os analíticos. O desenvolvimento considera meios dielétricos com perdas e uma camada de contorno absorvedora PML. Listamse programas completos em linguagem FORTRAN 77 e apresentam-se referências e implementações em linguagem $\mathrm{C}++$.

O método FDTD é tratado com bastantes detalhes e profundidade em [4]. O assunto parte dos conceitos fundamentais e analisa a dispersão e a estabilidade numérica, as condições para a aplicação de onda incidente, a implementação da PML, e a transformação de campo próximo para distante, o que permite determinar o comportamento do campo em regiões distantes do objeto em estudo sem a necessidade de aumentar a quantidade de células do problema. Considera materiais dispersivos e não-lineares e algumas outras técnicas de modelamento e simulação para problemas e situações encontrados na prática.

O trabalho [5] aplica o método FDTD para caracterizar antenas impressas planares complexas com várias estruturas de alimentação. Apresenta ainda um novo modelo tridimensional para a alimentação por cabo coaxial e o uso da condição de contorno absorvedora para antena impressa com alta constante dielétrica.

Já o trabalho [6] faz uso do método FDTD para analisar cavidades ressonantes carregadas com materiais dielétricos, com e sem perdas. Foi desenvolvido um modelo com o objetivo de observar a pertubação dos campos eletromagnéticos pelos corpos dielétricos inseridos na cavidade. Aplicando-se o modelo a casos de interesse, podese extrair correlações genéricas entre forma e condutividade equivalente dos corpos dielétricos, além da distribuição do campo eletromagnético. Os resultados permitem 
prever, em função dos corpos dielétricos, características de distribuição da energia no domínio da freqüência e da distribuição espacial dos campos elétrico e magnético para uma determinada freqüência.

Uma variante do método FDTD é apresentada em [7]. A formulação do método é modificada para reduzir a quantidade de memória necessária, permitindo um aumento de $50 \%$ no volume computacional para uma certa quantidade de memória disponível no computador, com pouco aumento da quantidade de cálculos e da complexidade do código. No método proposto, consegue-se uma redução por meio da associação espacial de uma componente de $\vec{E}$ e uma de $\vec{H}$ com as outras duas, sem a necessidade de subdividir o domínio computacional. Daí resulta o uso de apenas quatro componentes e não seis como originariamente, para armazenar as informações necessárias. Por meio do cálculo das cargas induzidas e do seu uso no divergente de $\vec{D}$, fica simples o tratamento de condutores e fontes. Com tal proposta, uma economia de $33 \%$ na quantidade de memória necessária é alcançada.

Apresenta-se em [8] uma condição de contorno absorvente por camada perfeitamente casada - Perfecty Matched Layer Absorbing Boundary Condition (PML ABC) - para a equação de onda escalar no domínio do tempo, para problemas gerais não-homogêneos, com ou sem perdas. A PML ABC proposta é aplicável praticamente a todos os esquemas de diferenças finitas que tratam da equação de onda no domínio do tempo, como a técnica do potencial de onda no domínio do tempo (TDWP) e as aproximações das equações de onda escalares no domínio do tempo para análise de estruturas ópticas. Como contribuições, o trabalho fornece a formulação da PML e sua discretização para ser aplicada ao método FDTD, propõe perfis modificados das variáveis da PML para obter desempenhos superiores, com menos reflexões numa faixa mais ampla de freqüências, quando comparado com os desenvolvimentos comuns, e investiga a influência da terminação da PML sobre seu desempenho geral, apontando as melhores opções disponíveis.

Quanto aos desenvolvimentos do código FDTD paralelizado, um dos primeiros 
trabalhos foi [9]. Neste, após dificuldades diversas quanto à implementação do código, conseguiu-se simular, com um computador multi-processado - o Connection Machine - 2 (CM-2), um problema de 126 x 126 células com um paralelepípedo ao centro, numa freqüência de $0,43 \mathrm{GHz}$. Os resultados foram coerentes com os valores experimentais.

Em [10] é realizado um descritivo bastante detalhado sobre a computação baseada num sistema Beowulf, que, de forma simples, caracteriza-se por computadores ligados em rede que usam sistema operacional e ferramentas de programação gratuitos, sendo a National Aeronautics and Space Administration (NASA) uma das primeira a explorar este sistema. Com as características de tal sistema, é destacado que há uma redução grande da relação custo-desempenho. Aplicações diversas foram desenvolvidas para simulação utilizando o Beowulf, como código gravitacional para N-corpos e química quântica. Expõem-se os programas e ferramentas que podem ser utilizados no desenvolvimento e questões relativas à escalabilidade e à computação heterogênea. Na data de publicação, havia a expectativa de crescimento das aplicações em sistemas Beowulf, principalmente por causa das possibilidades com reduzido custo, mas também tinha-se ciência de algumas limitações devido ao volume de comunicação e temporizações necessárias.

É relatada por [11] uma análise de quatro pacotes de programa envolvidos na comunicação entre computadores de um sistema Beowulf: o Parallel Virtual Machine (PVM), o Local Area Multicomputing (LAM), o MPICH e o BNM. São abordadas questões relativas à arquitetura, o que envolve a forma de depuração de um programa, sua inicialização e execução, aos aspectos de criação de tarefas remotas, aos protocolos de comunicação, Transfer Control Protocol (TCP) e User Datagram Protocol (UDP), e, por último, aos desempenhos obtidos e confiabilidade de cada pacote.

Em [12], o estudo concentra-se em traçar um comparativo entre o tempo de processamento, necessário para solucionar um determinado problema, para uma 
implementação seqüencial e para implementações paralelas, estas por meio de estações de trabalho, de rede Transputer e com o uso da arquitetura Single-Instruction Multiple-Data (SIMD) . O tempo de processamento pode ser bastante reduzido dependendo do tipo de computador utilizado. Conclui-se que o paralelismo, utilizando oito estações de trabalho e sem custos adicionais, apresenta um ganho de velocidade de 1,43 vezes em relação ao seqüencial, sendo o fator limitante deste ganho a taxa de transferência das ligações Ethernet.

Cita-se, em [13], uma solução para contornar as restrições de memória existentes para códigos seqüenciais do FDTD, o que permite a simulação apenas de problemas pequenos: o uso de uma implementação paralela do FDTD de baixo custo utilizando redes de estações de trabalho existentes. Isto caracteriza uma arquitetura de computação com memória distribuída. Teoricamente, ao se aumentar o número de processadores, a quantidade de memória também aumentaria e o tempo de processamento cairia. Um exemplo prático é simulado, validando as afirmações anteriores, sendo o ganho de velocidade igual a 7,57 para 8 processadores numa malha contendo 768000 células. Em seguida, abordam-se topologias de arquitetura para implementação distribuída e a topologia utilizada para a divisão dos dados nesta arquitetura, salientando a necessidade da troca de informações entre "vizinhos" e enumerando a seqüência dos cálculos e transmissões/recepções de dados.

O trabalho [14] faz um apanhado geral sobre as características e vantagens de um sistema com processamento paralelo para os cálculos do método FDTD, utilizandose computadores pessoais. É citado, ainda, que todo o trabalho baseou-se num sistema operacional livre - o Linux - e, da mesma forma, todas as ferramentas de programação necessárias. Na parte prática, realizam-se diversos comparativos entre a quantidade de processadores/computadores (nós) e o ganho de velocidade de processamento, chegando-se à conclusão que a relação é linear para problemas suficientemente grandes, pois o tempo de processamento fica muito maior que o tempo de comunicação entre os nós. 
Um comparativo de processamento paralelo entre um computador multiprocessado e um conjunto de estações de trabalho é feito em [15]. O computador multiprocessado é o ALEX AVX2 com topologia Multiple-Instruction Multiple-Data (SPMD) e as estações de trabalho do conjunto possuem processador de $450 \mathrm{MHz}$ e são interligadas por placa de rede Ethernet. O ganho de velocidade foi satisfatório para o computador multiprocessado; contudo, para as estações de trabalho, o resultado não foi satisfatório, pois a taxa de transferência de 10 Mbits/s da placa Ethernet é muito baixa para o processamento requerido.

Comenta-se em [16] que (na data da publicação) muitas pesquisas foram feitas para paralelizar códigos FDTD, contudo baseando-se em computadores de processamento em massa, que não são muito comuns, e paralelizando-se o problema apenas espacialmente, mantendo a seqüencialidade do cálculo das componentes dos campos. Há então a proposta de se usar PCs com mais de um processador, algo que tenderia a se tornar comum, e paralelizar o problema segundo o cálculo das componentes, pelo fato de, num dado instante, algumas não dependerem de outras. Assim, cada cálculo seria atribuído a uma tarefa e cada tarefa seria atribuída a um processador. Executaram-se simulações para diversos esquemas multitarefas de FDTD e ganhos de velocidade de 1,5 e 2,1 para duas e três tarefas foram obtidos. Tais resultados correspondem a uma eficiência de $70 \%$, abaixo dos $90 \%$ possíveis para computadores de processamento em massa, porém próximo aos obtidos com um CRAY Solaris. Por fim, cita-se que é possível mesclar tal técnica de paralelização com a técnica tradicional de divisão no espaço.

Duas outras contribuições são encontradas em [17]. Uma é o fato de considerar uma camada de sobreposição na interface entre nós, o que viria a facilitar a programação. Outra, é a consideração da memória cache do processador, o que requer um algoritmo e uma compilação adequados. Associando-se essas contribuições, tem-se um melhor desempenho do programa como um todo.

O trabalho [18] faz um estudo comparativo dos aspectos necessários para a im- 
plementação de um algoritmo para simulação baseada em eventos discretos distribuídos. Associados com a questão encontram-se os três aspectos importantes, que é o balanceamento de carga, o gerenciamento de sincronização e o gerenciamento de memória. Quanto aos algoritmos de sincronização, pode-se ter uma simulação assíncrona, em que qualquer evento pode ocorrer ao mesmo tempo nos vários processadores, porém há possibilidades de ocorrência de erros causais; ou, então, pode-se ter uma simulação síncrona, que se divide em esquemas conservativo, o qual evita a possibilidade de ocorrência de erros causais, otimístico, o qual permite os erros causais, mas fornece mecanismos para a detecção e remoção destes erros, e híbrido, o qual combina os dois esquemas anteriores. E quanto ao gerenciamento de memória, há duas formas para limitá-la, uma por técnicas passivas, as quais podem adotar o critério de armazenamento por estados incrementais ou por estados não freqüentes (de freqüência reduzida), e a outra por técnicas ativas, as quais requisitam memória de acordo com a demanda. A efetividade dos esquemas de sincronização e seus protocolos foi comparada por meio de simulações experimentais de quatro tipos de algoritmo: conservativo CMB (com mensagens nulas), conservativo WIN (protocolo de janela conservativa), otimístico Time Warp (TW) e híbrido Moving Time Window (MTW), com cálculos GVT. Os tempos medidos foram apresentados para os diversos casos, em alguns sistemas.

Já em [19], abordam-se os conceitos fundamentais da formulação dos métodos FDTD e Finite-Element Time-Domain (FETD) (Finite-Element Time-Domain) em 3D e faz-se um comparativo entre algumas propriedades de ambos. Há um outro comparativo que mostra a quantidade de variáveis, tamanho necessário de memória e quantidade de operações em ponto-flutuante para estes métodos (incluem-se também informações para o Boundary Element Method (BEM). Em seguida, são discutidas as topologias da seqüência de cálculo e troca de dados entre os vários nós numa implementação distribuída do FDTD e do FETD. Certos detalhes quanto à programação e à arquitetura são reportados, salientando-se o uso da biblioteca Local 
Area Multicomputing/Message Passing Interface (LAM/MPI) para a comunicação entre os nós. Como resultados do trabalho, têm-se diversos comparativos entre os dois métodos em diferentes pontos de vista: quantidade relativa de variáveis locais e globais, tamanho relativo máximo do modelo distribuído, quantidade relativa de transferências de dados, ganho de velocidade nas fases de montagem e de solução de problema. Termina-se evidenciando o ganho de velocidade e citando algumas vantagens e desvantagens de um método em relação ao outro.

O uso da biblioteca Message Passing Interface (MPI) na programação paralela do método FDTD é abordado em [20]. Citam-se características essenciais presentes num problema que será paralelizado e recursos para simplificação e aceleração do algoritmo, que são o uso da topologia cartesiana 2D e a otimização da comunicação por meio dos tipos de dados derivados. Como resultado, obteve-se que para subespaços com 20 células ou mais por direção, há uma eficiência mínima de 90\%. Quanto à implementação de outras tarefas no código, como, por exemplo, a computação das componentes de campo-distante e da PML, destaca-se a necessidade de equilibrar a carga computacional entre os nós e a vantagem de se usar uma formulação para a PML que não separa as componentes do campo.

Encontra-se em [21] a implementação de um código paralelo de uma técnica híbrida de cálculo numérico, a qual associa o FDTD e a BIE (Boundary Integral Equation), sendo a primeira a responsável pelas partes não-homogêneas da configuração e a segunda a responsável pelo modelamento da característica aberta do problema e pelas interações entres as diferentes sub-regiões. Nesta técnica, há processamentos bastantes extensos e independentes um do outro, o que justifica e permite sua paralelização. Realizaram-se implementações em um computador multiprocessado e em um conjunto de estações de trabalho.

Em [22] apresenta-se um método de decomposição de domínio. Apontam-se algumas desvantagens dos métodos tradicionais, como o FDTD e o Method of Moments (MoM), e propõe-se este método para solucionar vários problemas. Basicamente, o 
método decompõe todo o domínio do problema em diversos subdomínios acoplados, sendo que cada um poderá usar o método de resolução mais apropriado e ter suas próprias grades. Isto torna o método útil para problemas com formas especiais. Um exemplo prático é abordado, validando sua funcionalidade. Esta técnica pode ser viável para a aplicação em processamento paralelo.

Nessa linha, [23] desenvolveu uma implementação do FDTD em conjunto com o DDM (Domain Decompositon Method), o Domain Decomposition Finite-Difference Time-Domain (DD-FDTD). A técnica consiste em dividir o domínio original (região do problema) em sub-domínios, como citado em parágrafo anterior, de forma a melhor atender os requisitos da simulação. Cada um desses domínios é passado a um nó computacional diferente, e esses nós comunicam-se entre si ao longo do tempo, por meio da biblioteca MPI. Como exemplo, simulou-se o acoplamento de um pulso numa janela em um cubo.

É feita uma implementação paralela em [24] da simulação de um caso prático envolvendo um transformador. O foco principal do trabalho reside em abordar as vantagens conseguidas ao se empregar uma interface de rede entre computadores baseada em placas Scalable Coherent Interface (SCI). Tais placas apresentam um menor tempo de comunicação quando comparadas com as placas Ethernet ou Fast Ethernet e este fato viabiliza o processamento paralelo utilizando estações de trabalho, com possibilidades de ganho de velocidade equiparado aos computadores multiprocessados.

O trabalho em [25] utiliza a técnica de paralelização para diminuir o tempo de processamento de uma simulação numérica de instabilidades em dispositivos tunneling em escala nanométrica. O método utilizado não é o FDTD, mas, de forma semelhante, apresenta evidências de paralelização. Utilizando-se um computador com três processadores, obteve-se resultado satisfatório, levando à expectativa de facilitar diversos trabalhos futuros em circuitos nanométricos operando em freqüências muito altas. A ferramenta de paralelização empregada foi o OPEN-MP. 
Em outra aplicação prática, o trabalho em [26] aplica o FDTD paralelizado num simulador de onda completa para análise da interferência eletromagnética Electromagnetic Interference (EMI) - para projetos em placas de circuito impresso - Printed Wiring Board (PWB), com consideração da compatibilidade eletromagnética - Electromagnetic Compatibility (EMC)- e da integridade da relação potência/sinal. Exemplos de tais tipos de circuitos, os quais possuem alta densidade e devem ter alta confiabilidade, são: notebooks, PDAs (assistentes pessoais digitais) e dispositivos móveis (como o celular). O desenvolvimento, na data da publicação, permite a simulação de problemas com até 100 milhões de células e, com a técnica do paralelismo, consegue-se resolver um problema com 4 milhões de células em $50 \mathrm{~s}$. É também apresentado um algoritmo que realiza a transmissão apenas das componentes de $\vec{E}$ entre os nós, o que diminui um pouco mais o tempo total de execução do programa.

Em [27], foi desenvolvido um trabalho de programação paralela utilizando-se as boas técnicas de programação. Como exemplo de técnicas avançadas, com as quais podem-se obter diversas vantagens, foi otimizada a implementação da fonte de campo eletromagnético, a fim de se flexibilizar as escolhas de suas características, e também foi otimizada a implementação da PML, de forma a manter o código reduzido, o que apresentou vantagens para a paralelização. Por último, apresentouse um exemplo de aplicação prática, mostrando-se a funcionalidade do programa desenvolvido.

As vantagens do método FDTD paralelizado também são obtidas na análise da propagação de sinal em linhas de sinal diferencial de alta velocidade encontrados em circuitos multi-camada, conforme descrito em [28]. As interconexões existentes devem levar em consideração a compatibilidade, a potência dissipada, os custos de encapsulamento, a área de circuito impresso e a área de silício, que devem ser balanceados para se alcançar o desempenho desejado, a um custo viável, e ainda estar de acordo com os limites de ondas eletromagnéticas radiadas. Por isso, a necessidade 
de simulações, com o objetivo de realizar otimizações antes da implementação. E como deve haver um certo detalhamento, o tamanho do problema torna-se grande, justificando o emprego do processamento paralelo.

Fora do aspecto de simulações de problemas de eletromagnetismo e do método FDTD, a computação paralela encontra ainda muitos campos. Como exemplo, citase o estudo realizado em [29], que trata de uma simulação de evento lógico paralelo. Este assunto entra na questão da programação paralela de simuladores das áreas de projetos de circuitos. Ainda não existem muitas aplicações dos desenvolvimentos dos códigos paralelizados neste ramo devido à grande quantidade de pequenas mensagens que seriam necessárias de serem transmitidas, o que dificulta a obtenção das vantagens estimadas. Mesmo assim, este campo de pesquisa apresenta boas oportunidades de desenvolvimento. No trabalho, um ganho de velocidade de 3 foi obtido com o uso de 8 processadores de $600 \mathrm{MHz}$, podendo chegar até 5 se os atrasos de comunicação forem reduzidos de 20 para $7 \mu$ s.

Em [30], é apresentada uma implementação do método Trasmission-Line Matrix (TLM), em que a "propagação" dos dados nas matrizes é muito semelhante ao FDTD, em computador de processamento em massa, o DECmpp 12000, relatando técnicas de computação distribuída num ambiente UNIX, associado ao DECmpp 12000, e a combinação da análise TLM com o método de Prony e com o processamento de sinal por média de movimento auto-regressivo (ARMA), com o objetivo de reduzir o tempo de simulação e também de predizer um resposta futura baseada em resposta passada. O DECmpp possui um processador mestre, comandado por uma estação de trabalho, e grande quantidade (8192) de processadores escravos, cada um com uma pequena quantidade de memória e conectados uns aos outros de acordo com uma topologia toroidal. A arquitetura caracterizada é uma SIMD. As técnicas foram aplicadas para obter resultados para o estado estável no domínio da freqüência de problemas que envolvem campos eletromagnéticos em estruturas de microondas. Um ganho de velocidade da ordem de 50 vezes foi observado, compro- 
vando a eficiência dessas técnicas.

Uma vez realizadas as simulações numéricas, torna-se necessário observar os resultados e uma forma desejada pode ser a análise do comportamento do campo ao longo do tempo. Em [31] é realizado um desenvolvimento neste sentido, no qual, simultaneamente com os cálculos, visualizam-se os resultados parciais. Consegue-se o efeito concatenando-se os resultados de cada nó num nó central, o qual irá gerar a imagem. Da forma como foi implementado, quando se habilita o recurso da visualização, o tempo total de execução do programa aumenta consideravelmente, anulando os ganhos de velocidade anteriores. Há, contudo, expectativas de se contornar tal problema. A ferramenta de visualização utilizada é o OpenGL Utility Tool (GLUT).

Fatores bastantes importantes a serem considerados são os periféricos de rede que constituem uma rede de computadores, do ponto de vista do processamento paralelo. Entre os periféricos, encontram-se as placas de rede, com diversas características. Em [32] há um estudo comparativo entre as placas Ethernet, Fast Ethernet, Gigabit Ethernet, Myrinet e SCI. Na ordem, a taxa de transferência é de 10, 100, 1000, 1200 e $1600 \mathrm{Mbits} / \mathrm{s}$. A Gigabit Ethernet pode atingir uma taxa máxima de 44 Mbytes/s via Transfer Control Protocol/Internet Protocol (TCP/IP), para mensagens de tamanho mínimo de 1024 kbytes, ou 25 Mbytes/s via programação com MPI, para mensagens com tamanho mínimo de 64 Kbytes. Desta forma, a placa Gigabit Ethernet é comparável à Myrinet e SCI em desempenho, com o adicional de apresentar um custo reduzido em relação a elas (considerando também os outros equipamentos necessários). 


\section{Capítulo 2}

\section{BASES DO ESTUDO}

A realização de um estudo, qual seja, parte sempre de alguns princípios, que fornecem toda a base de apoio para os desenvolvimentos decorrentes.

Ao visar a elaboração de um sistema paralelizado aplicado à simulação de problemas de eletromagnetismo, o trabalho envolve assuntos diversos, embora correlacionados entre si na área da computação.

Abordam-se, na seqüência, as formulações matemáticas, uma visão geral sobre as tecnologias e recursos atuais para o processamento e transferência de dados e as diretrizes essenciais das técnicas de programação, com as devidas justificativas.

\subsection{Formulação Matemática}

A formulação matemática consiste em descrever por meio de equações um determinado comportamento físico. A elaboração de um programa, para realizar a simulação de algum problema físico, deverá representar, computacionalmente, as equações descritivas do comportamento físico. E esta tarefa, por sua vez, implementa-se pelo processo de discretização das equações, pois o computador não é capaz de manipular funções contínuas, mas, sim, apenas discretas. 


\subsubsection{Diferenças Finitas}

Essencialmente, o método das diferenças finitas baseia-se na obtenção da derivada de uma função através da aproximação numérica utilizando-se uma discretização das variáveis e, conseqüentemente, da função. Dado um ponto central, entre dois outros pontos, numa curva qualquer, é possível escrever as equações de diferenças

$$
\begin{aligned}
f^{\prime}\left(x_{0}\right) & \approx \frac{f\left(x_{0}+\Delta x\right)-f\left(x_{0}\right)}{\Delta x} \\
f^{\prime}\left(x_{0}\right) & \approx \frac{f\left(x_{0}\right)-f\left(x_{0}-\Delta x\right)}{\Delta x} \\
f^{\prime}\left(x_{0}\right) & \approx \frac{f\left(x_{0}+\Delta x\right)-f\left(x_{0}-\Delta x\right)}{2 \Delta x} .
\end{aligned}
$$

É demonstrável, utilizando-se a Série de Taylor, que o erro de truncamento para (2.1a) e (2.1b) é da ordem de $(\Delta x)$, enquanto que para (2.1c) é de $(\Delta x)^{2}[3]$.

A aplicação deste resultado para encontrar a solução de um determinado problema descrito por uma equação diferencial requer que a região em estudo seja subdividida em grade, o que define um conjunto de pontos ou células e, para cada ponto resultante, escreve-se, por exemplo, (2.1c). Assim, obtém-se um sistema com $n$ equações e $n$ incógnitas, o qual fornece uma solução única se forem dadas as condições de contorno.

\subsubsection{O Método das Diferenças Finitas no Domínio do Tempo}

Por meio da formulação matemática consegue-se adequar as equações que regem os fenômenos eletromagnéticos, permitindo que essas possam ser reescritas na forma de diferenças. Tem-se, assim, realizado o processo de discretização, viabilizando a programação de um código de computador que represente o fenômeno. A discretização espacial é realizada adotando-se uma grade com células de arestas $\Delta x, \Delta y \mathrm{e}$ $\Delta z$ e a discretização temporal é obtida com a definição de um passo de tempo $\Delta t$. Contudo, este processo acarreta efeitos adicionais que deverão ser considerados: são 
as questões relativas à estabilidade e à dispersão numérica.

\section{Formulação para Aplicação em Problemas de Eletromagnetismo}

A fim de se empregar este método em problemas de eletromagnetismo, deve-se discretizar as equações de Maxwell

$$
\begin{aligned}
\vec{J}+\frac{\partial \vec{D}}{\partial t} & =\operatorname{rot} \vec{H} \\
\frac{\partial \vec{H}}{\partial t} & =-\frac{1}{\mu} \operatorname{rot} \vec{E},
\end{aligned}
$$

com

$$
\vec{D}=\epsilon_{0} \cdot \epsilon_{r} \vec{E}
$$

O processo de discretização ocorre tanto no tempo quanto no espaço, caracterizando o método das diferenças finitas no domínio do tempo - FDTD. Por questões de minimização de erro, os campos $\vec{E}$ e $\vec{H}$ estão deslocados entre si de meia célula no espaço e seus valores são atualizados intercaladamente a cada meio passo de tempo[4].

A aplicação deste método a problemas em 3D é viabilizada ao se utilizar a proposta de Yee [1], que representa as componentes dos campos elétrico e magnético no espaço respeitando-se as relações (2.2a) e (2.2b).

Para o caso de meios dielétricos, se não forem considerados meios ferromagnéticos, uma formulação um pouco diferenciada pode ser empregada [2]:

$$
\begin{aligned}
\frac{\partial \vec{D}}{\partial t} & =\operatorname{rot} \vec{H} \\
\vec{D} & =\epsilon_{0} \cdot \epsilon_{r} \cdot \vec{E} \\
\frac{\partial \vec{H}}{\partial t} & =-\frac{1}{\mu_{0}} \operatorname{rot} \vec{E} .
\end{aligned}
$$


Para levar em conta as perdas dos dielétricos, define-se $\epsilon_{r}$ complexo, numa análise no domínio da freqüência.

Os valores numéricos de $\vec{E}$ e $\vec{H}$ diferem bastante em magnitude, o que, computacionalmente, deve ser evitado sempre que possível. Por isso, pode-se fazer uma normalização das equações através da troca de variáveis [2;4]

$$
\begin{aligned}
& \tilde{E}=\sqrt{\frac{\epsilon_{0}}{\mu_{0}}} \cdot \vec{E} \\
& \tilde{D}=\sqrt{\frac{1}{\epsilon_{0} \cdot \mu_{0}}} \cdot \vec{D},
\end{aligned}
$$

resultando em

$$
\begin{aligned}
\frac{\partial \tilde{D}}{\partial t} & =\frac{1}{\sqrt{\epsilon_{0} \mu_{0}}} \operatorname{rot} \vec{H} \\
\tilde{D} & =\epsilon_{r} \cdot \tilde{E} \\
\frac{\partial \vec{H}}{\partial t} & =-\frac{1}{\sqrt{\epsilon_{0} \mu_{0}}} \text { rot } \tilde{E} .
\end{aligned}
$$

As equações de diferenças podem, então, ser obtidas substituindo-se as derivadas temporais e em relação a $x, y$ e $z$ por aproximações de diferenças finitas.

Assim, por exemplo, considerando, em (2.6a), o termo correspondente à componente $D_{z}$ e adotando-se $\Delta x=\Delta y=\Delta z=\delta$, obtém-se, após manipulação matemática:

$$
\begin{aligned}
D_{z}^{n+1 / 2}(i, j, k+1 / 2)= & D_{z}^{n-1 / 2}(i, j, k+1 / 2)+ \\
& \frac{\Delta t}{\delta \cdot \sqrt{\epsilon_{0} \mu_{0}}}\left[H_{y}^{n}(i+1 / 2, j, k+1 / 2)-\right. \\
& H_{y}^{n}(i-1 / 2, j, k+1 / 2)- \\
& H_{x}^{n}(i, j+1 / 2, k+1 / 2)+ \\
& \left.H_{x}^{n}(i, j-1 / 2, k+1 / 2)\right],
\end{aligned}
$$


em que o sobrescrito $n$ indica o valor correspondente ao passo $n$ no tempo.

Tal equação é semelhante para todas as outras componentes dos campos.

\section{Critério de Estabilidade}

De acordo com o critério de estabilidade, deve-se garantir que a onda não se propague por mais de uma célula durante um passo no tempo [4]. Isto é alcançado respeitando-se a relação

$$
\frac{v_{\max } \Delta t}{\delta} \leq \frac{1}{\sqrt{n_{d}}}
$$

em que são considerados: velocidade máxima de propagação $v_{\max }$, passo no tempo $\Delta t$, célula cúbica de aresta $\delta$ e dimensão espacial $n_{d}-$ o qual, para o caso em três dimensões, tem o valor 3.

\section{Dispersão Numérica}

O erro de dispersão numérica deve-se ao fato da velocidade de fase da onda na simulação não ser igual à do sistema real e depende da direção de propagação na malha e dos parâmetros de discretização [4].

Considerando, por exemplo, como apresentado em [33], uma onda plana propagando-se na direção $z$ e polarizada em $x$, tem-se:

$$
E_{x}=E_{0} e^{j(\omega t-\beta z)}
$$

sendo $\beta=\omega / v$ o número de onda.

A solução numérica, no instante $t=n \Delta t$ e no ponto $z=k \delta$, tem a forma

$$
E_{x}=E_{0} e^{j(\omega n \Delta t-\widehat{\beta} k \delta)},
$$

com $H_{y}=E_{x} / \eta$ e sendo $\widehat{\beta}$ o número de onda na simulação. 
Substituindo-se $E_{x}$ e $H_{y}$ na equação

$$
\frac{\partial \vec{H}}{\partial t}=-\frac{1}{\mu} \operatorname{rot} \vec{E}
$$

discretizada, resulta

$$
\begin{array}{r}
\frac{E_{0}}{\eta} e^{j(\omega n \Delta t-\widehat{\beta} k \delta)}-\frac{E_{0}}{\eta} e^{j[\omega(n-1) \Delta t-\widehat{\beta} k \delta]}= \\
-\frac{\Delta t}{\mu \Delta z}\left\{E_{0} e^{j[\omega(n-1 / 2) \Delta t-\widehat{\beta}(k+1 / 2) \delta]}-E_{0} e^{j[\omega(n-1 / 2) \Delta t-\widehat{\beta}(k-1 / 2) \delta]}\right\} .
\end{array}
$$

Após manipulação algébrica, obtém-se:

$$
\frac{1}{v \Delta t} \operatorname{sen}\left(\frac{\omega \Delta t}{2}\right)=\frac{1}{\delta} \operatorname{sen}\left(\frac{\widehat{\beta} \delta}{2}\right)
$$

donde

$$
\frac{\widehat{\beta}}{\beta}=\frac{\lambda}{\pi \delta} \operatorname{arcsen}\left[\frac{1}{p} \operatorname{sen}\left(\pi p \frac{\delta}{\lambda}\right)\right] \text {, }
$$

sendo $p=(v \Delta t) / \delta$ e $\lambda$ o comprimento de onda.

Na tabela 2.1 pode-se observar a influência dos parâmetros de discretização sobre o número de onda $\widehat{\beta}$, ligado à velocidade de fase $\widehat{v}$, na simulação, pois $\widehat{\beta}=\omega / \widehat{v}$.

Tabela 2.1: Influência dos parâmetros de discretização sobre o número de onda na simulação.

\begin{tabular}{c|c||c}
$\delta / \lambda$ & $p$ & $\widehat{\beta} / \beta$ \\
\hline $1 / 10$ & 0.25 & 1.0161 \\
$1 / 20$ & 0.25 & 1.0039 \\
$1 / 10$ & 0.50 & 1.0129 \\
$1 / 20$ & 0.50 & 1.0031 \\
$1 / 10$ & 0.75 & 1.0075 \\
$1 / 20$ & 0.75 & 1.0018 \\
qualquer & 1.00 & 1.0000
\end{tabular}

Na tabela, percebe-se que, $\operatorname{com} p=1$, isto é, $v \Delta t=\delta$, o erro de dispersão resulta nulo. 


\subsubsection{PML}

Durante o processo de simulação, se nenhum cuidado adicional for considerado, haverá a reflexão de campos nas bordas do volume analisado no problema. Uma maneira para se contornar tal situação é obtida ao utilizar-se uma camada absorvedora perfeitamente casada (PML - Perfectly Matched Layer) colocada nas paredes do volume. Essa camada apresenta uma impedância casada na interface entre ela e o meio existente nas suas proximidades e, também, equivale a um meio dielétrico com perdas tanto maiores quanto mais próximo se estiver das bordas do volume. Tais características tendem a evitar a reflexão dos campos quando eles atinjem a camada e os atenuam totalmente antes que alcancem as bordas.

A formulação matemática, a seguir, resume o desenvolvimento apresentado em [2] e parte das equações de Maxwell no domínio da freqüência. Assim, por exemplo, para um caso em 2D, tem-se:

$$
\begin{aligned}
j \omega D_{z} & =c_{0} \cdot\left(\frac{\partial H_{y}}{\partial x}-\frac{\partial H_{x}}{\partial y}\right) \\
j \omega H_{x} & =-c_{0} \frac{\partial E_{z}}{\partial y} \\
j \omega H_{y} & =c_{0} \frac{\partial E_{z}}{\partial x}
\end{aligned}
$$

$\operatorname{com} c_{0}=1 / \sqrt{\epsilon_{0} \mu_{0}}$ e com $D$ e $E$ já normalizados.

As características citadas acima, para eliminação das reflexões, podem ser implementadas criando-se "permissividades" e "permeabilidades" fictícias $\epsilon_{F z}^{*}, \mu_{F x}^{*}, \mu_{F y}^{*}$ [2], resultando em

$$
\begin{aligned}
j \omega D_{z} \cdot \epsilon_{F z}^{*}(x) \cdot \epsilon_{F z}^{*}(y) & =c_{0} \cdot\left(\frac{\partial H_{y}}{\partial x}-\frac{\partial H_{x}}{\partial y}\right) \\
j \omega H_{x} \cdot \mu_{F x}^{*}(x) \cdot \mu_{F x}^{*}(y) & =-c_{0} \frac{\partial E_{z}}{\partial y} \\
j \omega H_{y} \cdot \mu_{F y}^{*}(x) \cdot \mu_{F y}^{*}(y) & =c_{0} \frac{\partial E_{z}}{\partial x}
\end{aligned}
$$


$\operatorname{com} D_{z}(\omega)=\dot{\epsilon_{r}} \cdot E_{z}(\omega)$.

Adicionalmente, deve-se ter as seguintes relações para obterem-se os efeitos esperados da PML:

$$
\eta_{0}=\eta_{\text {meio }}=\sqrt{\frac{\mu_{F x}^{*}}{\epsilon_{F x}^{*}}}=1
$$

$\mathrm{e}$

$$
\begin{aligned}
\epsilon_{F x}^{*} & =\frac{1}{\epsilon_{F y}^{*}} \\
\mu_{F x}^{*} & =\frac{1}{\mu_{F y}^{*}}
\end{aligned}
$$

O valor de 1 para a impedância é devido à normalização realizada nas variáveis. Escrevendo-se $\epsilon_{F}^{*}$ e $\mu_{F}^{*}$ da forma

$$
\begin{aligned}
\epsilon_{F}^{*} & =\epsilon_{F}+\frac{\sigma_{D}}{j \omega \epsilon_{0}} \\
\mu_{F}^{*} & =\mu_{F}+\frac{\sigma_{H}}{j \omega \mu_{0}},
\end{aligned}
$$

conclui-se que a escolha

$$
\begin{aligned}
\epsilon_{F} & =\mu_{F}=1 \\
\frac{\sigma_{D}}{\epsilon_{0}} & =\frac{\sigma_{H}}{\mu_{0}}=\frac{\sigma}{\epsilon_{0}}
\end{aligned}
$$

satisfaz as relações (2.21), (2.22) e (2.23).

Considerando a implementação da PML somente na direção $x$, isto é, deixando de considerar as variações com $y$ de $\epsilon_{F}^{*}$ e $\mu_{F}^{*}$, e substituindo-se em $(2.18),(2.19)$ e 
(2.20) as escolhas anteriores, obtém-se

$$
\begin{aligned}
j \omega\left[1+\frac{\sigma(x)}{j \omega \epsilon_{0}}\right] D_{z} & =c_{0} \cdot\left(\frac{\partial H_{y}}{\partial x}-\frac{\partial H_{x}}{\partial y}\right) \\
j \omega\left[1+\frac{\sigma(x)}{j \omega \epsilon_{0}}\right]^{-1} H_{x} & =-c_{0} \frac{\partial E_{z}}{\partial y} \\
j \omega\left[1+\frac{\sigma(x)}{j \omega \epsilon_{0}}\right] H_{y} & =c_{0} \frac{\partial E_{z}}{\partial x},
\end{aligned}
$$

com $\sigma(x)$ sendo responsável pelas perdas crescentes ao aproximar-se das bordas do volume.

Passando-se, em seguida, ao domínio do tempo, encontram-se as equações de diferenças correspondentes, após algumas manipulações matemáticas.

Assim, por exemplo, tem-se que (2.28a) pode ser escrita na forma

$$
\begin{aligned}
D_{z}^{n+1 / 2}(i, j)= & g_{i 3}(i) \cdot D_{z}^{n-1 / 2}(i, j)+g_{i 2}(i) \cdot 0,5 . \\
& {\left[H_{y}^{n}(i+1 / 2, j)-H_{y}^{n}(i-1 / 2, j)\right.} \\
& \left.-H_{x}^{n}(i, j+1 / 2)+H_{x}^{n}(i, j-1 / 2)\right],
\end{aligned}
$$

$\operatorname{adotando}\left(\Delta t c_{0}\right) / \delta=1 / 2$.

Os parâmetros $g_{i 2}(i)$ e $g_{i 3}(i)$ são dados por

$$
\begin{aligned}
g_{i 2}(i) & =\frac{1}{1+\sigma(i) \cdot \Delta t /\left(2 \epsilon_{0}\right)} \\
g_{i 3}(i) & =\frac{1-\sigma(i) \cdot \Delta t /\left(2 \epsilon_{0}\right)}{1+\sigma(i) \cdot \Delta t /\left(2 \epsilon_{0}\right)} .
\end{aligned}
$$

A equação (2.28c) toma a forma discretizada

$$
\begin{aligned}
H_{y}^{n+1}(i+1 / 2, j)= & f_{i 3}(i+1 / 2) \cdot H_{y}^{n}(i+1 / 2, j)+ \\
& f_{i 2}(i+1 / 2) \cdot 0,5 \cdot\left[E_{z}^{n+1 / 2}(i+1, j)-E_{z}^{n+1 / 2}(i, j)\right],
\end{aligned}
$$


sendo

$$
\begin{aligned}
& f_{i 2}(i+1 / 2)=\frac{1}{1+\sigma(i+1 / 2) \cdot \Delta t /\left(2 \epsilon_{0}\right)} \\
& f_{i 3}(i+1 / 2)=\frac{1-\sigma(i+1 / 2) \cdot \Delta t /\left(2 \epsilon_{0}\right)}{1+\sigma(i+1 / 2) \cdot \Delta t /\left(2 \epsilon_{0}\right)}
\end{aligned}
$$

Já (2.28b), no domínio do tempo e em forma discretizada é implementada pelo conjunto de equações:

$$
\begin{aligned}
\text { rot_e }= & {\left[E_{z}^{n+1 / 2}(i, j)-E_{z}^{n+1 / 2}(i, j+1)\right] } \\
I_{H x}^{n+1 / 2}(i, j+1 / 2)= & I_{H x}^{n-1 / 2}(i, j+1 / 2)+\text { rot_e } \\
H_{x}^{n+1}(i, j+1 / 2)= & H_{x}^{n}(i, j+1 / 2)+0,5 \cdot \text { rot_e }+ \\
& f_{i 1}(i) \cdot I_{H x}^{n+1 / 2}(i, j+1 / 2),
\end{aligned}
$$

com

$$
f_{i 1}=\frac{\sigma(i) \cdot \Delta t}{2 \epsilon_{0}}
$$

Para o caso em 3D e considerando a variação de $\epsilon_{F}^{*}$ e $\mu_{F}^{*}$ nas três direções, tem-se, por exemplo, para uma das equações,

$$
j \omega\left[1+\frac{\sigma_{x}(x)}{j \omega \epsilon_{0}}\right]\left[1+\frac{\sigma_{y}(y)}{j \omega \epsilon_{0}}\right]\left[1+\frac{\sigma_{z}(z)}{j \omega \epsilon_{0}}\right]^{-1} D_{z}=c_{0} \cdot\left(\frac{\partial H_{y}}{\partial x}-\frac{\partial H_{x}}{\partial y}\right) .
$$

Agora, da mesma forma que para o caso em 2D, após as manipulações matemáticas, encontra-se a equação de diferenças correspondente. O mesmo procedimento aplica-se para todas as componentes dos campos $\vec{E}$ e $\vec{H}$.

\subsection{Tecnologia e Recursos: Panoramas Gerais}

É essencial, para o desenvolvimento, uma visão geral das tecnologias e recursos atualmente disponíveis, além de uma estimativa das suas tendências, ao menos, a 
médio prazo. Em tal contexto, o histórico também pode contribuir significativamente.

O material apresentado a seguir é composto de algumas pesquisas e consultas e de observações de casos no cotidiano.

\subsubsection{Breve Histórico dos Recursos Tecnológicos Atuais e do Processamento Paralelo $^{1}$}

Há alguns anos atrás, um grande fator limitante do uso de computadores na implementação dos métodos numéricos era justamente a quantidade de memória requerida, o que permitia apenas a simulação de problemas com dimensões pequenas e baixa acuracidade. Por outro lado, uma vez que um computador possuísse uma quantidade de memória razoável, outro fator limitante emergiria, que é a velocidade de processamento. O processamento paralelo veio, então, para contornar tais situações, com suas diversas arquiteturas conforme descrito na seção 4.4.

Atualmente, os computadores pessoais possuem uma quantidade de memória razoavelmente alta (na média de 128 a 512 Mbytes) e freqüência de clock de processador também alta (de 1,0 a 3,8 GHz), possibilitando, em um único computador, a resolução de problemas de tamanhos razoavelmente grandes em tempo reduzido. Mesmo assim, não deixam de existir aqueles problemas que requerem uma quantidade de memória ainda maior, seja devido à acuracidade desejada ou ao alto nível de detalhamento da região em estudo, com todas as diferentes características existentes nessa região. Por estes fatos, novamente, os computadores pessoais isolados tornam-se insuficientes para encontrar as soluções procuradas. Como os computadores multiprocessados continuam com alto custo e incomuns, aplica-se a alternativa de utilizar os computadores pessoais que já se encontram ligados em rede.

Existem, também, os computadores pessoais com mais de um processador. Eles

\footnotetext{
${ }^{1}$ Os recursos tecnológicos abordados são os correlacionados ao trabalho desenvolvido e o processamento paralelo é apresentado com foco sob o ponto de vista do cálculo numérico.
} 
poderiam apresentar um ganho de velocidade de processamento e, eventualmente, até de quantidade de memória disponível. Contudo, provavelmente por terem um custo um pouco maior do que os computadores de um único processador, eles não são comuns, além de não apresentarem a mesma capacidade de um conjunto de, por exemplo, dez computadores.

Em relação a anos anteriores, a velocidade de processamento aumentou bastante, por volta de 40 a 50 vezes. Juntamente, as placas e os vários periféricos de rede também foram melhorados, com novos conceitos de protocolo de comunicação e com aumentos de taxa de transmissão de até 1000 vezes. Entre as várias placas de comunicação existentes, as placas da "família" Ethernet continuam sendo as mais comuns, embora existam outras. As taxas de transmissão mais freqüentemente encontradas são as de $10 \mathrm{Mbits} / \mathrm{s}, 100 \mathrm{Mbits} / \mathrm{s}$ e $1 \mathrm{Gbits} / \mathrm{s}$. De acordo com a tendência de mercado atual, os novos computadores já vêm equipados com uma placa com taxa de, ao menos, $100 \mathrm{Mbits} / \mathrm{s}$ (que é a Fast Ethernet).

Da mesma forma que os computadores e seus periféricos, os periféricos específicos para a implementação de uma rede, como hubs, switches, roteadores, vêm apresentando avanços tecnológicos. Num primeiro momento, têm-se bastante comuns os equipamentos com taxa de transmissão de $10 \mathrm{Mbits} / \mathrm{s}$. Mas, aos poucos, estes estão sendo substituídos por outros com maiores taxas.

Por fim, o perfil atual médio mais encontrado de rede de computadores, provavelmente, é aquele com computadores com alta freqüência de clock, placa de rede de média taxa de transferência (Fast Ethernet) e circuitos de rede com baixa taxa de transferência, tendendo a ser alterada por uma com média taxa. 


\subsubsection{Arquiteturas de Computador e Sistemas de Processa- mento}

A implementação de um programa com processamento paralelo requer a escolha de uma determinada arquitetura de computador dentre as várias disponíveis. De forma geral, pode-se ter as seguintes arquiteturas:

Computador de processamento em massa: possui diversos processadores, em quantidade muito superior ao computador multiprocessado, por exemplo, 100 processadores, e a memória é distribuída, ou seja, cada processador tem sua própria memória.

Computador multiprocessado: constitui-se de diversos processadores que, normalmente, compartilham a mesma memória; como exemplo, podem possuir 30 processadores.

PC multiprocessado: é um computador pessoal com mais de um processador, mas em quantidade muito menor que um computador multiprocessado, podendo, por exemplo, possuir 4 processadores; a memória é compartilhada.

PC monoprocessado: é um computador pessoal padrão, com um único processador e memória própria.

As arquiteturas multiprocessadas podem ser implementadas com processadores padrão ou processadores desenvolvidos especialmente para esta função, como os transputers, os quais contemplam uma série de otimizações específicas para manipulação e troca de dados e chaveamento entre tarefas, envolvendo os diversos processadores do sistema paralelizado.

Considerando-se as informações acima, percebe-se a existência dos seguintes sistemas de processamento, com significados claros:

- Sistema monoprocessado 
- Sistema multiprocessado com memória compartilhada

- Sistema multiprocessado com memória distribuída

- Sistema multiprocessado com memória compartilhada e distribuída

Obtém-se um sistema multiprocessado por meio de arquiteturas multiprocessadas ou, extensível ou alternativamente, por arquiteturas multi ou monoprocessadas interligadas por rede de comunicação. Neste caso, o sistema também irá apresentar a característica de memória distribuída ou compartilhada e distribuída.

\subsubsection{Periféricos de Rede}

A criação de uma rede de computadores requer periféricos adequados para tal.

A interface entre um computador e a rede propriamente dita é feita por meio de uma placa de rede, a qual pode ser de diferentes tipos. A seguir, encontramse algumas placas de rede com sua taxa de transmissão e uma breve descrição de apresentação:

Ethernet: $10 \mathrm{Mbits} / \mathrm{s}$; foi desenvolvida há pouco mais de 25 anos e é a mais difundida placa de rede.

Fast Ethernet: $100 \mathrm{Mbits} / \mathrm{s}$; desenvolvida para suprir as necessidades de maiores taxas de transmissão numa rede local.

Gigabit Ethernet: 1 Gbits/s; visa atender às situações que requerem taxas ainda maiores.

10 Gigabit Ethernet: 10 Gbits/s; para aplicações em casos especiais onde a quantidade de dados que trafegam em determinado trecho da rede é bastante elevada; foi desenvolvida em anos recentes. 
SCI - Scalable Coherent Interface: 5,33 Gbits/s; possui características notáveis como flexibilidade, escalabilidade, baixa latência, transmissão e recepção simultânea de dados com a taxa especificada, sendo que a alta taxa de transferência de dados não visa apenas a interface numa rede comum, mas sim numa rede de multiprocessamento; nos próximos desenvolvimentos, espera-se atingir taxas de 10,66 Gbits/s.

Myrinet: 2 Gbits/s; suas características notáveis são semelhantes à da SCI; tem-se disponível placa com taxa de 10 Gbits/s.

Daqui em diante, chamar-se-á a associação de um computador com uma placa de rede de ponto da rede ou, simplesmente, ponto.

Para realizar as interconexões da rede, tem-se, essencialmente, os seguintes equipamentos:

$H u b$ : é equivalente a um barramento, de forma que os dados enviados entre um ponto e outro são lidos/filtrados por todos os pontos conectados a ele.

Chaveador (switch): realiza uma conexão lógica direta entre dois pontos enquanto ocorre uma transmissão.

Roteador (router): direciona os dados (pacotes de dados) entre diferentes redes.

Salientando-se a diferença entre hubs e chaveadores, pode-se dizer que os chaveadores conseguem garantir a taxa máxima de transferência de dados entre dois pontos se que comunicam, mesmo se houver mais de um par de pontos em comunicação por meio de um mesmo equipamento simultaneamente, enquanto que os hubs apresentam uma redução na taxa de transferência efetiva entre dois pontos, caso haja mais de um par se comunicando ao mesmo tempo por meio do mesmo equipamento. Por isso, é esperado que, para efeitos de paralelização, o uso de chaveadores apresente uma eficiência maior. 


\subsubsection{Topologias de Redes}

A topologia de rede informa como os pontos de uma rede estão interconectados. Três são os seus tipos, descritos a seguir:

Em estrela: há um elemento central, por exemplo um hub, e os diversos pontos da rede são ligados a este elemento.

Em anel: os pontos são interligados um ao outro seqüencialmente, formando um anel.

Em barramento: os pontos são conectados a um único barramento, constituído por um único cabo (apropriado) conhecido como tronco ou, também, backbone ou segmento.

\subsubsection{Topologias de Processamento Paralelo}

A topologia de um processamento paralelo descreve as características do programa paralelizado a ser executado por cada um dos processadores empregados no sistema. Portanto, em tal contexto, não é única a topologia que se pode adotar. Entre as principais, citam-se as seguintes:

SIMD - single-instruction multiple-data: todos os processadores executam a mesma instrução e são sincronizados no tempo por meio de um seqüenciador.

MIMD - multiple-instruction multiple-data: cada processador envolvido executa seu próprio conjunto de instruções, ficando o sincronismo por conta do programador.

SPMD - single-program multiple-data: cada processador executa um mesmo programa, porém cada um é independente do outro, ficando o sincronismo, também, por conta do programador. 


\subsubsection{Recursos Computacionais}

Aqui, considerar-se-á o recurso computacional como sendo o Sistema Operacional de um computador juntamente com outros programas que poderão ser utilizados para uma determinada tarefa.

Dentre os sistemas operacionais, encontra-se o Windows, bastante difundido e em versão comercial apenas, e o Linux, com considerável popularidade (com tendência de crescimento) e em versão gratuita.

Quanto às ferramentas de desenvolvimento, elas também encontram-se tanto em versões comerciais quanto em gratuitas, para ambos os sistemas operacionais citados. Têm-se disponíveis ambientes de desenvolvimento, compiladores, entre eles o compilador C, depuradores, visualizadores gráficos de dados, bibliotecas para suporte ao processamento paralelo, linguagens para fácil criação de interfaces com o usuário. No Capítulo 4, serão apresentados mais detalhes sobre tais ferramentas.

\subsection{Técnicas de Programação}

\subsubsection{Apresentação}

Realizar uma programação significa escrever o código, na linguagem escolhida, que irá executar uma tarefa de acordo com a lógica desejada.

A tradução desta lógica para um código de computador muitas vezes não é imediata, o que gera a necessidade do desenvolvimento e uso de técnicas adequadas para a sua efetivação.

Antes, contudo, do início da elaboração da lógica, deve-se optar por uma programação estruturada ou não estruturada. Como esta segunda pode causar efeitos secundários indesejados de difícil detecção, o uso da primeira torna-se preferível. ${ }^{2}$

\footnotetext{
${ }^{2} \mathrm{~A}$ programação não estruturada é conveniente de ser utilizada quando se necessita otimizar um trecho de código que não foi possível de ser otimizado da forma desejada ao se utilizar a programação estruturada.
} 
A etapa que precede a escrita do código é a construção de um algoritmo, o qual descreve, em tópicos, toda a lógica seqüencial do programa, mas de uma forma generalizada, ou seja, sem entrar nas "minúcias" específicas do código.

A elaboração do algoritmo, dependendo de sua complexidade, pode tornar-se trabalhosa e ficar muito susceptível a erros de lógica. Neste contexto, simplificando a elaboração do algoritmo, a visualização gráfica da lógica apresenta-se como um elemento auxiliar bastante importante. Dentre as ferramentas utilizadas, encontrase o fluxograma e o Diagrama de Nassi-Schneidermann, sendo a primeira utilizada em qualquer tipo de programação e, a segunda, mais apropriada para programações estruturadas. Um exemplo comparativo entre ambas as ferramentas observa-se na Figura 2.1 e Figura 2.2.

\section{Diagrama de Nassi-Schneidermann - Exemplo}

\begin{tabular}{|l|l|}
\hline \multicolumn{2}{|l|}{$\ldots$} \\
\hline $\mathrm{i}<\mathrm{N}$ & Comando 3. \\
\hline Comando 1. & Comando 4. \\
\hline $\mathrm{N}$ Comando 2. & \\
\hline $\mathrm{j}=\mathrm{K}$ & \\
\hline $\mathrm{i}=\mathrm{i}+1$ & \\
\hline
\end{tabular}

Figura 2.1: Exemplo de um diagrama de Nassi-Schneidermann. Percebe-se que a lógica é representada de forma bastante estruturada e, por isso, este diagrama torna-se uma ferramenta útil para a programação estruturada.

De maneira "sistemática", as etapas envolvidas para a elaboração de um programa são as seguintes:

1. Descritivo, textual, de toda a lógica do programa (o que pode envolver modelamentos físicos, formulações e desenvolvimentos matemáticos). 


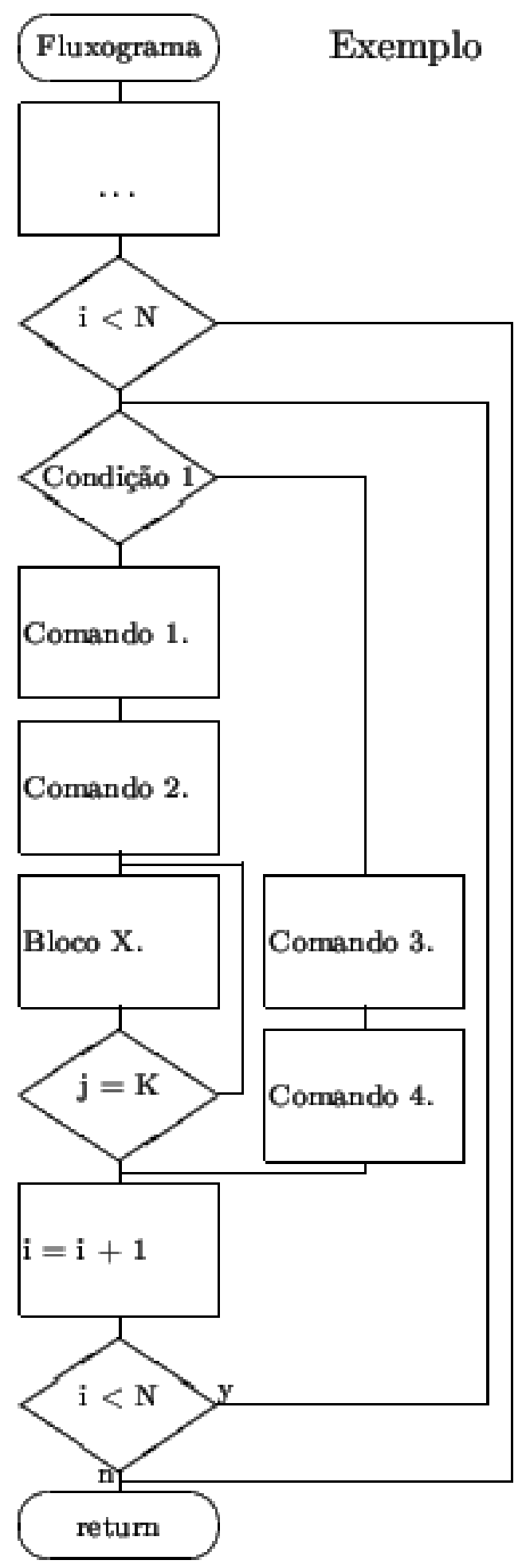

Figura 2.2: Exemplo de um fluxograma. A lógica apresentada é a mesma que a do diagrama de Nassi-Schneidermann, na Figura 2.1. Percebe-se que o desenho ocupa uma área maior, sendo mais volumoso, visualmente, que o diagrama de Nassi-Schneidermann. 
2. Elaboração da lógica por meio de alguma ferramenta gráfica.

3. Escrita do algoritmo.

\section{Codificação.}

Uma técnica adicional, conveniente de ser citada, é a da depuração, com a qual testa-se a lógica e a funcionalidade final do programa e que permite identificar e corrigir eventuais erros que ocorrem ou poderiam ocorrer. E, mesmo após a depuração, muitas vezes tornam-se necessários inúmeros testes sob as diversas situações possíveis de ocorrer, a fim de garantir que o programa não apresente efeitos inesperados - ao máximo que se conseguir em tempo de desenvolvimento, embora ainda exista a probabilidade de, durante o uso, encontrar-se uma situação diferenciada, não testada, com efeitos inesperados, levando a uma nova revisão do programa.

Por fim, durante a programação, torna-se importante dar ao programa - e ao código - certas características especiais, as quais fazem parte das boas práticas de programação, descritas no trecho seguinte.

\subsubsection{Boas Práticas de Programação}

As boas práticas de programação irão garantir ao programa como um todo, e ao código em particular, as características seguintes, com suas respectivas descrições:

Flexibilidade: permite fácil adaptação a diferentes situações.

Consistência: mantém sob a mesma estrutura a escrita do código e o tratamento das informações que se correlacionam.

Redução de código: minimiza as estruturas lógicas e dos laços de forma a obter códigos menores, o que facilita sua implementação e depuração, além de auxiliar na obtenção de executáveis ordinariamente menores. 
Facilidade de depuração: visa a escrita de códigos de tal forma que a depuração torna-se mais simples do que se fosse escrito de outra forma; neste sentido, também contribuem a consistência e a redução de código.

Otimizações: implementa um melhor uso da memória, muitas vezes reduzindo a quantidade total necessária, e gera um código binário capaz de ser executado em menor tempo, devido ao maior aproveitamento dos recursos do processador e (ou) das propriedades da lógica do programa.

Manutenção futura: considera que alterações futuras no código poderão ser necessárias e, por isto, deve-se realizar o desenvolvimento com consciência deste fato.

Expansibilidade: permite agregar novos módulos de cálculo ao programa, mantendo ainda funcionais e independentes os módulos já existentes.

Aplicabilidade: garante que o programa final seja aplicável ao fim para o qual foi desenvolvido.

Interatividade: apresenta condições facilitadas para as interações com o usuário do programa.

Alcançam-se tais características ao serem aplicadas as seguintes técnicas de programação:

Generalidade: desenvolvimento de código com nomeação de constantes e criação de variáveis de forma a tornar o programa suficientemente flexível para uma dada aplicação, o que não seria possível caso fosse utilizada uma codificação "rígida".

Modularidade: implementação de pequenos blocos de programa (sub-rotinas) que executam uma tarefa específica dentre todas as necessárias; cria-se, assim, um módulo responsável por resolver uma parte do problema. 
Estruturação do código: uso de blocos lógicos e de laços com saltos condicionais e de tal forma a não abandonar algum bloco antes do seu término e a não entrar em outro bloco sem passar por sua parte inicial, evitando-se, portanto, efeitos secundários indesejados.

Estruturação dos dados: agrupamento de informações ou variáveis correlacionadas, a fim de facilitar a codificação, contribuir para a consistência e permitir a criação de instâncias de variáveis que descrevem um determinado comportamento.

Reaproveitamento de código: uso enfatizado de sub-rotinas para a realização de tarefas semelhantes, permitindo que, nestes casos, um mesmo código seja executado.

Simplificação de lógica: consideração das propriedades da lógica do programa e dos recursos da linguagem para minimizar a codificação da lógica de um determinado trecho de uma rotina.

Emprego dos recursos da linguagem de programação: implementação do código utilizando os recursos oferecidos pela linguagem de programação, a fim de aumentar a eficácia e a eficiência do código, o que significa obter a funcionalidade desejada com a menor quantidade de instruções possível.

Presença de comentários: escrita de comentários relevantes para o entendimento da lógica e (ou) função implementada em cada bloco de código; este item auxilia no desenvolvimento do programa $^{3}$ e é essencial para a realização de manutenções futuras ${ }^{4}$.

Interfaceamento com o usuário: criação de uma interface de interação com o usuário, em modo texto ou gráfico, que permitirá a entrada dos dados - e parâme-

\footnotetext{
${ }^{3}$ Ao sintetizar o que realiza (ou deverá realizar) certo trecho do programa e, dada a síntese, ajudar a lembrar o que o trecho do programa faz.

${ }^{4}$ Ao lembrar o que cada trecho do programa faz
} 
tros - da tarefa a ser executada, a exibição do estágio atual da execução do programa e a análise dos resultados computados, quando for o caso.

\subsubsection{Nota sobre a Programação Orientada a Objeto}

Com relação à programação orientada a objeto, cabe uma nota especial. Neste tipo de recurso associam-se dados e códigos numa mesma "entidade", o objeto. Assim, conseguem-se características bastante procuradas na programação, como a diminuição de código redundante, pelo reaproveitamento de funções para diferentes dados, e a estruturação dos dados e do próprio código, pela natureza da implementação de tal recurso. Obtêm-se, ainda, algumas outras características adicionais, como a hereditariedade, o encapsulamento e a facilidade de criação de instâncias de um mesmo tipo de objeto, a qualquer momento. Por fim, é perceptível que a programação orientada a objeto apresenta os tópicos citados há pouco, na seção anterior. 


\section{Capítulo 3}

\section{"PARADIGMAS" E SOLUÇÕES}

Os métodos numéricos, por trabalharem sobre uma aproximação matemática de um modelo físico discretizado, não são capazes de resolver todo e qualquer tipo de problema, de forma coerente com o que se observa na realidade e em tempo praticável. Este fato irá acarretar vantagens e desvantagens aos métodos padrão e estas, por suas vezes, tornam-se temas de desenvolvimentos com o intuito de manterem-se as vantagens e encontrarem-se alternativas para minimizar ou anular as desvantagens.

Ainda neste sentido, a programação apresenta-se como um fator importante a ser considerado, pois ela poderá dar ao programa algumas características vantajosas a mais.

É notável, também, que a discretização e a escolha dos "parâmetros" envolvidos influenciarão os resultados.

A seguir, abordam-se os assuntos relativos a tais questões.

\subsection{Vantagens e Desvantagens do FDTD}

O FDTD apresenta as seguintes vantagens, de acordo com suas características:

- Formulação simples; 
- discretização trivial;

- entrada das propriedades dos meios, isotrópicos ou anisotrópicos, de forma direta;

- algoritmo e programação dos cálculos imediatos.

Já as desvantagens associadas ao método, em sua formulação e uso padrão, são as seguintes:

- Geometrias curvas ou com faces ou arestas inclinadas em relação aos eixos principais - considerando-se grades no sistema cartesiano - irão apresentar o efeito de "escadas", isto é, uma descontinuidade na geometria devido a suas discretizações de acordo com a grade;

- alta quantidade de memória requisitada, em problemas que exigem muitos detalhes, tanto por questões de acuracidade quanto pelas dimensões elétricas envolvidas;

- alto tempo de processamento necessário, nas situações apontadas pelo tópico anterior;

- compromisso entre critério de estabilidade, dispersão numérica e discretização, o que influenciará o tamanho computacional do problema e o tempo de processamento.

As vantagens citadas oferecem ao método flexibilidades e facilidades de simulação consideráveis, muitas vezes não encontradas em outros métodos e, por isto, são justificáveis os empenhos para minimizar ou anular as desvantagens, conforme já comentado no início do capítulo. 


\subsection{Processamento Paralelo}

O uso do processamento paralelo aplicado ao método FDTD oferece a oportunidade de se solucionar, ou amenizar consideravelmente, a questão da quantidade de memória necessária para uma determinada simulação e para a redução do correspondente tempo de processamento.

O efeito da redução do tempo de processamento poderá ser alcançado subdividindo-se o volume do problema em mais de uma unidade de processamento e conduzindo-se simultaneamente os cálculos realizados por elas. Para possibilitar o aumento da quantidade de memória disponível, a fim de atender às necessidade de um problema, cada unidade de processamento deverá possuir a sua própria memória. Portanto, percebe-se que a escolha de um determinado tipo de sistema de processamento com a arquitetura de computador correlacionada irá permitir obter o primeiro ou ambos os efeitos desejados.

Contudo, o processamento paralelo requisitará a troca de informações entre as unidades de processamento, seja por questões de sincronismo dos cálculos ou para a troca de dados da interface do volume subdividido. A realização de tal fato exigirá a implementação dos meios adequados de comunicação entre as unidades, o que acarretará num tempo adicional ao de processamento, podendo ser maior ou menor (ou até muitas vezes maior ou menor) dependendo do sistema de processamento e da arquitetura de computador escolhida.

Os computadores mais otimizados para o processamento paralelo são os computadores de processamento em massa, seguidos pelos computadores multiprocessados, utilizados num sistema multiprocessado com memória distribuída e (ou) compartilhada. Nestes casos, o tempo para comunicação entre as unidades de processamento tende a ser bastante baixo. Os custos, entretanto, são consideravelmente elevados.

Como alternativa, é possível utilizar os PCs multiprocessados, que caracterizam, essencialmente, um sistema multiprocessado com memória compartilhada, com me- 
nor custo, embora com capacidade de processamento não tão alta quanto a das duas opções citadas acima.

Outra alternativa é a implementação de um sistema multiprocessado com memória distribuída por meio de computadores ligados em rede. Um sistema assim constituído é normalmente encontrado em instituições de ensino e em empresas. Por isso, seu uso para processamento paralelo, a princípio, não exigirá investimentos adicionais e, portanto, o custo com equipamentos tende a ser nulo. Em contrapartida, o uso de rede irá influenciar bastante no tempo necessário para a troca das informações necessárias. Tal tempo irá ser maior que o de todas as alternativas citadas anteriormente, porém o custo nulo e a já existência das redes são fatores altamente relevantes e que justificam o empenho para uso desse tipo de recurso.

Neste aspecto, ainda, tem-se, nos últimos anos, evoluções consideráveis nos periféricos de rede, tendendo a diminuir os tempos de comunicação entre os computadores, o que viabilizaria, ainda mais, a aplicação de tal sistema para o processamento paralelo.

Se, por fim, for associado ao sistema com computadores interligados por rede o uso de um Sistema Operacional e ferramentas de desenvolvimento e operação livres, tem-se caracterizado um agrupamento do tipo Beowulf.

\subsection{Implementação do Programa}

A maneira mais imediata e - aparentemente - mais rápida de implementação de um programa é a escrita de um código rígido, com uso apenas dos recursos básicos da linguagem de programação e focado em resolver, também apenas, a proposta central, sem dar a devida atenção a outros fatores. Assim, não se utilizam as técnicas disponíveis - muitas vezes convenientes - e não se torna possível obter as características citadas na seção 2.3.

Por outro lado, ao se considerar alguns detalhes adicionais, além da proposta 
central, e dando-se atenção a técnicas mais avançadas de programação, assim como às características citadas na seção 2.3, obtém-se um código mais eficaz e eficiente e, conseqüentemente, um programa mais adequado para ser utilizado como uma ferramenta de trabalho, pesquisa e desenvolvimento.

\subsection{O Uso de Outros Métodos Numéricos}

O método FDTD, como já informado, não é perfeito. Ele não é capaz de resolver todo e qualquer tipo de problema. Há, de fato, inúmeros métodos numéricos e um pode adaptar-se melhor que outro para a resolução de um determinado caso, embora esforços sejam realizados a fim de que um método resolva a maior quantidade possível de casos.

Com o objetivo de salientar a existência de outros métodos, citam-se, a seguir, alguns:

1. FDFD - Diferenças Finitas no Domínio da Freqüência (Finite-Difference Frequency-Domain);

2. FETD - Elementos Finitos no Domínio do Tempo (Finite-Element TimeDomain);

3. MoM - Método dos Momentos (Method of Moments);

4. TLM - Matriz de Linha de Transmissão (Trasmission-Line Matrix);

5. BEM - Método dos Elementos de Contorno (Boundary Element Method).

Existem, ainda, variantes dos métodos padrão. Citando-se algumas variantes do FDTD, como exemplo, tem-se:

1. FE-FDTD - Elementos Finitos associados ao FDTD;

2. ADI-FDTD - FDTD associado à técnica implícita de direções alternadas; 
3. LOD-FDTD - FDTD associado à técnica localmente unidimensional;

4. D-FDTD - FDTD alterado por Diaz Frits Gerald;

5. DD-FDTD - decomposição de domínio aplicado ao FDTD.

\subsection{Considerações para o Uso do FDTD}

Embora haja, "naturalmente", bastante flexibilidade, o uso do FDTD requer um conjunto de atenções para o ajuste dos parâmetros ou estipulação dos dados do problema a simular, a fim de que ele corresponda a uma boa aproximação do caso real em estudo.

Seguem, então, conforme relatado por [33], orientações e sugestões práticas para o uso do FDTD, principalmente quanto à aplicação da fonte e à escolha do espaçamento da grade:

- Aplicação das fontes:

- A fonte não deverá ser, se possível, uma função da freqüência, a fim de evitar a ocorrência de uma convolução;

- para os casos em três dimensões, a fonte não deve possuir nível CC;

- há duas formas de aplicação da fonte

* por especificação como uma condição de contorno;

* por especificação de uma corrente elétrica ou magnética;

- as simulações que requisitarem análises em regime permanente, poderão fazer uso de fontes senoidais;

- o uso de pulsos - ou seja, formas de onda não contínuas no tempo requer um comportamento, no tempo, apropriado, a fim de satisfazer certas características citadas nos outros tópicos; exemplos: derivada de 
pulso gaussiano, pulso gaussiano modulado, pulso de um único período de seno;

- o tipo do pulso deve ser escolhido com base na maior freqüência de interesse; assim, após a Transformada de Fourier do pulso, considera-se a máxima freqüência como a correspondente a uma amplitude de 5 a $10 \%$ da amplitude máxima do espectro; esta escolha irá interferir no ajuste do espaçamento da grade;

- pelo fato da amplitude do pulso ser nula para tempos anteriores aos do início da simulação, pode haver a necessidade de minimizar a descontinuidade que pode aparecer no momento de aplicação da fonte, pelo fato de ela representar a presença de componentes em alta freqüência.

- Determinação do espaçamento da grade:

- o nível de acuracidade deve ser considerado;

- diferentes saídas de interesse requerem diferentes espaçamentos;

- a geometria, a fonte e a freqüência de interesse influenciam os espaçamentos da grade;

- o espaçamento nunca deve ser maior que $\lambda / 8$, sendo que $\lambda$ é o comprimento de onda no meio de interesse.

- Quanto à dispersão numérica:

- depende fortemente da freqüência;

- depende da direção de propagação na malha, apresentando, então, valores diferentes, por exemplo, na direção de algum eixo e na direção diagonal;

- os erros de fase são cumulativos e, por isso, quanto maior o problema, menor deverá ser o espaçamento da grade.

- Quanto à estabilidade: 
- Deve-se observar o critério de estabilidade, após a consideração dos fatores listados acima.

\subsection{Problemas de Eletromagnetismo que Justificam o Paralelismo}

De maneira geral, os problemas que justificam o paralelismo são aqueles com grandes dimensões físicas, mas com a presença de pequenos detalhes geométricos, relativos ao volume total, com a necessidade de discretizações refinadas, ou aqueles com dimensões elétricas grandes, isto é, nos quais o comprimento de onda é muito pequeno frente às dimensões geométricas envolvidas. Outro fator justificativo é a necessidade de maior acuracidade dos resultados, os quais são, num primeiro momento, tanto mais próximos do real quanto maior o detalhamento do volume analisado.

Nesses casos, haverá uma grande quantidade de células, o que poderá requerer muita memória e (ou) tempo computacional para se realizar a simulação e, com o paralelismo, ambas as questões poderão ser amenizadas ou solucionadas.

Como exemplo prático, cita-se o estudo das tensões induzidas, causadas por descargas atmosféricas, numa linha de distribuição situada próxima a regiões com edifícios. Com um considerável número de células, torna-se possível a discretização de um volume bastante grande, com dimensões da ordem de quilômetros, e detalhamento suficiente para descrever edificações com dimensões da ordem de metros.

Outro exemplo é a conformação de campos eletromagnéticos no interior de uma cabine blindada, a fim de se obter uma certa distribuição dos campos e, assim, otimizar a realização de medições. Implementa-se a conformação dos campos por meio da colocação de placas dielétricas com propriedades adequadas no interior da cabine. E, quanto mais exatidão for desejada na distribuição dos campos, maior refinamento geométrico se deve ter para melhor detalhar as placas acrescentadas, o 
que requererá, novamente, uma maior quantidade de células.

Num terceiro exemplo, tem-se a situação do estudo da distribuição de campos num sistema de aterramento. A princípio, cálculos podem ser realizados considerando-se um condutor equivalente para as várias hastes de aterramento utilizadas num determinado tipo de solo. Realizando-se uma simulação com discretizações bastante refinadas, possibilita-se a consideração da situação real com cada uma das hastes de aterramento e suas propriedades, além das características não homogêneas de um solo real, numa região relativamente grande quando comparada com o tamanho das hastes. Portanto, uma vez mais, muitas células serão necessárias.

Finalizando-se os exemplos, tem-se ainda a simulação da distribuição de campos e determinação de outros parâmetros de uma antena em microfita impressa. As dimensões geométricas são pequenas, mas o comprimento de onda do campo é também, por sua vez, muito pequeno. A presença de leves alterações na geometria somente poderá ser avaliada se a discretização apresentar células com dimensões inferiores a estas alterações, requerendo, então, grande quantidade de células. 


\section{Capítulo 4}

\section{DESENVOLVIMENTOS}

Tendo-se um certo conjunto de conceitos e informações de base, torna-se possível a realização de estudos e trabalhos a fim de se obter novas conclusões e ferramentas, para novos estudos, trabalhos e aplicações práticas.

Abordam-se, a seguir, em detalhes, a proposta de desenvolvimento e todas as etapas do desenvolvimento propriamente dito, com as quais se poderão ter referências à metodologia empregada, aos algoritmos, às técnicas avançadas utilizadas na implementação do programa e às estimativas matemáticas generalizadas do tempo de processamento da simulação, do ganho e eficiência e da quantidade de memória necessária.

\subsection{Proposta}

A proposta de implementação do programa, parte essencial do desenvolvimento, é

"Elaborar um programa de simulação numérica para problemas de eletromagnetismo em três dimensões utilizando o Método das Diferenças Finitas no Domínio do Tempo padrão, prevendo o uso de camadas absorvedoras do tipo PML às margens do volume envolvido, e com o emprego 
do processamento paralelo, num agrupamento de computadores do tipo Beowulf."

A proposta para resolver casos em 3D foi adotada pelo fato de se poder simular problemas mais próximos aos da situação real. As camadas absorvedoras permitem simulações de problemas no espaço livre. Dentre as camadas absorvedoras existentes, optou-se pela PML, por ser bastante difundida e eficaz. O emprego do processamento paralelo, o qual se dará num sistema multiprocessado com memória distribuída utilizando computadores monoprocessados, visa contornar o problema da maior quantidade de memória e do maior tempo de processamento necessários durante a simulação de problemas com alto nível de detalhamento. Escolheu-se o agrupamento do tipo Beowulf para a realização de uma implementação a baixo custo, tendendo a zero, dada a disponibilidade de programas gratuitos que permitem esta implementação. Por fim, o método FDTD foi escolhido por causa de sua simplicidade de programação e sua flexibilidade para as simulações, principalmente quanto à especificação das geometrias e das propriedades dos materiais envolvidos.

\subsection{Metodologia}

Durante o desenvolvimento do estudo e do programa, adotou-se uma metodologia gradativa, partindo-se de uma situação em 1D (uma dimensão), depois em 2D (duas dimensões) e, finalmente, em 3D (três dimensões). A cada estágio, diversas simulações foram realizadas com o objetivo de verificar a validade do código implementado, comparando-se os resultados obtidos com os teóricos. De forma também gradativa, foram-se agregando os outros recursos e características ao programa, como a consideração de meios dielétricos sem perdas, em seguida com perdas, a presença de camadas absorvedoras (inicialmente em 2D), os variados tipos de fontes e o interfaceamento com o usuário. Desde os casos em 1D, o paralelismo foi sendo empregado e os testes realizados, num primeiro momento, em nós computacionais 
virtuais e, da implementação em $2 \mathrm{D}$ em diante, em nós computacionais virtuais e reais.

Entenda-se por nó computacional, referenciado acima, como uma unidade de processamento constituída, neste trabalho, de acordo com as escolhas expostas na seção 4.1, por um computador monoprocessado com sua própria memória, que se encontra conectado a uma rede de computadores semelhantes. Ainda, deste ponto em diante, o nó computacional será referenciado apenas por nó. As unidades resultantes da subdivisão por meio de uma grade serão chamadas, neste texto, apenas de células e não de nós, como às vezes são chamadas.

A diferença entre nós virtuais e reais será exposta na seção 4.4.2.

\subsection{Ambiente e Ferramentas}

O Sistema Operacional adotado foi o Linux, que possui diversas distribuições livres disponíveis na internet.

$\mathrm{Na}$ internet também encontram-se, gratuitamente, todas as ferramentas utilizadas no desenvolvimento do trabalho.

O pacote LAM/MPI oferece os recursos para a paralelização de código. A linguagem de programação escolhida foi a Linguagem $\mathrm{C}$ e o compilador é o $G N U$ Compiler Collection (GCC), também conhecido como GNU C Compiler. Os depuradores de código utilizados foram o GNU Debugger (GDB) com a interface gráfica The Data Display Debugger (DDD). A ferramenta de visualização empregada foi o Visualization Tool Kit (VTK), o qual contém um conjunto de objetos bastante extenso e completo para a visualização de dados e possui suporte para integração com a Linguagem $\mathrm{C}++$, Phyton e Tool Command Language/Tool Kit (Tcl/Tk). Em se tratando dessas linguagens, a escolhida foi a $\mathrm{Tcl} / \mathrm{Tk}$, com a qual, além de utilizar os recursos do VTK, criou-se a interface de interação com o usuário. Em certa etapa do desenvolvimento, empregou-se, também para a visualização, o ImageMagik e o 
Octave. O editor de textos empregado foi o Vi Improved (VIM), o qual apresenta inúmeros recursos de edição. Durante os testes, a necessária análise do fluxo de dados pela rede pôde ser realizada com o uso do Ethereal (The Ethereal Network Analyser). A documentação foi gerada por meio do $\mathrm{LT}_{\mathrm{E}} \mathrm{X}$, algumas figuras e gráficos por meio do MetaPost e algumas imagens, para melhor expressarem as informações nelas contidas, foram editadas por meio do Gimp (The Gimp). O programa faz uso da alocação dinâmica de memória, implementada com auxílio da biblioteca Dynamic Array Allocator (daa).

Opcionalmente, na elaboração do programa, poderia ter sido empregado o ambiente de desenvolvimento integrado do KDE, o KDevelop, mas optou-se por não utilizá-lo, a fim de realizar tal tarefa totalmente em modo texto, devido a algumas vantagens de edição. Outro recurso conveniente de ser citado, embora não utilizado, é o Parallel Visualization Application (ParaView), o qual, tendo sido desenvolvido com base no Tcl/Tk, fazendo uso do VTK e do MPI, permite a visualização de dados num sistema paralelizado, sem a necessidade da transferência dos dados para um único computador, o que pouparia tanto o tempo para a reunião dos dados quanto para a visualização propriamente dita, pelo fato de cada computador possuir menos informações a processar.

Em relação à programação, uma referência bastante completa a respeito de bibliotecas que podem ser utilizadas pela Linguagem C encontra-se em [34].

Quanto à escolha de um pacote com os recursos para a paralelização, cabem alguns esclarecimentos.

Qualquer que seja a topologia de processamento ou a arquitetura de computador, a realização do processamento paralelo requer uma troca de dados entre os nós de forma sincronizada. O próprio Sistema Operacional, por sua vez, já fornece meios para troca de informações e sincronismo. Contudo, a programação pode tornar-se extensa e muito susceptível a erros. Com o objetivo de contornar esta questão, ferramentas próprias foram desenvolvidas, de forma que para o programador basta 
usar um conjunto de funções de alto nível que executam as tarefas desejadas. A complexidade do programa ficará por conta do tipo de problema a se resolver.

São diversas as ferramentas existentes, entre as quais encontram-se a C paralelo (Cpar), a PVM, a MPI, a Power C e a High Performance Fortran (HPF).

Justifica-se a escolha da MPI por sua grande popularidade, flexibilidade, facilidade de uso e pelo fato de haver versões gratuitas. Complementando, a MPI é uma biblioteca com suporte para a linguagem de programação $\mathrm{C}, \mathrm{C}++$ e Fortran e as distribuições livres mais comuns são a LAM/MPI, a MPICH e a Object-Oriented MPI (OOMPI), esta última apresentando recursos de programação orientada a objeto. A distribuição MPI adotada é a LAM/MPI.

Todos esses programas são licenciados por alguma licença gratuita, como, por exemplo, a General Public License (GPL), mantida pela Free Software Foundation (FSF). GNU's Not UNIX (GNU) é um projeto que surgiu com o objetivo de criar um sistema semelhante ao UNIX, mas com programas livres.

\subsection{Processamento Paralelo}

\subsubsection{Características}

Um dos principais tópicos que devem ser definidos na etapa de desenvolvimento de um código para o processamento paralelo é o sincronismo entre os nós necessário para a realização das trocas de informações entre eles, no momento certo

As trocas poderão ser feitas por comunicação bloqueante ou não-bloqueante. $\mathrm{Na}$ primeira, o programa pára no ponto de troca e espera o término da transação dos dados para continuar, sendo o sincronismo, por isso, implícito. Na segunda, inicia-se a transação dos dados e o programa continua o processamento das instruções que se seguem; haverá, contudo, em algum momento adiante, a necessidade de executar um comando para o sincronismo entre os nós, definindo, assim, um sincronismo 
explícito. A vantagem desta segunda aproximação é o aproveitamento do tempo de comunicação, que pode ser longo, para "adiantar" alguns cálculos. Como desvantagem, um cuidado adicional é requisitado para o sincronismo, a fim de não se realizar cálculos que dependam de dados de outros nós antes que estes tenham sido obtidos.

No presente momento, optou-se pela escolha do primeiro tipo, a bloqueante, ficando a outra opção como proposta de um trabalho investigativo futuro.

A topologia do processamento paralelo, conforme o sistema de processamento e o tipo de agrupamento adotados, é o Single-Program Multiple-Data (SPMD). Por isso, todos os computadores irão executar o mesmo programa, mas cada um terá seu próprio conjunto de dados a processar.

Na rede de computadores, haverá um deles que será definido como nó gerenciador, o qual se responsabilizará pela etapa de definição do problema, subdivisão dos dados entre os demais nós e, após o término dos cálculos, concatenação dos resultados obtidos pelos nós. Ele também realizará os cálculos sobre o trecho de dados que lhe for destinado.

\subsubsection{Uso da Biblioteca de Comunicação LAM/MPI}

Antes do uso de qualquer função da biblioteca LAM/MPI, responsável pelas tarefas de troca de informação entre os nós, deve-se realizar uma operação de boot, de tal forma que os nós a participarem do processamento sejam visíveis uns aos outros e saibam quem é quem.

Para tanto, o recurso de acesso remoto do Sistema Operacional é empregado. Há, basicamente, duas possibilidades: utilizar o rsh ou o ssh. O primeiro é um simples programa para acesso remoto e, o segundo, um programa com algoritmos mais eficientes, quanto ao aspecto da segurança, confidenciabilidade e integridade dos dados. Ainda quanto ao segundo, as versões 1 e 2 do protocolo de autenticação são suportadas. As propriedades previamente citadas são obtidas por meio da versão 
2.

Por tais motivos, será escolhido o ssh com a versão 2 do protocolo de autenticação.

Devido aos fatores de segurança de acesso, no momento em que um nó conecta-se a outro, a senha do usuário no nó remoto é pedida. Contudo, isto não é desejável, a fim de que o programa não pare a cada simulação para a digitação da senha para cada um dos nós utilizados. Com o intuito de contornar este fator, pode-se criar uma chave de acesso, um código criptografado que fará a identificação do usuário de um nó que requer uma conexão a outro nó. Esta chave subdivide-se em duas partes: uma chave pública e uma chave privada. O nó com o usuário que possui a chave privada poderá acessar todos os nós, com o mesmo usuário, a princípio, que possuírem a chave pública. Evita-se, assim, a necessidade de se digitar a senha do usuário.

Por outro lado, durante a criação da chave, existe a possibilidade de se criar uma frase de passagem (passfrase), para garantir a segurança do acesso, dificultando invasões, e esta frase é pedida durante a requisição de uma conexão. Novamente, isto não é desejado e técnicas existem para se criar uma frase de passagem e realizar a conexão sem que ela tenha que ser digitada. Outra alternativa, é a definição de uma frase nula, garantindo-se que nada terá que ser digitado no momento da conexão, porém haverá uma maior susceptibilidade a invasões.

O uso da frase de passagem apresenta-se interessante quando se considera a implementação do sistema paralelizado em computadores que são normalmente utilizados para trabalhos de acesso restrito, como no caso dos computadores existentes num departamento de recursos humanos de uma empresa. Em outras situações, a possibilidade de invasões ou o risco de se perder trabalhos ou informações importantes é baixo e a frase de passagem não precisa ser criada.

De forma resumida, a criação da chave e a cópia de sua parte pública aos nós que irão receber a conexão, dá-se pela seguinte seqüência de comandos, no shell do 
Linux:

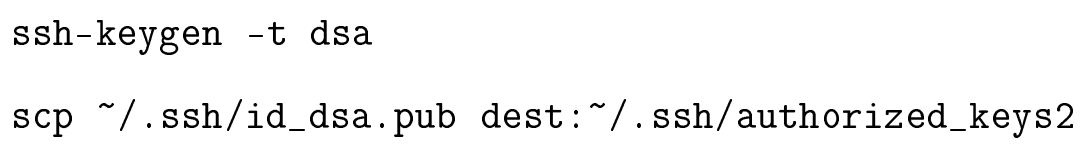

A primeira linha realiza a criação da chave utilizando a versão 2 do protocolo de autenticação, momento em que é pedida também a frase de passagem (isto é, ela foi definida como sendo nula). Neste trabalho, optou-se por não criar a frase de passagem. A segunda linha irá copiar a parte pública para um nó a ser acessado, o nó dest. Ela deverá ser repetida para todos os nós a serem acessados. dest é especificado como um endereço IP ou um nome de máquina e, opcionalmente, domínio conhecido pelo sistema.

Após a criação da chave, um teste pode ser realizado por meio de

ssh dest

Se a chave foi adequadamente criada e instalada, com este comando deve ocorrer a conexão em dest sem a necessidade de se digitar senha ou frase de passagem. (Somente durante o processo de cópia da parte pública da chave é que será pedida a senha.)

Ainda, há quatro observações relevantes quanto a esta etapa:

- Em / .ssh/ dos nós a receberem a conexão, deve-se deixar apenas o arquivo authorized_keys2, a princípio;

- o diretório .ssh, que é criado durante a criação da chave, se não existir, deverá possuir o modo 700; caso contrário, a chave não será reconhecida;

- o arquivo authorized_keys2 deverá possuir o modo 600, para que a chave seja reconhecida; e

- se for necessário obter mais informações sobre as transações realizadas durante o processo de conexão, pode-se fazer um teste com ssh -v dest. 
Mais detalhes sobre este assunto poderão ser encontrados nas páginas de manual dos comandos envolvidos e através de [35].

Neste ponto, o sistema encontra-se preparado para a realização do boot da biblioteca LAM/MPI propriamente dito. Essencialmente, o comando seguinte deverá ser executado:

lamboot -ssi boot_rsh_agent ssh -v hostfile

O parâmetro boot_rsh_agent ssh passada à opção -ssi indica ao programa de boot lamboot que a conexão será inicializada por meio de ssh. Esta escolha se faz necessária porque o padrão é realizar a inicialização por meio de $r$ sh. A opção -v simplesmente faz com que o programa exiba algumas informações enquanto é executado. Já hostfile é o nome do arquivo que contém uma lista de nós que farão parte do sistema paralelizado. A especificação dos nomes dá-se um por linha e da mesma forma que a de dest, como citado anteriormente na página 56. Adicionalmente, neste arquivo, as linhas iniciadas por \# serão tratadas como um comentário. O uso dos nós, assim inclusos, num determinado processamento, realizar-se-á de acordo com o que será requerido na inicialização do programa paralelizado, podendo-se não empregar todos os nós ou, ao contrário, algum nó sendo empregado mais de uma vez, de acordo com a seqüência cíclica da listagem presente no arquivo hostfile.

Concluído o boot, o sistema torna-se apto a executar um programa paralelizado, por meio de mpirun. Uma forma de chamada é a seguinte:

$$
\text { mpirun -c nn prg_paralelizado args_prg_paralelizado }
$$

O parâmetro nn da opção -c especifica quantos nós deverão ser utilizados para a execução do prg_paralelizado. Após esta opção, vem o nome do programa a executar e seus argumentos. Todos os nós, por suas vezes, deverão possuir uma cópia do binário de tal programa. Convém ressaltar que mpirun não realizará a subdivisão dos dados entre os nós. Ele, de forma geral, irá apenas estabelecer quais 
e quantos nós farão parte da execução do programa. A subdivisão dos dados ficará, portanto, por conta do próprio programa.

No decorrer de várias execuções do programa paralelizado, principalmente durante a etapa de testes, há a possibilidade de ficarem vestígios de objetos na memória e erros de comunicação ocorrerem. Com o intuito de removê-los, tem-se o lamclean. Acrescentando-se a opção -v, será exibida a ação em progresso.

Após o término da execução do programa, pode-se fechar as conexões entre os nós por meio de wipe. Mais uma vez, o uso da opção -v fornecerá informações sobre o progresso.

Uma nova seção de boot se fará necessária para a execução de um programa paralelizado sempre que as conexões tiverem sido fechadas ou quando desejar-se alterar a quantidade total dos nós disponíveis.

Um recurso, que neste trabalho não foi investigado, mas que se apresenta ser bastante útil, é o suporte à depuração do programa paralelizado, de forma a terse um acompanhamento dos detalhes de sua execução em todos os nós. Ficará, portanto, como proposta de um estudo futuro.

Detalhes adicionais sobre o processo de boot e outros recursos de programas que acompanham a biblioteca LAM/MPI encontram-se em [36].

A biblioteca apresenta-se bastante flexível quanto às possibilidades de execução paralelizada de um programa. Em mpirun pode-se especificar mais nós que a quantidade total realmente disponível. Neste caso, algum nó real receberá mais de um "pacote" para processar e isto é concretizado por se criar uma tarefa para cada "pacote". Considerando-se o uso de computadores monoprocessados, as tarefas serão chaveadas ao longo do tempo. Se fossem empregados computadores multiprocessados, as tarefas seriam distribuídas entre os processadores (provavelmente, esta distribuição é de responsabilidade do Sistema Operacional - tal questão também é tema de um trabalho investigativo futuro). Portanto, pode-se definir duas terminologias adicionais: a de nó real, quando existe um computador físico em uso para as 
várias subdivisões, e a de nó virtual, quando são criadas tarefas concomitantemente num mesmo computador, para as várias subdivisões. Os nós virtuais tornam-se bastante interessantes na fase de desenvolvimento do programa, para fins de testes e depurações, poupando o tempo de preparo dos nós reais e a necessidade de suas disponibilidades.

Após a inicialização do sistema e programa paralelizados, por meio da etapa de boot e do uso de mpirun, os nós envolvidos, presentes na listagem do arquivo hostfile, recebem uma numeração seqüencial crescente a partir de zero, a qual será a responsável pela identificação do nó no programa paralelizado. Para um nó, por exemplo, enviar dados a algum outro, basta que ele saiba qual o número de identificação deste outro.

Muitas vezes, contudo, a forma de subdivisão do problema a resolver-se fornecerá maiores ou menores simplificações de programação. Por exemplo, um volume a ser processado poderá ser subdividido segundo uma topologia bidimensional, conforme será discutido na seção 4.7.6. A transferência de dados entre dois nós que se encontram "um acima do outro" iria requerer, por cada nó, um cálculo para a determinação do número de identificação do outro nó, considerando-se a numeração seqüencial da esquerda para a direita e de cima para baixo, conforme mostra-se na Figura 4.10 à página 84. Embora o cálculo não seja complicado, todo programa com uma subdivisão deste tipo teria que realizar esta operação, prevendo, por questões de flexibilidade, quantidade de nós e de subdivisões quaisquer. Além disto, a subdivisão pode assumir outra topologia, como, por exemplo, a tridimensional. Neste caso, novamente, os cálculos de identificação deveriam prever também esta situação.

A fim de facilitar a identificação dos nós nestes casos, pode-se criar uma topologia entre eles, conhecida como topologia cartesiana. Com tal recurso e com algumas funções existentes na biblioteca MPI, a referência aos nós passa a ser por meio de suas coordenadas segundo um eixo cartesiano. Assim, conforme o exemplo citado há pouco, numa topologia de subdivisão bidimensional, os nós que estariam "um 
acima do outro" poderiam ser identificados pelas coordenadas $(x, y)$ e $(x, y+1)$, sem a necessidade de cálculos adicionais. As vantagens do emprego desta topologia entre os nós completam-se ao se realizar uma subdivisão do volume de dados com a mesma topologia. A topologia de subdivisão bidimensional foi a adotada no trabalho, por ser suficiente para atender os requisitos inicialmente propostos de desenvolvimento.

Considerando-se tal topologia, a transferência dos planos de dados na interface entre os nós não se realizará de forma direta. A transferência será otimizada se forem transmitidos blocos de dados lineares na memória, isto é, dados que se encontram numa faixa de endereços seqüenciais na memória. Devido à forma como os dados do volume são armazenados, certamente em algum plano da interface eles não serão lineares. Com o objetivo de criar uma forma simples de linearização dos dados antes da transferência, foram disponibilizados, pela biblioteca, tipos especiais de dados, conhecidos como dados definidos pelo usuário, os quais são nada mais que mapeamentos da estrutura de ordenação sob a qual os dados se encontram. Utilizando-se estes tipos de dados nas funções de transferências, a própria biblioteca irá linearizar os dados antes de transmiti-los. Esta funcionalidade, contudo, apresenta certas limitações com quantidades muito elevadas de dados. Observaram-se erros ao se utilizar este recurso para realizar a transferência dos subvolumes aos nós correspondentes. Contudo, na transmissão dos planos de dados não houve erros. A princípio, há indicativos de que o limite dos dados mapeados pelo tipo especial seja, no total, de um tamanho máximo de 128 kbytes.

As funções e outras características para a implementação propriamente dita do programa paralelizado poderão ser encontradas em [37].

Mais adiante, no documento, abordar-se-ão alguns aspectos, com certo detalhamento, para a implementação propriamente dita do programa paralelizado. 


\subsection{Recursos do Programa}

Com o objetivo de atender às boas práticas de programação, já descritas, algumas técnicas e providências foram consideradas na implementação do programa.

Devido à correlação existente entre muitas variáveis, por exemplo, as do campo elétrico juntamente com as do campo magnético, criaram-se estruturas de variáveis, forma pela qual as variáveis correlacionadas passam a pertencer a uma única entidade. Este recurso fornece, assim, consistências adicionais à programação e simplificação, otimização e flexibilidade ao código, por realizarem-se referências à correta entidade e suas variáveis para um determinado contexto e por possíveis tratamentos sobre toda ela, como no caso de se passar uma entidade como parâmetro a uma função - o que, por sua vez, viabiliza a criação de várias instâncias de uma mesma entidade a fim de que cada uma represente uma situação própria, porém com contexto semelhante, como, por exemplo, a criação de diferentes fontes, conforme será abordado em seção futura.

Além do uso das estruturas de variáveis, especial atenção foi dada, também, à modularidade do código, construindo-se sub-rotinas, normalmente pequenas, que executassem uma certa atividade dentro das atividades necessárias do programa. Por exemplo, há sub-rotinas para a transmissão e recepção dos dados entre os nós, para a criação da geometria, para a aplicação da fonte, para os cálculos dos coeficientes da PML e para a gravação dos resultados em disco. Este tópico é uma das características essenciais que darão ao programa flexibilidade e possibilidade de expansão.

Para adicionar, ainda, mais algumas propriedades flexíveis ao programa quanto à elaboração do problema e à simulação, o desenvolvimento adotado possibilitou que o volume do problema fosse ajustável, de acordo com a situação, e a quantidade de nós - lembrando-se, nós computacionais - envolvidos também fosse ajustável. Desta forma, aloca-se apenas a quantidade de memória realmente necessária em cada nó, deixando o restante livre para alguma tarefa em "paralelo" que esteja em execução. 
Permite-se, também, realizar estudos da influência da quantidade de nós no tempo de simulação ou mesmo escolher a quantidade ótima de nós. O recurso utilizado para estes fins foi o da alocação dinâmica de memória.

Os aspectos da consistência do código e da programação foram empregados por meio de: (a) adequadas nomeações de variáveis e funções; (b) pela adoção de um estilo de escrita de código; (c) emprego dos devidos comentários, os quais contribuem consideravelmente para a consistência do programa; (d) atenção à solução da lógica do programa, procurando-se implementá-la da forma mais otimizada sempre que possível e conveniente; e (e) pela reutilização de código, evitando-se redundâncias. Complementa este item, a nível de programa como um todo, a consideração de ocorrência de erros em determinadas operações do programa, como na alocação de memória ou na gravação de dados em disco, e a implementação de funções que intervêm nestas ocasiões, impedindo que o programa termine anormalmente.

Outro fator importante é a interação com o usuário. Quanto mais opções de ajuste de parâmetros relativos ao problema ou à simulação o usuário puder especificar, mais o programa adequar-se-á à situação em estudo e oferecerá maiores liberdades para as pesquisas e investigações de um problema. Com tal intuito, o programa aceita, via linha de comando, a especificação de algumas opções que irão ajustar certos parâmetros do problema, como as dimensões, em número de células nas três direções, a quantidade de subdivisões do volume, em duas direções, e a espessura, também em número de células, da PML. Atualmente, nem todos os parâmetros ajustáveis podem ser alterados pela linha de comando, devendo-se, por isso, realizar alterações diretamente no código. Um exemplo deste fato é a escolha do campo a ser gravado em disco: sua seleção ocorre por diretivas no início do código-fonte, mas melhor seria se pudesse ser escolhido via linha de comando. Tal fato deve-se às "características" de uma implementação que é inicial, ficando as complementações como propostas para um trabalho futuro.

Mais algumas complementações úteis, para flexibilizar o uso do programa, são 
a especificação da geometria do problema, das características de seus materiais e das fontes por meio de arquivos próprios, do tipo texto com descritivos, externos ao programa e que por ele seriam lidos. No momento, novamente, estas especificações devem ser realizadas diretamente como alteração no código; o código, no entanto, já encontra-se preparado para aceitar as especificações conforme citado, bastando apenas a criação de funções para a interpretação dos arquivos. Adicionando-se, ainda, a criação de uma interface gráfica para esta tarefa poderia dar consideráveis contribuições ao usuário, principalmente na elaboração de geometrias mais complexas e (ou) utilização de grande quantidade de materiais diferentes. Mais uma vez, têm-se estas questões como propostas de trabalhos futuros.

Continuando-se ainda com a interação com o usuário, tem-se a opção de exibiremse informações relativas à atividade atualmente em execução pelo programa. Sua utilidade encontra-se tanto no momento de desenvolvimento, permitindo a verificação da evolução do programa, quanto para o usuário manter-se informado sobre o que é realizado. Também, estimativas do tempo restante de simulação são relatadas. Na ocorrência de erros, como já brevemente citado, uma mensagem descritiva do tipo de erro é exibida e, para algumas situações, apontam-se eventuais causas ou soluções para os erros, se for algo previsível. E, ao término da simulação, exibem-se as estatísticas de tempo, útil para analisar o desempenho do programa. As informações fornecidas referem-se ao tempo de inicialização, ao tempo de execução do laço FDTD, subdividido em tempo utilizado para gravações em disco, comunicação e cálculos matemáticos, ao tempo de finalização, subdividido em tempo para a liberação da memória alocada, de agrupamento e gravação final dos resultados e de outras atividades, e ao tempo total, que é o tempo total de execução do programa, igual à soma dos tempos anteriores.

A etapa de visualização dos resultados também é bastante importante e quanto mais recursos forem disponibilizados para a extração das informações dos resultados, mais empregabilidade o programa - ou melhor, o programa principal em conjunto 
com programas auxiliares - encontrará. No presente momento, são oferecidos alguns recursos básicos de visualização: extração de planos de corte, deformação do plano conforme a magnitude da componente de campo analisada, extração do perfil do comportamento do campo ao longo de uma linha, em dois dos três eixos, efeitos de rotação, translação e zoom, seleção do instante de tempo a observar, evolução automática ao longo do tempo - como uma animação -, com tempo inicial e final e passos de tempo ajustáveis - que devem estar de acordo com os resultados gerados pela simulação - e opção de gerar um arquivo em formato POSTSCRIPT com a imagem visualizada.

Quanto aos parâmetros passados pela linha de comando responsáveis por definir o volume do problema, eles terão seus valores corrigidos automaticamente, a fim de que após a subdivisão do volume, com base na quantidade de subdivisões e na topologia de subdivisão, todos os subvolumes possuam a mesma quantidade de células. Adotou-se tal procedimento para simplificar a implementação de alguns trechos do programa. Como conseqüência, obtém-se também um melhor balanceamento computacional entre nós, ou seja, todos os nós irão processar a mesma quantidade de dados, minimizando os efeitos de atraso de processamento por espera de dados de um determinado nó.

Inclui-se também uma comparação entre a quantidade de nós disponíveis e a topologia de subdivisão fornecida na linha de comando, gerando uma mensagem de erro e terminando o programa caso os valores não apresentem compatibilidade, pois o produto do número de subdivisões em $x$ e $y$ deve igualar-se à quantidade de nós disponíveis.

A forma de subdivisão do problema também irá interferir no tempo de comunicação necessário para as trocas de dados. Portanto, tem-se outro fator que influenciará no desempenho final do programa. Este assunto será tratado com detalhes na seção 4.8. A flexibilidade do programa, por sua vez, irá permitir a escolha da topologia de subdivisão que permitirá obter o maior desempenho do programa. 
Há, ainda, o recurso de se obter os máximos dos campos em determinado intervalo de tempo, em cada ponto do volume. Entende-se por "máximo" a amplitude máxima ao longo do tempo, em módulo, do campo num ponto do volume. Este recurso é útil, por exemplo, quando realiza-se uma simulação com fonte senoidal e procura-se encontrar os modos numa cavidade ressonante. Por enquanto, o programa faz a obtenção dos máximos apenas para a componente $E_{z}$.

Adicionalmente, poder-se-ia implementar a verificação automática e eventualmente o ajuste também, dos limites mínimo e máximo para o tamanho das células, considerando o critério de estabilidade e procurando a minimização de erros de dispersão numérica, com o objetivo de evitar que um engano na especificação de algum dado apresente resultados incoerentes inadvertidamente.

Convém salientar, por fim, que o desempenho do programa depende da forma como os dados estão organizados na memória. Utilizando-se a linguagem C, e as definições de variáveis adotadas no programa, tem-se que os dados ao longo de z encontram-se lineares na memória, isto é, em endereços seqüenciais da memória. Assim, os primeiros $X_{z}$ dados seqüenciais da direção $z$, correspondem a pontos com $x$ e $y$ nulos. Após os primeiros $X_{z}$ dados, vêm outros $X_{z}$ dados, mas agora correspondendo a pontos com $x$ nulo e $y$ igual a um. Isto continua para as $X_{y}$ quantidades de seqüências de $X_{z}$ dados. E, após as primeiras $X_{y}$ quantidades, vê m os dados que correspondem a pontos com $x$ igual a um e $y$ nulo. Este processo, então, repete-se $X_{x}$ vezes, completando-se todo um determinado volume alocado na memória. Portanto, o acesso a posições excursionadas em $x$ e $y$ irá requerer multiplicações para a determinação do endereço correto do dado a ser acessado. Tal fato, por sua vez, acarretará maior tempo de execução de um problema. Conclui-se, então, que quanto mais dados se tiver ao longo de $z$, menos multiplicações deverão ser feitas para acessá-los. Por este motivo, no processo de subdivisão do volume, considerou-se o particionamento do volume em $x$ e $y$, mantendo-se $z$ com a dimensão original. 


\subsection{Uso do Programa}

Dados os recursos e características do programa, a sua implementação provê a seguinte sintaxe:

fdtd3d-paralelizado $\left[\begin{array}{llllllllll}-\mathrm{x} & -\mathrm{y} & -\mathrm{X} & -\mathrm{Y} & -\mathrm{Z} & -\mathrm{P} & -\mathrm{t} & -\mathrm{m} & -\mathrm{s} & -\mathrm{h}\end{array}\right]$

em que:

$-\mathrm{x}-\mathrm{y}$ : quantidade de subdivisões em $x$ e $y$

-X -Y -Z: quantidade de células em cada dimensão do volume do problema

-P: quantidade de células da PML

-t: quantidade total de passos no tempo para a simulação

-m: quantidade de passos no tempo a partir do qual serão armazenados os valores máximos do campo

-s: intervalo, em quantidade de passos no tempo, a realizar a gravação das componentes dos campos

-h: exibe a sintaxe com a descrição das opções e encerra normalmente o programa

As opções não inclusas na linha de comando assumirão valores padrão, conforme a tabela 4.1 a seguir, na qual excetuam-se as que não aceitam parâmetros.

Assim, um exemplo de uso, considerando um único nó, seria:

fdtd3d-paralelizado $-\mathrm{X} 100 \quad-\mathrm{Y} 150 \quad-\mathrm{Z} 150$-P8 $-\mathrm{t} 1001$-s10

Desta forma, especifica-se que a subdivisão do problema em $x$ e $y$ é 1 x 1 - ou seja, sem subdivisão -, o volume do problema é de 100 x 150 x 150 células, a PML possui uma espessura de 8 células, serão realizadas 1001 iterações no tempo e serão gravadas as componentes dos campos a cada 10 passos no tempo. 
Tabela 4.1: Valores padrão das opções da linha de comando.

\begin{tabular}{c|c} 
Opção & Valor padrão \\
\hline$-\mathrm{x}$ & 1 \\
$-\mathrm{y}$ & 1 \\
$-\mathrm{X}$ & 100 \\
$-\mathrm{Y}$ & 100 \\
$-\mathrm{Z}$ & 80 \\
$-\mathrm{P}$ & 7 \\
$-\mathrm{t}$ & 1 \\
$-\mathrm{m}$ & sem valor padrão \\
$-\mathrm{S}$ & 10
\end{tabular}

Outro exemplo, semelhante ao anterior, mas agora requisitando a subdivisão do problema na topologia de subdivisão 2 x 2, poderá ser:

mpirun -c 4 fdtd3d-paralelizado -x2 -y2 -X100 -Y150 -Z150 -P8 -t1001 -s10

Quanto à definição de geometrias do problema, conforme já salientado anteriormente, na presente implementação do programa ela deverá ser realizada por meio de alteração no próprio código. Para este fim, foram disponibilizadas funções para facilitar a sua definição, como a Cubo( ), que permite desenhar paralelepípedos, planos e linhas nas direções dos eixos.

As fontes, da mesma forma, deverão ser definidas via código, também possuem funções e, adicionalmente, outros recursos para facilitar sua estipulação.

As componentes dos campos a serem salvas igualmente são selecionáveis, mas por meio de diretivas no código do programa.

Por fim, embora até o presente momento haja a necessidade do fornecimento de muitas informações por meio de código, os ajustes já disponibilizados por opções via linha de comando permitiram a simplificação de uma etapa dos testes realizados - como o estudo do comportamento do tempo total de processamento em função do número de nós. Como outra proposta de trabalho futuro, pretende-se permitir a entrada dos diversos dados e características do problema a simular de forma interativa, sem a necessidade de alterações no código do programa. 


\subsection{O Método FDTD Paralelizado: Algoritmos do Programa}

O programa, como um todo, possui um algoritmo global que define seu comportamento, sendo isto o que é muitas vezes visto pelo usuário. O algoritmo global, contudo, é obtido por meio de uma série de detalhes, que são tratados por algoritmos próprios. Conforme a aplicação, não basta conhecer apenas o comportamento global, mas deve-se ter também um conhecimento dos detalhes, já que o programa não cobre todas as situações possíveis. Considerar este fato poderá apresentar um indicativo se o problema será corretamente simulado, evitando-se que resultados espúrios sejam obtidos como representações do fenômeno em estudo.

Além disto, o conhecimento do comportamento do global e dos detalhes é importante para a manutenção e a extensão do programa, tanto pelo próprio desenvolvedor inicial quanto pelos desenvolvedores posteriores, ou auxiliares. Ainda, torna-se possível a reprodução do programa por outros desenvolvedores, eventualmente contemplando alterações para adaptar-se a um determinado grupo de problemas que o novo desenvolvedor pretende resolver, sendo, neste caso, este programa um programa de base, o mesmo ocorrendo com os algoritmos.

Por tais motivos, são apresentados, nesta seção, os algoritmos global e dos detalhes, relevantes para a implementação do programa.

\subsubsection{Algoritmo Global}

O algoritmo global descreve, de forma resumida, o comportamento global do programa, que é o comportamento com o qual o usuário irá ter contato durante sua execução. Inicialmente, há a especificação e o reconhecimento dos parâmetros passados via linha de comando, seguida pela definição do problema propriamente dito, por meio do "desenho" dos objetos envolvidos, dos materiais que os compõem 
e das caracterizações das fontes a aplicar. Depois, alocam-se regiões de memória para as matrizes a serem utilizadas nos cálculos, tanto para as variáveis quanto para coeficientes e cálculos prévios de valores, a fim de não sobrecarregar o laço do método. As matrizes são, assim, inicializadas e, na próxima etapa, realiza-se a subdivisão e a distribuição do problema aos vários nós computacionais disponibilizados para o processamento. Executam, todos os nós, a partir deste momento, o laço do método FDTD. Ao término, liberam-se as regiões de memória alocadas e os resultados são enviados para um único nó - o nó gerenciador -, que irá concatená-los. Os resultados concatenados serão apenas aqueles salvos de acordo com a escolha das componentes de campo a se salvar e com o ajuste do intervalo de gravação - por meio da opção -s na linha de comando. A Figura 4.1 ilustra este algoritmo.

\section{Algoritmo Global — Comportamento global do programa}

Entrada dos parâmetros.

Entrada do problema.

Alocações de memória para as matrizes.

Inicializações de matrizes.

Subdivisão e distribuição do problema aos nós.

Execução do método FDTD por todos os nós.

Liberações de memória alocada.

Agrupamento dos resultados por um único nó.

Figura 4.1: Algoritmo global do programa, salientando-se, resumidamente, as etapas principais do seu comportamento.

\subsubsection{Algoritmo do Programa Principal}

O programa principal é o responsável pela seqüência de evolução de todo o programa.

No inicio, como é comum, há a declaração de variáveis. Depois, os parâmetros 
das opções da linha de comando são lidos e atribuídos às respectivas variáveis variáveis globais -, para uso nas demais partes do programa. As diversas variáveis e estruturas de dados são inicializadas adequadamente, em seguida.

Na continuação, a biblioteca MPI é inicializada e, a partir deste estágio, têm-se informações a respeito da quantidade de nós empregados no processamento, cada nó obtém também sua numeração de identificação, cria-se a topologia cartesiana bidimensional entre eles, a qual será a mesma da subdivisão do volume do problema, cada nó identifica seus vizinhos adjacentes e define-se o nó gerenciador, que é o próprio nó no qual especifica-se o problema e o qual irá disparar todo o processo. Neste estágio verifica-se, ainda, a consistência quanto à quantidade de nós disponíveis e a topologia de subdivisão fornecida na linha de comando.

Em seguida, os nós irão alocar memória para uma matriz de correlação entre os índices dos dados locais, isto é, em seu próprio subvolume, e os globais, isto é, no volume original do problema. Realizam-se, então, os cálculos necessários para esta correlação. Também, calculam-se as excursões locais, isto é, os índices iniciais e finais, do subvolume de cada nó, para cada componente dos campos elétrico e magnético. Nestes cálculos considera-se a presença de uma margem nos subvolumes, a qual é utilizada durante o envio e recepção dos dados de um nó a outro. Este recurso garante a flexibilidade quanto ao tamanho do volume e à quantidade de nós envolvidos.

Depois, criam-se o tipos MPI especiais, cuja função é mapear os dados dos subvolumes na interface entre os nós, permitindo que eles sejam "linearizados" em um buffer de memória antes de serem transferidos.

A próxima etapa consiste na criação de uma matriz, alocando-a para a definição das propriedades dos materiais envolvidos. Cada linha desta matriz conterá colunas com informações relativas à permissividade elétrica relativa, à condutividade e à permeabilidade magnética relativa. Na formulação implementada, não se consideram materiais ferromagnéticos, mas já se reservou este campo na matriz sob a hipótese 
de futura expansão da formulação. Os objetos, com suas geometrias e meios constituintes, definir-se-ão pela especificação dos índices de linha desta matriz na posição desejada no volume do problema. Assim, nos cálculos futuros, bastarão referências a tais índices para a determinação das propriedades do material em cada ponto do volume.

Prosseguindo-se, cada nó aloca memória para armazenar os subvolumes que lhes serão transmitidos.

Realiza-se, agora, pelo nó gerenciador, o preenchimento do volume com os objetos desejados, estipulam-se os trechos do volume que serão enviados a cada um dos nós e realizam-se as transferências dos subvolumes correspondentes.

Note-se que, apesar do problema ser definido no nó gerenciador, todos os nós possuem as mesmas variáveis e recebem todas as informações passadas pela linha de comando, garantindo o correto conhecimento por eles dos subvolumes e demais parâmetros.

Alocam-se, então, regiões de memória para as componentes dos campos elétrico, magnético e densidade de fluxo elétrico, para constantes matemáticas do meio físico e para os coeficientes e matrizes de integração da PML. Na seqüência, as constantes matemáticas do meio físico são inicializadas, com alguns cálculos prévios utilizando as propriedades dos materiais dos objetos, a fim de não sobrecarregar o laço do FDTD. Os coeficientes da PML são também inicializados.

Entrando-se, neste momento, na execução do método FDTD, tem-se os cálculos iterativos, passo-a-passo no tempo e ponto-a-ponto - célula-a-célula - no volume, da propagação do campo eletromagnético. A cada passo no tempo, trocas de dados entre os nós ocorrem para garantir-se a continuação da propagação do campo pelos vários subvolumes.

Ao término, liberam-se as regiões de memória previamente alocadas, com exceção da região relativa às relações entre os dados locais e globais, que ainda serão utilizadas no agrupamento dos dados. 
Em seguida, agrupam-se os dados e, finalmente, libera-se o restante da memória alocada.

Por último, finaliza-se a biblioteca MPI e o programa, enviando ao Sistema Operacional um código de sucesso de execução (tal código é diretamente enviado porque, na ocorrência de algum erro, o programa não atingiria este ponto).

Encontra-se na Figura 4.2 o algoritmo descrito.

\subsubsection{Algoritmo do Carregamento e Distribuição do Meio Fí- sico}

A função deste estágio é a de carregar as propriedades de cada ponto do meio físico pertencente ao volume do problema em estudo, subdividir os dados do volume em subvolumes e transmitir estes aos demais nós.

Inicialmente, o nó gerenciador aloca, temporariamente, memória para uma matriz suficiente para todo o volume do problema a ser preenchido com os materiais e também para outra matriz, com as mesmas dimensões, que conterá os dados linearizados a serem transmitidos.

"Carregar as propriedades de cada ponto" significa atribuir a cada ponto do volume um índice de material, conforme já descrito na seção 4.7.2, formando, através do posicionamento adequado destes índices no volume, as geometrias desejadas.

Atualmente, esta tarefa é realizada por, praticamente, uma função: a Cubo( ). Esta função aceita como parâmetros a matriz a ser preenchida, no caso, a matriz do volume, as coordenadas de dois vértices diametralmente opostos de um paralelepípedo ("cubo"1), indicando qual região do volume será preenchida, e o valor a ser atribuído aos pontos durante o preenchimento, sendo este o índice do material desejado. De forma simplificada, pode-se dizer que assim se define a geometria. Uma alternativa a esta técnica seria a leitura de um volume, já com os índices dos

\footnotetext{
${ }^{1} \mathrm{O}$ nome "cubo" foi adotado, a exemplo do VTK, por simplicidade de escrita, mas tem-se implementado realmente o código de um paralelepípedo
} 


\section{Programa Principal — Responsável pela seqüência de evolução do programa}

Declaração de variáveis.

Obtenção dos parâmetros da linha de comando.

Inicialização de variáveis e estruturas de variáveis.

Inicialização do MPI.

Alocação de memória para as relações entre os dados locais e globais.

Cálculos das excursões de cada nó e relações entre os dados locais e globais.

Criação de tipos MPI especiais.

Alocação de memória para as propriedades dos materiais.

Alocação de memória para os subvolumes.

Inicialização das propriedades dos materiais.

Carregamento, subdivisão e distribuição do problema aos nós.

Alocação de memória para os campos elétricos e magnéticos.

Alocação de memória para constantes matemáticas do meio físico.

Alocação de memória para a PML.

Inicialização e cálculo de coeficientes da PML.

Cálculo das constantes matemáticas do meio físico.

Execução do método FDTD paralelizado.

Liberação da memória alocada para os campos, constantes matemáticas, PML e das propriedades dos materiais.

Liberação da memória alocada para os subvolumes.

Agrupamento dos resultados por um único nó.

Liberação da memória alocada para as relações entre os dados locais e globais

Finalização do MPI.

Finalização do programa.

Figura 4.2: Algoritmo do programa principal, definindo-se as etapas de evolução do programa. 
materiais, de um arquivo gerado por outro programa.

Após carregar-se a geometria, tem-se a opção de salvá-la em arquivo, indicandose a escolha por meio de uma diretiva.

Com base nas dimensões totais do volume e da quantidade de nós, realiza-se a subdivisão do volume. Antes, contudo, dos subvolumes serem transmitidos, os dados devem ser linearizados na memória, a fim de se enviar, de uma única vez, um bloco completo de dados, o que otimiza a comunicação. Nesta tarefa, a matriz dos dados linearizados é utilizada.

A próxima etapa é a transferência dos dados pelo nó gerenciador aos demais nós. Salienta-se que os nós, neste momento, já possuem memória alocada para a recepção, conforme as etapas apontadas na seção 4.7.2.

Os dados recebidos pelos nós são, então, reordenados ("deslinearizados") na própria matriz de recepção. Neste processo, já se consideram as margens, alocando-se os dados de forma a não ocupar as primeiras e últimas posições da matriz em $x$ e $y$. Novamente, estas margens serão utilizadas durante o processamento do método, para as trocas de dados.

É conveniente notar que o próprio nó gerenciador, o qual transmite os subvolumes, irá também receber um dos subvolumes, o que dá consistência à implementação. Portanto, durante o processamento do método, o nó gerenciador, igualmente aos outros, realizará cálculos.

Finalizando-se, o nó gerenciador libera as memórias temporariamente alocadas. Na Figura 4.3 tem-se o diagrama deste algoritmo.

\subsubsection{Algoritmo do Laço do Método FDTD}

O laço do método FDTD realiza a simulação do fenômeno físico propriamente dita.

O laço é repetido pela quantidade de passos no tempo fornecido pela linha de 
Carregamento e Distribuição do Meio Físico — Obtenção das propriedades do meio físico e sua distribuição aos nós

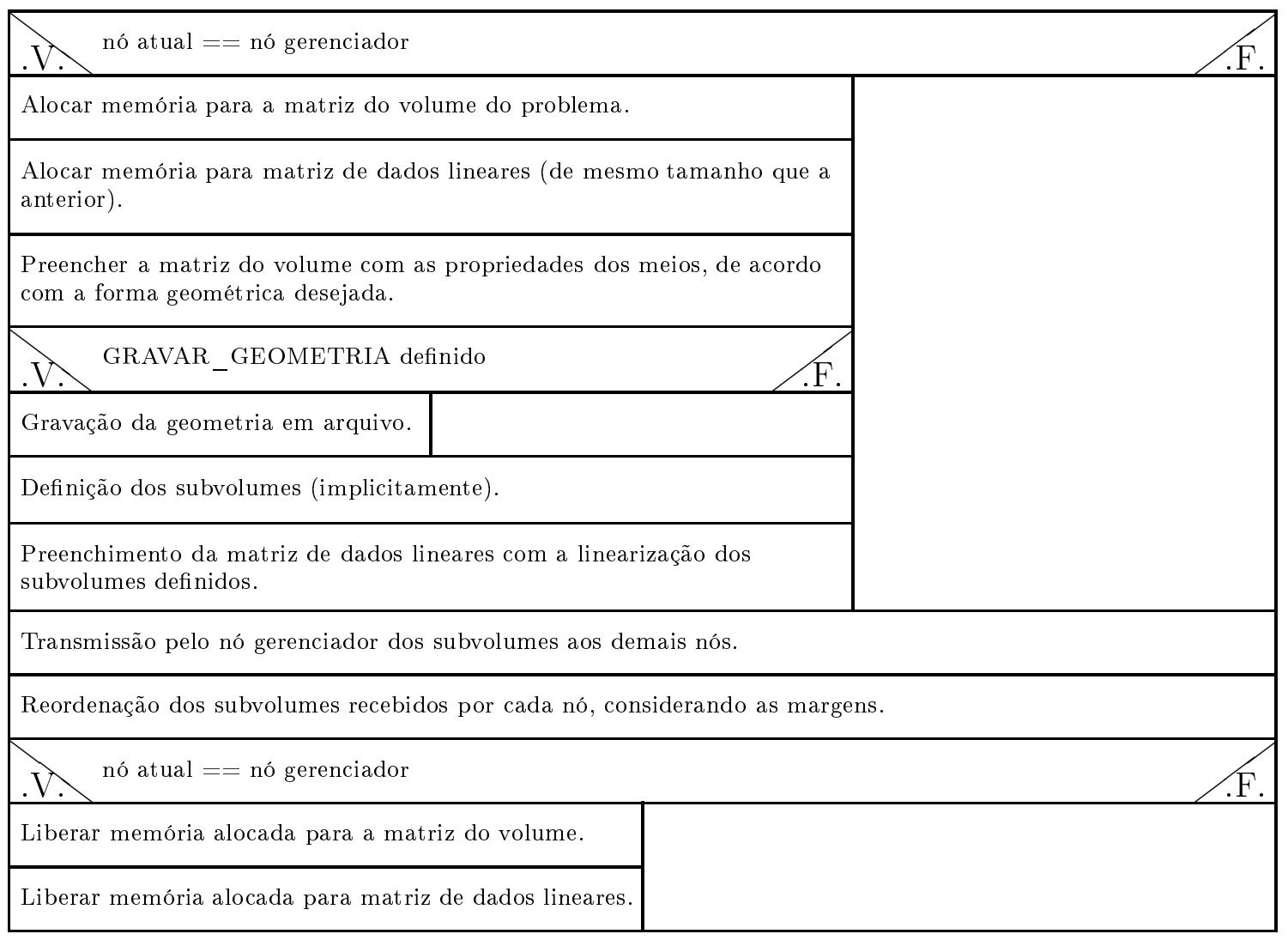

Figura 4.3: Algoritmo para o carregamento das propriedades do meio físico e sua distribuição aos demais nós. 
comando. Na Figura 4.4 apresentam-se as etapas que ocorrem a cada iteração.

Laço do Método FDTD — Implementação do método FDTD paralelizado

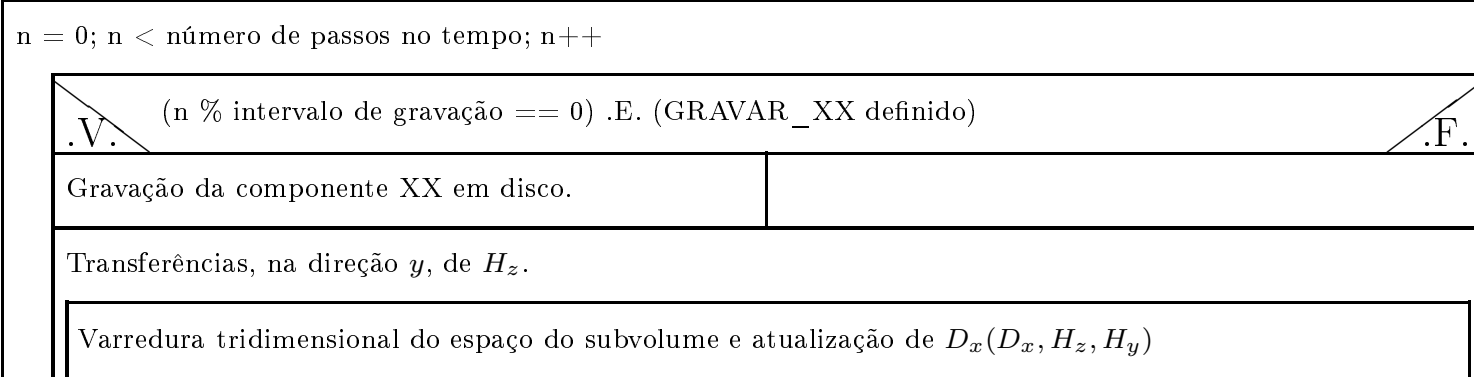

Transferências, na direção $x$, de $H_{z}$.

Varredura tridimensional do espaço do subvolume e atualização de $D_{y}\left(D_{y}, H_{x}, H_{z}\right)$

Transferências, na direção $y$, de $H_{x}$, e na direção $x$, de $H_{y}$.

Varredura tridimensional do espaço do subvolume e atualização de $D_{z}\left(D_{z}, H_{x}, H_{y}\right)$

Aplicação da fonte nas componentes de $\vec{E}$ desejadas.

Cálculos de $\vec{E}(\vec{D})$.

Fixação de $\vec{E}=0$ nas bordas do problema, devido à PML.

. V. (OBTER_MAXIMOS definido) .E. (n>n_LIMIAR_MAXIMOS) .F.

Armazenamento da intensidade absoluta (módulo)

máxima para cada ponto do espaço.

Transferências, na direção $y$, de $E_{z}$.

Varredura tridimensional do espaço do subvolume e atualização de $H_{x}\left(H_{x}, E_{y}, E_{z}\right)$

Transferências, na direção $x$, de $E_{z}$.

Varredura tridimensional do espaço do subvolume e atualização de $H_{y}\left(H_{y}, E_{x}, E_{z}\right)$

Transferências, na direção $y$, de $E_{x}$, e na direção $x$, de $E_{y}$.

Varredura tridimensional do espaço do subvolume e atualização de $H_{z}\left(H_{z}, E_{x}, E_{y}\right)$

Aplicação da fonte nas componentes de $\vec{H}$ desejadas.

Figura 4.4: Implementação do método FDTD paralelizado, podendo-se observar as trocas de dados para o prosseguimento dos cálculos.

Primeiramente, o programa verifica se, no passo de tempo no qual se encontra, deve salvar as componentes de campo, indicadas para gravação por meio de diretivas. 
Na figura, "XX" poderá ser qualquer componente do campo elétrico ou magnético ou do vetor densidade de fluxo elétrico.

Em seguida, antes da atualização de cada componente dos campos, efetivamse as transferências das componentes necessárias, que se encontram na interface entre os subvolumes, para os cálculos poderem proceder. Os cálculos consistem em, numa varredura de todo o volume, encontrar o valor da componente em cada ponto com base em seu valor anterior e no valor das componentes suplementares do outro campo.

Na seqüência, aplicam-se as fontes às componentes dos vetores. Técnicas e características para essa aplicação serão abordadas na seção 4.7.7.

Obtém-se, então, o campo elétrico $(\vec{E})$, calculado por meio de $\vec{D}$ e das características do meio em cada ponto, utilizando-se a matriz das constantes matemáticas do meio físico, a qual também recebe atualizações.

A implementação da PML escolhida requer uma complementação, a fim de se anular o campo elétrico nas bordas do volume do problema. De fato, num caso de PML ideal, o campo que atinge esta região deveria ter valor nulo, a fim de não haver qualquer reflexão indesejada. O que realmente se espera é, então, o anulamento de um campo, nesta região, com amplitude já bastante reduzida.

Continuando-se, caso a opção de obtenção de máximos, conforme abordado na seção 4.5, esteja habilitada e o número de passos no tempo atingiu o limiar especificado pela linha de comando, armazena-se, para cada ponto, a intensidade absoluta máxima da componente de campo em observação.

Na segunda parte do laço, seguem-se as etapas de transferências, cálculos e aplicação de fonte de forma semelhante ao executado para o vetor $\vec{D}$, mas agora para o campo magnético $(\vec{H})$. 


\subsubsection{Algoritmo da Implementação da PML}

Para a implementação da PML, faz-se necessária uma abordagem mais detalhada devido à técnica alternativa empregada.

Após a realização da formulação, do desenvolvimento matemático e da discretização, obtém-se as equações de diferenças seguintes, utilizadas no cálculo da componente $D_{z}$, considerando-se também a PML [2]:

$$
\begin{aligned}
r o t_{-} h= & H_{y}^{n}(i+1 / 2, j, k+1 / 2)-H_{y}^{n}(i-1 / 2, j, k+1 / 2)- \\
& H_{x}^{n}(i, j+1 / 2, k+1 / 2)+H_{x}^{n}(i, j-1 / 2, k+1 / 2) \\
I_{D_{z}}^{n}(i, j, k+1 / 2)= & I_{D_{z}}^{n-1}(i, j, k+1 / 2)+r o t_{-} h \\
D_{z}^{n+1 / 2}(i, j, k+1 / 2)= & g i 3(i) \cdot g j 3(j) \cdot D_{z}^{n-1 / 2}(i, j, k+1 / 2)+g i 2(i) \cdot g j 2(j) . \\
& 0.5 \cdot\left[\text { rot_h } h+g k 1(k) \cdot I_{D_{z}}^{n}(i, j, k+1 / 2)\right] .
\end{aligned}
$$

Para as demais componentes, as equações são análogas.

Como pode ser observado em (4.1), (4.2) e (4.3), há a necessidade de matrizes unidimensionais para os coeficientes $g$ (estes são coeficientes relacionados à atenuação do campos) e matrizes de integração tridimensionais $I_{D}(i, j, k)$ e $I_{H}(i, j, k)$, para a consideração da PML. Estas últimas são tridimensionais e, portanto, ocuparão bastante espaço na memória, salientando-se que existe uma para cada componente do vetor densidade de fluxo elétrico e para cada do campo magnético. Já as matrizes unidimensionais não terão efeito significativo, pois são bem menores.

Analisando-se a região onde a PML está definida, nota-se sua presença apenas nos planos próximos às bordas do volume do problema e chega-se à conclusão que a matriz de integração pode ser definida apenas nestas bordas [27], conforme visualizase na Figura 4.5. No restante do volume não haverá influência alguma da PML.

No processo de codificação, uma solução possível seria criar duas matrizes distintas para cada trecho da PML. Assim, a equação (4.2) poderia ser substituída 


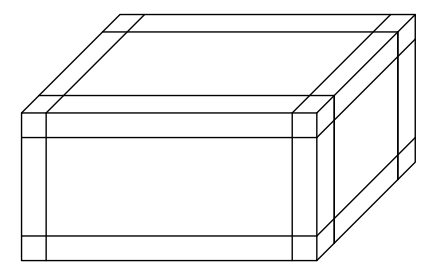

Figura 4.5: Regiões da PML nas faces do problema. Para a implementação da PML, em cada uma destas regiões, há uma matriz tridimensional de integração para o campo elétrico e outra para o magnético.

por duas outras equações, iguais, porém com $I_{D_{z}}$ alterado para $I_{D_{z} 1}$ e $I_{D_{z} 2}$, correspondendo, respectivamente, ao primeiro e ao segundo trecho da PML. Conseqüentemente, para (4.3) incorporar tais mudanças, ela deverá ser implementada em três partes: uma a considerar o primeiro trecho da PML, outra, a região sem PML e outra, o segundo trecho da PML. No trecho sem PML, a parcela relativa a $I_{D_{z}}$, nesta equação, simplesmente não existiria. Por isso, três laços computacionais distintos se fariam necessários para a atualização de cada uma das três componentes de $\vec{D}$, como indicado na Figura 4.6 para a componente $D_{z}$. E o mesmo ocorre para $\vec{H}$. Portanto, a implementação do método conteria um total de 18 laços computacionais.

Percebe-se que, com esta solução, o código ficaria muito extenso, aumentando o potencial de erros de escrita das equações e também o tempo e o trabalho de depuração, além de dificultar futuras manutenções ou alterações nesta parte do código. A paralelização do programa, igualmente, seria dificultada, pelo aumento da quantidade de linhas de código e das hipóteses a considerar.

Realizando-se, agora, uma nova análise da questão, nota-se que a única diferença de cálculo entre a região que possui a PML e a que não possui é a consideração ou não da matriz de integração da PML. Recorrendo-se, ainda, ao fato de que os coeficientes $f$ e $g$ são nulos onde não há PML, chega-se à conclusão de que apenas uma matriz de integração poderá ser definida para atender aos trechos do volume com PML e ao trecho sem PML, pois a multiplicação de um valor nulo por qualquer outro valor fornece um resultado nulo e, portanto, seria equivalente à parcela relativa a esta matriz (no caso das equações exemplificadas, $I_{D_{z}}$ em (4.3)) não estar presente. 
Cálculo de $D_{z}$ - Atualização de $D_{z}$, considerando a PML e utilizando uma técnica padrão

Excursão total em $x$
\[ \begin{array}{r}\text { Excursão total em } y \\ \text { Excursão parcial em } z \text { - trecho } 1 \\ \text { Atualizações de } D_{z}, \text { considerando a PML }\end{array} \]

Excursão total em $x$

Excursão total em $y$

Excursão parcial em $z$ - trecho central

Atualizações de $D_{z}$, sem a PML

Excursão total em $x$

Excursão total em $y$

Excursão parcial em $z$ - trecho 2

Atualizações de $D_{z}$, considerando a PML

Figura 4.6: Diagrama com a lógica para o cálculo da componente $D_{z}$ utilizando uma técnica de implementação padrão. 
Este fato permitirá, então, a implementação de apenas um laço de cálculo para cada componente de campo, como observa-se na Figura 4.7, reduzindo a quantidade total de laços computacionais do método para 6.

Cálculo de $D_{z}$ — Atualização de $D_{z}$, considerando a PML e utilizando uma técnica otimizada

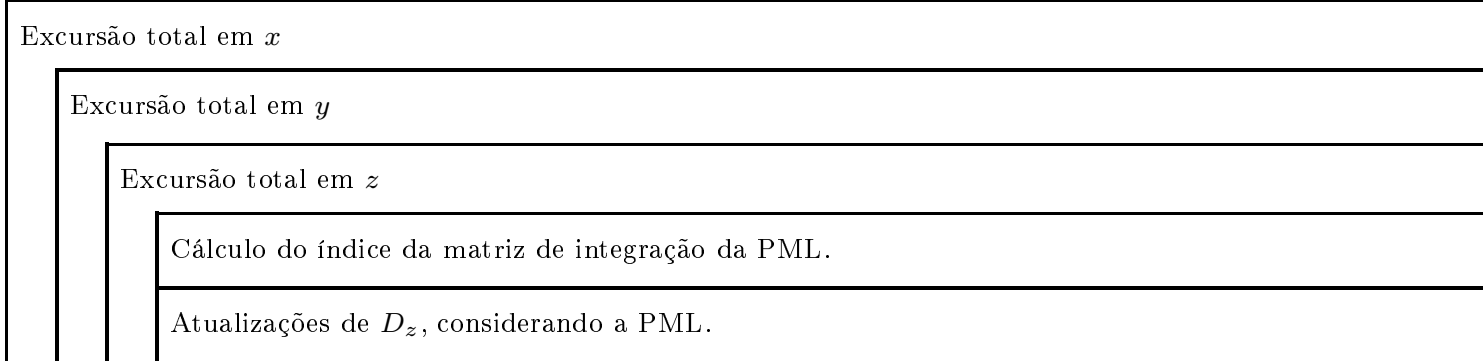

Figura 4.7: Diagrama com a lógica para o cálculo da componente $D_{z}$ utilizando uma técnica de implementação otimizada.

Tal matriz de integração, esboçada na Figura 4.8, é definida na direção da componente à qual ela se aplica e se constitui de três partes: uma região central, bidimensional, de índice nulo, que será utilizada durante os cálculos do trecho central do volume, onde não há PML; uma primeira região extrema, tridimensional, de índices negativos (de -1 a -NCELPML), que conterá elementos cujos valores corresponderão ao cálculo da integral em cada ponto do primeiro trecho de PML do volume, na direção da componente; e uma segunda região extrema, tridimensional, de índices positivos (de +1 a + NCELPML), que terão a mesma função que a primeira, porém para o segundo trecho de PML do volume, na mesma direção.

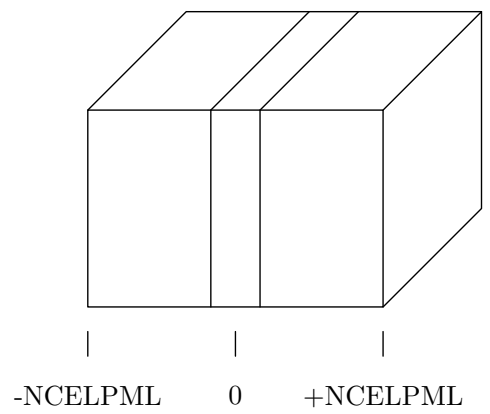

Figura 4.8: Matriz única de integração da PML e seus índices, para a implementação da técnica otimizada. 
Para esta topologia de implementação tornar-se funcional, deve-se gerar uma correta indexação da matriz de integração de acordo com o ponto atual durante a varredura espacial, do laço. Contudo, é aconselhável que o código de indexação não contenha saltos, pois isto iria aumentar razoavelmente o tempo de processamento. A tarefa foi, então, realizada empregando-se recursos oferecidos pela linguagem de programação, permitindo a geração de um código otimizado. Convém notar, contudo, que a otimização só é alcançada se o compilador for instruído a gerar códigos otimizados (utilizando o compilador gcc, a opção -0 deve ser fornecida).

O trecho de código seguinte ilustra a indexação da matriz de integração da PML. Note-se, também, que a somatória da integral é feita no "momento de uso" do valor da integral.

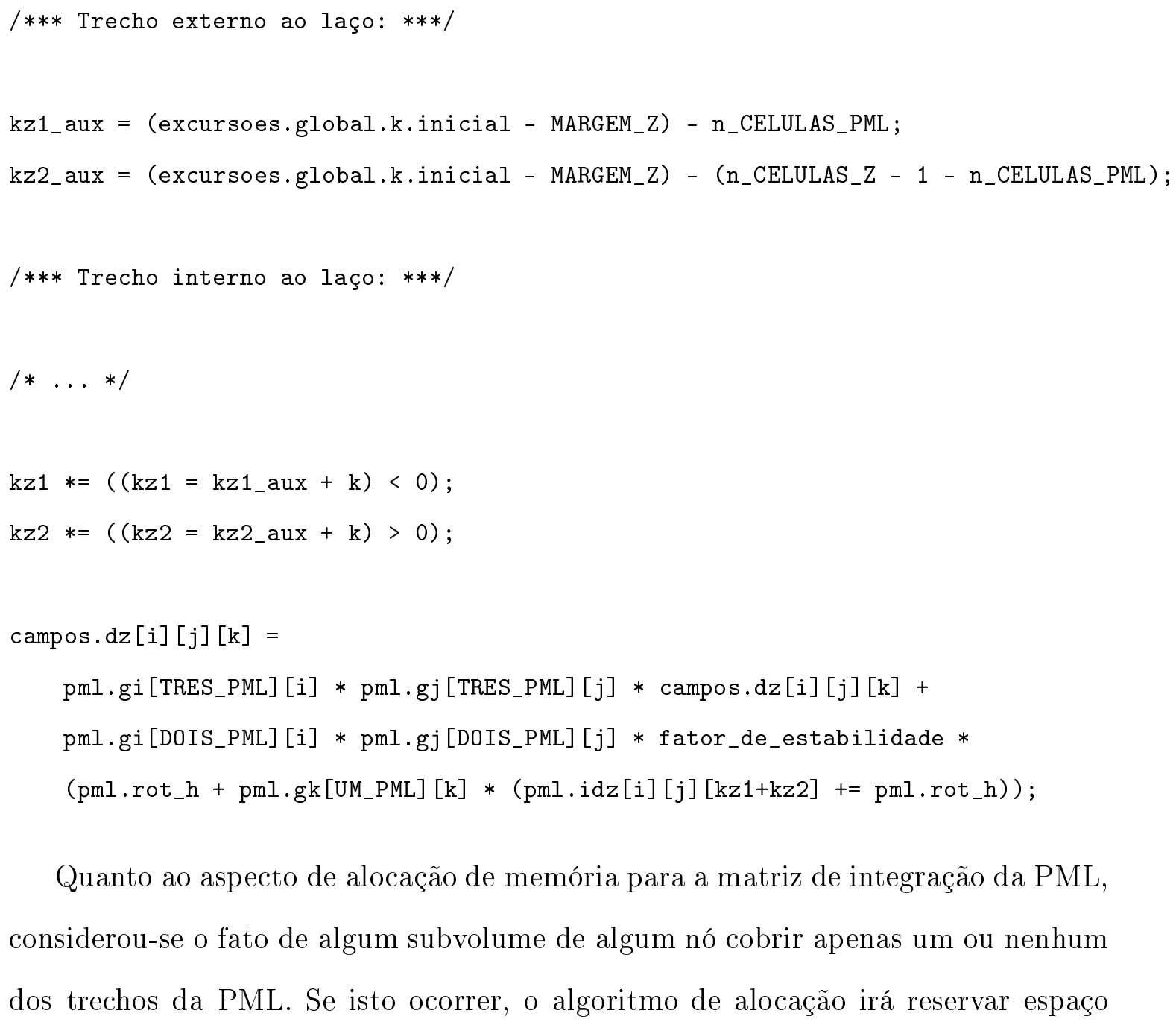

Quanto ao aspecto de alocação de memória para a matriz de integração da PML, considerou-se o fato de algum subvolume de algum nó cobrir apenas um ou nenhum dos trechos da PML. Se isto ocorrer, o algoritmo de alocação irá reservar espaço 
apenas para um trecho, o primeiro ou o segundo, da PML e para a região central, ou somente para a região central, respectivamente. E, quanto ao cálculo da indexação, o código apresentado já considera este fato implicitamente, pois a técnica de cálculo faz referência da posição do ponto no subvolume à posição do ponto no volume total.

Mesmo com a otimização da indexação, o código extra gerado em cada laço, para esta aproximação, acarreta num aumento de 10\% no tempo de cálculo. Contudo, avaliando-se a relação custo/benefício, tem-se um resultado final consideravelmente positivo, pois a minimização do código irá, além de evitar os inconvenientes já citados, permitir uma programação da paralelização dos laços de uma forma mais simples e direta.

\subsubsection{Algoritmo da Transferência dos Dados}

Após o processo de discretização das equações de Maxwell, percebe-se que para se calcular as componentes do vetor $\vec{D}$ e de $\vec{H}$, são necessárias, com o adequado intervalo espacial, as componentes de $\vec{H}$ e de $\vec{E}$, respectivamente. Esta relação pode ser observada graficamente na Figura 4.9. O conhecimento desta relação tem importância essencial para o processo de paralelização, pois irá definir os nós de origem e os de destino, conforme a componente que for transmitida.
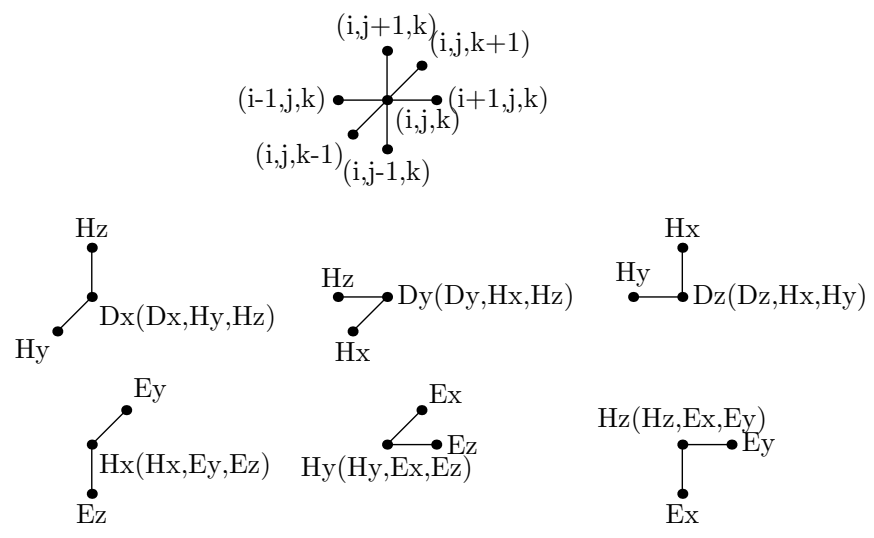

Figura 4.9: Dependências para o cálculo de cada componente dos campos.

Uma vez que cada nó contenha um subvolume de acordo com a subdivisão 
com topologia cartesiana, podem-se traçar as referências apontadas na Figura 4.10. Identificando-se os nós por suas coordenadas cartesianas e seus vizinhos por pontos cardeais, isto é, NORTE, SUL, LESTE, OESTE, e notando que os nós das bordas não possuem todos os vizinhos, traça-se o fluxo de troca de dados, entre os cálculos das componentes, conforme visualizado na Figura 4.11.

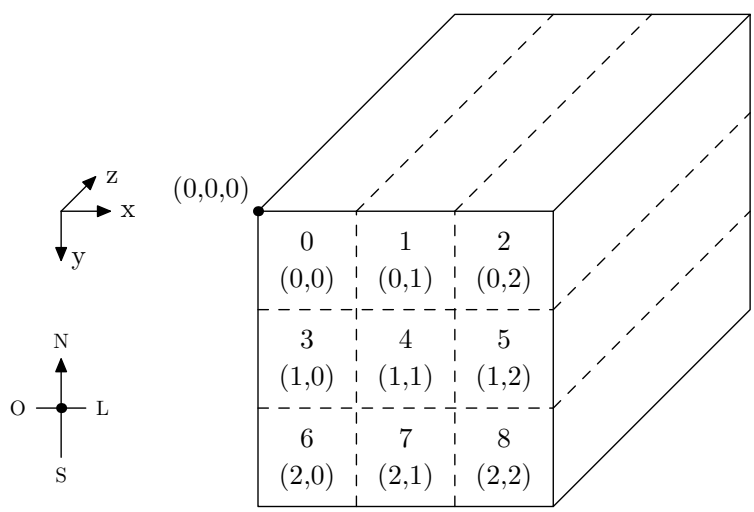

Figura 4.10: Região do problema com as subdivisões e as referências adotadas.

Com tais informações, identifica-se exatamente o momento em que uma transmissão de dados deve ser realizada e, como já dito, sua origem e destino. Daí, é possível perceber também o envolvimento de dados no plano yz para as transmissões LESTE-OESTE, e o envolvimento de dados no plano $x z$, para as NORTE-SUL.

Faz-se importante incluir uma nota quanto ao aspecto de codificação do programa para o envio e recepção dos dados. Os subvolumes de cada nó consideram a existência de um plano de margem às suas bordas, nas direções $x$ e $y$, que são utilizados como buffer de recepção, como já comentado. O objetivo de tal aproximação é o de não quebrar os laços de cálculo durante a atualização das componentes que dependam dos valores recebidos de outro nó. Assim, apenas a parte central destas matrizes possuirá significado físico. Seu esboço encontra-se na Figura 4.12. 
$\operatorname{lin}(\mathrm{no})<\mathrm{ult} \_l$ in $=>\mathrm{T}: H_{z}$ @ SUL

lin(no) $>$ prm_lin $=>\mathrm{R}: H_{z} @$ NORTE

- $D_{x}\left(D_{x}, H_{y}, H_{z}\right)$

$\operatorname{col}($ no $)<u l t \_c o l \Rightarrow T: H z @$ LESTE

$\operatorname{col}($ no) $>$ prm_col $=>R: H z$ Q OESTE

- $D_{y}\left(D_{y}, H_{x}, H_{z}\right)$

$\operatorname{lin}(\mathrm{no})<u l t \_l i n \Rightarrow \mathrm{T}: \mathrm{Hx} @$ SUL

lin(no) $>$ prm_lin $=>R: H x$ @ NORTE

$\operatorname{col}($ no $)<u l t \_c o l=>T$ : Hy $@$ LESTE

$\operatorname{col}($ no) $>$ prm_col $\Rightarrow$ R : Hy @ OESTE

- $D_{z}\left(D_{z}, H_{x}, H_{y}\right)$

$>\vec{E}(\vec{D})$

lin(no) > prm_lin $=>\mathrm{T}:$ Ez @ NORTE

lin(no) < ult_lin => R : Ez @ SUL

- $H_{x}\left(H_{x}, E_{y}, E_{z}\right)$

$\operatorname{col}(\mathrm{no})>$ prm_col $\Rightarrow \mathrm{T}: \mathrm{Ez}$ @ OESTE

$\operatorname{col}($ no $)<u l t_{-} \operatorname{col} \Rightarrow \mathrm{R}:$ Ez $@$ LESTE

- $H_{y}\left(H_{y}, E_{x}, E_{z}\right)$

lin(no) $>$ prm_lin $\Rightarrow \mathrm{T}$ : Ex @ NORTE

lin $($ no $)<u l t \_l i n=>R$ : Ex @ SUL

$\operatorname{col}(\mathrm{no})>$ prm_col $\Rightarrow \mathrm{T}$ : Ey @ OESTE

$\operatorname{col}($ no $)<u l t \_c o l \Rightarrow R$ : Ey @ LESTE

- $D_{z}\left(D_{z}, H_{x}, H_{y}\right)$

Figura 4.11: Fluxo de troca de dados entre os nós. Aqui, têm-se os seguintes significados: $\operatorname{lin}($ no) e $\operatorname{col}($ no) representam a linha e a coluna, respectivamente, do nó corrente, isto é, aquele que está executando este código, de acordo com sua coordenada cartesiana na topologia de subdivisão; prm_lin e ult_lin referem-se à primeira e última linha da grade formada pelos nós, conforme com a topologia de subdivisão; prm_col e ult_col é semelhante, mas para a coluna; $T$ indica transmissão e $R$, recepção; @ indica onde está o destino, para a transmissão, e onde está a origem, para a recepção. 


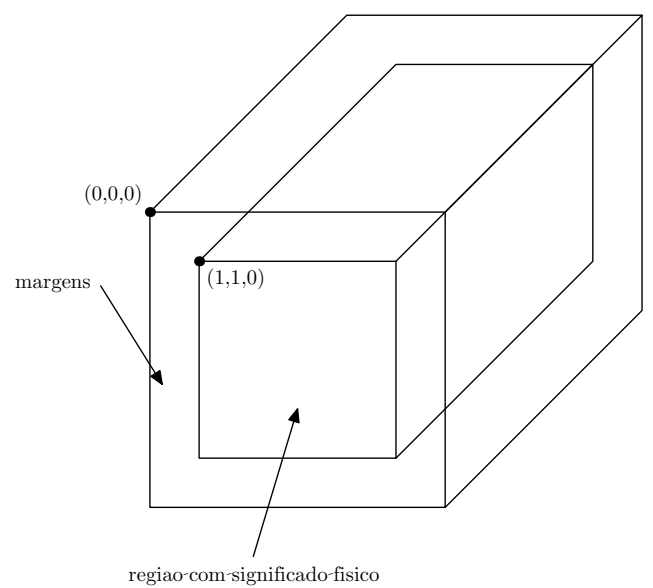

Figura 4.12: Sub-região do problema. Cada nó irá trabalhar com uma região como esta. Sua parte central é a parte que contém os dados propriamente ditos, com significado físico. As margens externas são utilizadas apenas como buffer de recepção durante a troca de dados entre os nós.

\subsubsection{Algoritmo da Aplicação da Fonte}

A aplicação da fonte consiste em atribuir um valor desejado de $\vec{E}$ - ou, equivalentemente, $\vec{D}$ - e (ou) $\vec{H}$, com um determinado comportamento espacial e temporal, a cada instante de tempo, a pontos específicos do volume.

Esta atribuição poderá ser rígida ou suave (hard source ou soft source). A primeira sobrescreve o valor do campo no ponto com o valor desejado. A segunda, atualiza o valor do campo no ponto, adicionando-se ao valor corrente o valor da fonte. O uso de uma ou outra dependerá dos efeitos de simulação desejados. Ainda, no caso da atribuição rígida, dependendo do comportamento temporal da função que define a amplitude do campo, pode-se fazer necessária a consideração de um limiar mínimo de amplitude a ser atribuído, pois, por exemplo, a imposição de um valor nulo para o campo elétrico irá denotar a presença de um metal, causando a reflexão da onda que incidir sobre a própria fonte, após ser refletida por outro material.

A fonte define-se por diversos parâmetros, os quais, por sua vez, podem ser agrupados em três espécies de configuração: o tipo, que rege o comportamento temporal ou perfil temporal; a geometria, que descreve o espaço ocupado pela fonte; e o perfil espacial, que caracteriza o comportamento da amplitude ao longo da geometria. Por exemplo, a fonte da Figura 4.13 apresenta um comportamento temporal senoidal, 
ocupa a região de um retângulo e fornece uma amplitude máxima no centro do quadrado, decrescendo senoidalmente até as bordas. Esta fonte é, portanto, do tipo senoidal, com geometria quadrada e perfil espacial senoidal.

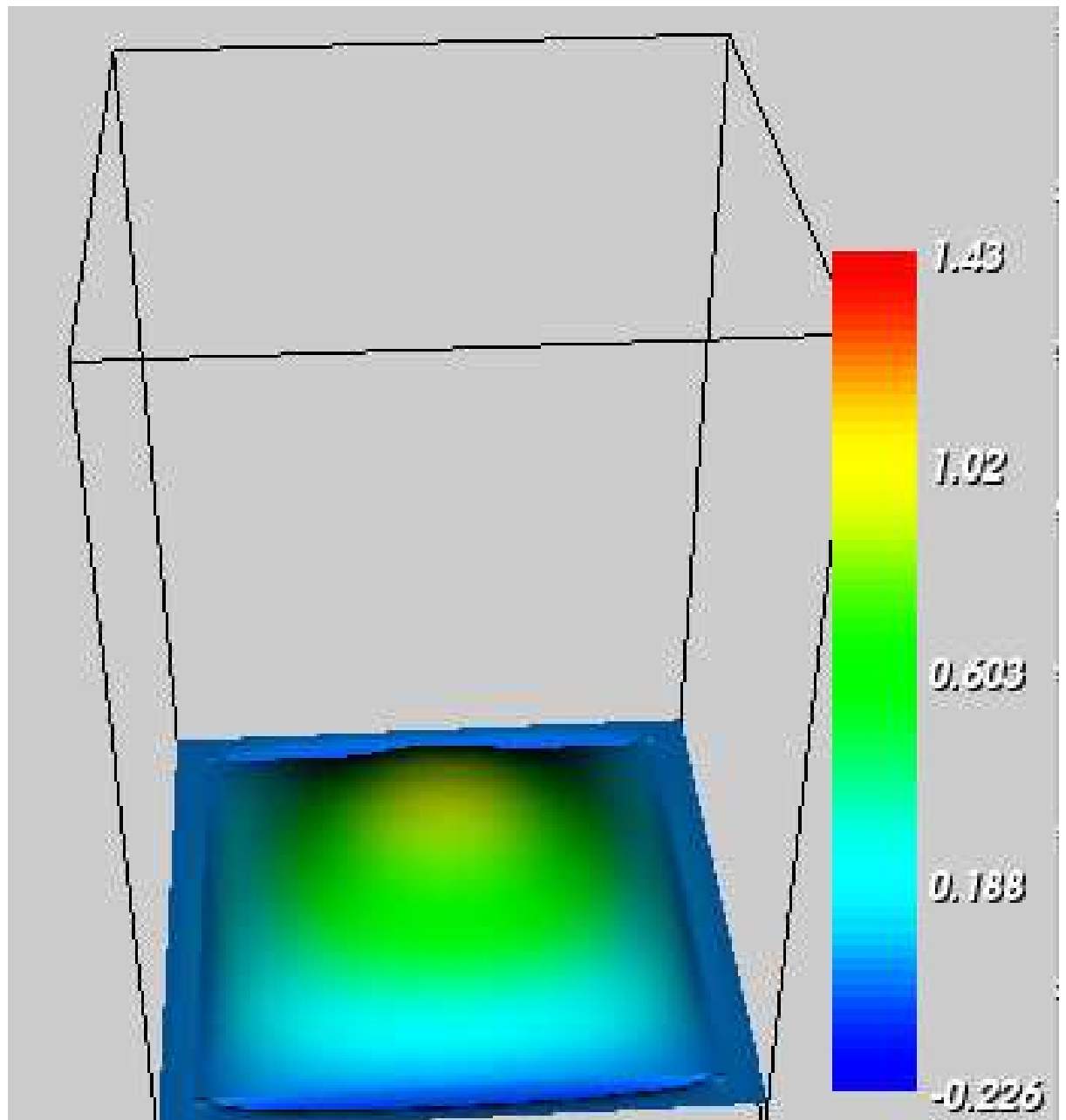

Figura 4.13: Exemplo de uma fonte, conforme as descrições. Percebe-se sua geometria quadrada e seu perfil senoidal, com máximo ao centro do quadrado. A variação das amplitudes mostradas ao longo do tempo poderão se dar segundo qualquer função; por exemplo, poderá ser uma variação senoidal ou tipo pulso gaussiano.

Como a fonte, em si, é um objeto com características próprias, pode-se agrupar tais característica numa única entidade - ou estrutura -, facilitando a sua manipulação e possibilitando a criação e aplicação de diferentes fontes numa mesma simulação. Assim, definem-se os campos de variável da entidade para cobrir as várias opções de fonte. Um exemplo desta estrutura apresenta-se abaixo. 


$\begin{array}{ll}\text { struct S_DESCR_FONTE }\{ & \\ \text {-T_DADO } & \text { amplitude; } \\ \text {-T_DADO } & \text { frequencia; } \\ \text {-T_DADO } & \text { espalhamento; } \\ \text {-T_DADO } & \text { to; } \\ \text {-T_DADO } & \text { ts; } \\ \text {-T_FONTE } & \text { fonte; } \\ \text { _DESCR_GEOMETRIA } & \text { geometria; } \\ \text {-T_PERFIL_FONTE } & \text { perfil; } \\ \text {-T_ATRIB_FONTE } & \text { atribuicao; } \\ \text { \}; } & \end{array}$

Neste exemplo, amplitude corresponde ao maior valor que a fonte assumirá, frequencia, à sua freqüência, quando aplicável, espalhamento, ao espalhamento, no caso das gaussianas no tempo, to, ao passo no tempo no qual a fonte começará a ser aplicada, ts, ao tempo de subida, quando aplicável. Os termos fonte, geometria e perfil correspondem ao tipo, geometria e perfil espacial, respectivamente, como descritos acima, e atribuicao refere-se à forma de atribuição da fonte, rígida ou suave.

Percebe-se, assim, que se instâncias de variáveis com a estrutura apresentada forem criadas, torna-se possível colocar no problema fontes com diferentes fases, geometrias, atrasos no tempo etc.

Para o programa apresentar flexibilidade em qualquer combinação entre estas espécies de configuração [27], o código foi subdividido em blocos, um para cada espécie. Passados à rotina de tratamento da fonte, entre outros parâmetros, o campo que será afetado e a estrutura de caracterização da fonte (parâmetros tipo ponteiro), a rotina executa a seguinte seqüência: num primeiro momento, verifica qual o tipo da fonte, e faz o cálculo do valor a ser aplicado ao campo para um instante de tempo atual; em seguida, analisa o perfil espacial e calcula os coeficientes, entre 0,0 e 1,0, que irão modificar a amplitude do campo para cada ponto do espaço, ao longo da 
geometria; por último, durante o processo de varredura da geometria, aplica-se o produto entre estes fatores.

Salientando-se que cada geometria diferente poderá ter perfis espaciais iguais, resulta que as rotinas do perfil deverão ser repetidas para cada geometria, como mostrado na Figura 4.14. Isto gerará redundância de código e aumentará o trabalho de futuras alterações, além de não ser uma implementação consistente. Uma outra forma seria repetir, para cada perfil espacial, o algoritmo da geometria. Mas assim o mesmo efeito anterior ocorre. Uma terceira proposta seria definir funções para cada perfil e, em cada geometria, durante a sua varredura, fazer a escolha da função a ser chamada. Com esta técnica, garante-se a consistência na rotina dos perfis, facilitamse as alterações futuras e diminui-se a redundância de código. Contudo, ainda haverá a repetição da escolha para as diferentes geometrias, além da existência de tomadas de decisão em laço. A recíproca, criando-se uma função para cada geometria e realizando-se sua escolha nas rotinas dos perfis, provoca o mesmo efeito. Por fim, com uma quinta proposta, utilizando-se o recurso computacional de se criar um ponteiro para uma função, consegue-se eliminar a redundância de escolhas citadas anteriormente e também não são realizadas tomadas de decisão durante a execução de um laço. Assim, adotar-se-á a chamada a um perfil durante a varredura da geometria, embora o complemento também seja aplicável. Ilustra-se essa escolha otimizada na Figura 4.15.

Agora, com esta técnica, basta escolher, uma única vez, antes de qualquer laço, qual função de perfil deverá ser chamada e armazenar seu endereço numa variável, do tipo ponteiro para função. A seguir, em qualquer rotina de varredura de geometria, basta chamar a função armazenada nesta variável.

O único detalhe adicional que passa a existir é que todas as funções de perfil espacial deverão aceitar a mesma quantidade de parâmetros, devido à forma como a variável do tipo ponteiro para função é declarada. No trecho de código abaixo, equivalente à Figura 4.15, demonstra-se, de forma simplificada, o uso de tal recurso. 


\section{Aplicação de Fonte — Técnica com redundâncias}

\begin{tabular}{|c|c|c|c|c|c|}
\hline \multicolumn{6}{|c|}{$\begin{array}{c}\text { Seleção do tipo de fonte e cál } \\
\text { Seleção da geometria }\end{array}$} \\
\hline \multicolumn{3}{|l|}{ CÍRCULO } & \multicolumn{3}{|l|}{ CUBO } \\
\hline \multicolumn{3}{|c|}{ Varredura da geometria "círculo" } & \multicolumn{3}{|c|}{ Varredura da geometria "cubo" } \\
\hline \multicolumn{3}{|c|}{ Seleção do perfil espacial } & \multicolumn{3}{|c|}{ Seleção do perfil espacial } \\
\hline Senoidal & Gaussiano & Linear & Senoidal & Gaussiano & Linear \\
\hline $\begin{array}{l}\text { perfil } \leftarrow \\
\text { Função senoidal } \\
(x, y, z)\end{array}$ & $\begin{array}{l}\text { perfil } \leftarrow \text { Função } \\
\text { gaussiana }(x, y, \\
z)\end{array}$ & $\begin{array}{l}\text { perfil } \leftarrow \\
\text { Função linear } \\
(x, y, z)\end{array}$ & $\begin{array}{l}\text { perfil } \leftarrow \\
\text { Função senoidal } \\
(x, y, z)\end{array}$ & $\begin{array}{l}\text { perfil } \leftarrow \text { Função } \\
\text { gaussiana }(x, y, \\
z)\end{array}$ & $\begin{array}{l}\text { perfil } \leftarrow \\
\text { Função linear } \\
(x, y, z)\end{array}$ \\
\hline \multicolumn{3}{|c|}{$\begin{array}{l}\text { Alteração da amplitude do pulso de acordo com } \\
\text { perfil. }\end{array}$} & \multicolumn{3}{|c|}{$\begin{array}{l}\text { Alteração da amplitude do pulso de acordo com } \\
\text { perfil. }\end{array}$} \\
\hline
\end{tabular}

Figura 4.14: Algoritmo para a aplicação da fonte, no qual são salientadas as múltiplas escolhas de geometria e de perfil espacial, ocasionando trechos redundantes.

\section{Aplicação de Fonte — Técnica otimizada}

Declaração de variável tipo ponteiro para função Perfil.

Seleção do tipo de fonte e cálculo da amplitude do pulso no instante atual.

\begin{tabular}{|c|c|c|c|}
\hline \multicolumn{4}{|l|}{ Seleção do perfil espacial } \\
\hline Senoidal & \multicolumn{2}{|l|}{ Gaussiano } & Linear \\
\hline $\begin{array}{l}\text { Perfil } \leftarrow \text { Endereço de "Função } \\
\text { senoidal" }\end{array}$ & \multicolumn{2}{|c|}{$\begin{array}{l}\text { Perfil } \leftarrow \text { Endereço de "Função } \\
\text { gaussiana" }\end{array}$} & $\begin{array}{l}\text { Perfil } \leftarrow \text { Endereço de "Função } \\
\text { linear" }\end{array}$ \\
\hline \multicolumn{4}{|l|}{ Seleção da geometria } \\
\hline \multicolumn{2}{|l|}{ CÍRCULO } & \multicolumn{2}{|l|}{ CUBO } \\
\hline \multicolumn{2}{|l|}{ Varredura da geometria "círculo" } & \multicolumn{2}{|c|}{ Varredura da geometria "cubo" } \\
\hline \multicolumn{2}{|l|}{ perfil $\leftarrow \operatorname{Perfil}(x, y, z)$} & \multicolumn{2}{|c|}{ perfil $\leftarrow \operatorname{Perfil}(x, y, z)$} \\
\hline \multicolumn{2}{|c|}{$\begin{array}{l}\text { Alteração da amplitude do pulso de acordo com } \\
\text { perfil. }\end{array}$} & \multicolumn{2}{|c|}{$\begin{array}{l}\text { Alteração da amplitude do pulso de acordo com } \\
\text { perfil. }\end{array}$} \\
\hline
\end{tabular}

Figura 4.15: Algoritmo para a aplicação da fonte com o auxílio de uma variável do tipo ponteiro para função, resultando num código otimizado. 


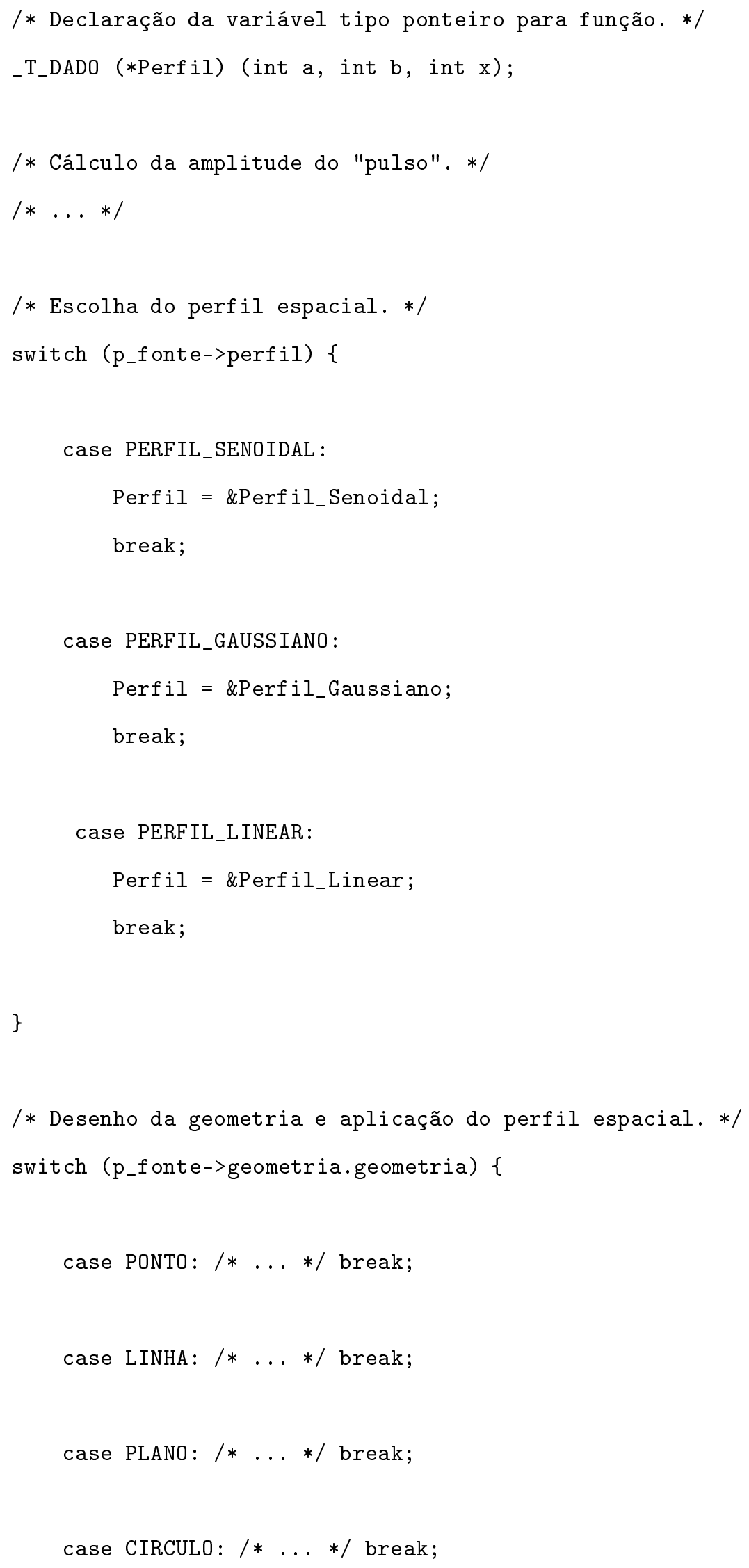


case CUBO:

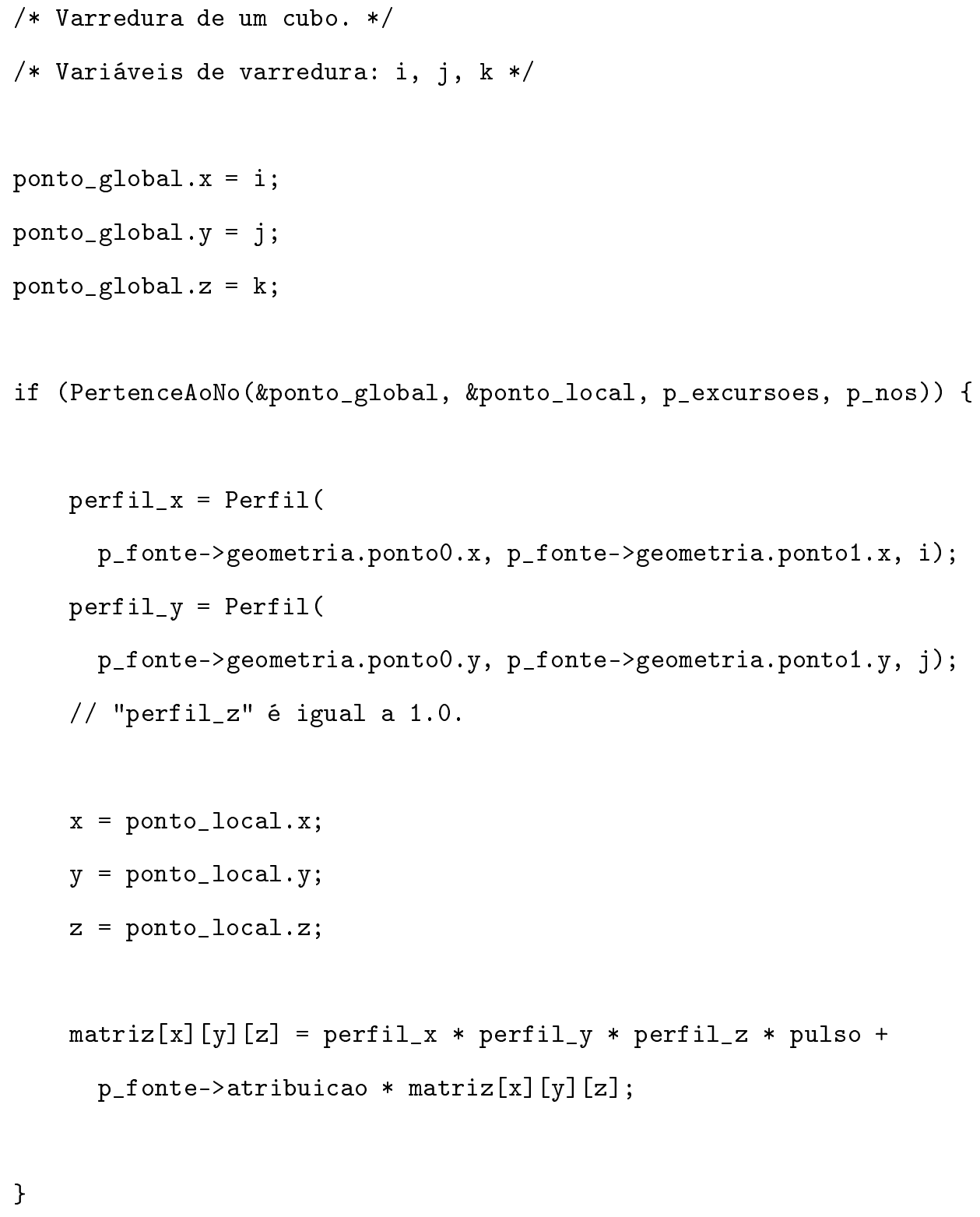

Neste trecho, declara-se, inicialmente, a variável do tipo ponteiro para função, a qual, no caso, irá aceitar três parâmetros inteiros. Em seguida, executa-se o cálculo da amplitude do pulso com base no passo de tempo atual, no tipo da fonte e em outros parâmetros que caracterizam a função utilizada para o cálculo. Faz-se, então, a 
seleção da função do perfil espacial a utilizar, armazenando seu endereço na variável declarada no início. Em seguida, escolhe-se a geometria da fonte. Exemplificando-se com uma parte do código utilizado para a definição de um "cubo", tem-se, internamente ao laço que realiza uma varredura com as variáveis $i, j$ e $k$, a chamada à função do perfil espacial previamente selecionado. O valor por ela retornado é empregado como um coeficiente multiplicador da amplitude do pulso, naquele instante, resultando, portanto, numa nova amplitude que será atribuída aos pontos do volume do problema correspondentes à geometria da fonte em questão.

No programa paralelizado, a identificação de qual o nó computacional que deve aplicar a fonte é feita por meio da função PertenceAoNo( ), que verifica se um determinado ponto global pertence ao nó corrente, já lhe informando as coordenadas da fonte relativas ao seu subvolume. Nota-se, por isso, que as coordenadas da geometria da fonte serão sempre expressas em coordenadas globais.

\subsubsection{Algoritmo do Agrupamento dos Dados dos Resultados}

O agrupamento dos dados realiza a reunião dos dados, num único computador, o do nó gerenciador, gravados por cada nó durante a simulação. Lembrando-se, os dados são as componentes dos campos escolhidas para gravação.

Para isto, cada nó gera uma lista dos arquivos gravados e aloca a quantidade de memória suficiente para lê-los. O nó gerenciador irá alocar memória adicional para poder armazenar todos os dados recebidos e depois para reordená-los.

Em seguida, um arquivo por vez é lido pelos nós, garantindo-se que arquivos referentes ao mesmo passo de tempo da simulação sejam lidos todos os nós num determinado momento. Após a linearização dos dados, eles são transmitidos ao nó gerenciador.

O nó gerenciador, então, reordena os dados recebidos, a fim de construir um volume com as componentes correspondentes ao volume físico do problema. Os 
dados reordenados são, pois, gravados, tendo-se a opção de escolha do formato do arquivo, por diretivas, a ser gerado. Um destes formatos é compatível com o VTK, a ferramenta utilizada para a visualização dos resultados.

Para encerrar, todos os nós liberam as memórias alocadas.

A Figura 4.16 apresenta este algoritmo em forma de diagrama.

Agrupamento dos Resultados - Concatenação dos resultados de cada nó pelo nó gerenciador

Obtenção da lista de arquivos gravados durante a simulação.

Alocação de memória para a leitura dos dados gravados.

nó atual $==$ nó gerenciador

Alocação de memória para armazenar todos os dados recebidos dos outros nós.

Alocação de memória para a reordenação dos dados recebidos.

Para toda a lista de arquivo

Leitura do arquivo do disco.

Linearização dos dados lidos para a transmissão.

Transmissão dos dados por todos os nós e recepção pelo nó gerenciador.

. nó atual == nó gerenciador

Reordenação dos dados recebidos.

Gravação dos dados recebidos em disco.

Liberação da memória alocada para a leitura dos dados.

. nó atual $==$ nó gerenciador

Liberação da memória alocada para a recepção dos dados.

Liberação da memória alocada para a reordenação dos dados.

Figura 4.16: Algoritmo para o agrupamento dos resultados gravados por cada nó. O agrupamento e a gravação final serão realizados pelo nó gerenciador. 


\subsection{Estimativas Matemáticas}

A fim de se otimizar a execução do sistema paralelizado, é conveniente realizar estudos sobre o seu comportamento, principalmente quanto ao tempo total de processamento e à quantidade de memória requisitada.

Nesses aspectos, tem influência considerável a topologia de subdivisão adotada. Com as aproximações e a análise matemática apresentada a seguir, torna-se possível estimar qual a topologia mais adequada para a otimização do sistema.

\subsubsection{Equacionamento dos Tempos Envolvidos}

A execução da simulação de um problema num programa paralelizado transcorre em determinado tempo total de processamento. Sem considerar, aqui, a etapa de inicialização do programa e a de agrupamento dos resultados, ou seja, considerando apenas o laço do método FDTD, e, ainda, desprezando-se o tempo, pequeno, de gravação dos resultados parciais que ocorrem durante o laço, nota-se que o tempo de processamento é constituído, essencialmente, pelo tempo de cálculo e pelo tempo de comunicação. Considerando-se os fatores presentes durante os cálculos e as transferências de dados numa comunicação entre os nós, concluiu-se ser possível encontrar uma aproximação matemática para estimar os tempos envolvidos.

O tempo de cálculo, $t_{c a l c}$, é o tempo envolvido no processamento matemático do método. Definindo-se um tempo equivalente de cálculo por célula, $T_{e q}$, pode-se expressar $t_{\text {calc }}$ como

$$
t_{\text {calc }}\left(n_{x}, n_{y}\right)=N_{T} \cdot T_{e q} \cdot N_{I} \cdot \frac{1}{n},
$$

em que

$N_{T}$ é o número total de células do volume do problema

$N_{I}$ é o número de iterações, ou passos, no tempo

$n$ é o número de nós envolvidos no problema 
com

$$
\begin{gathered}
N_{T}=N_{x} \cdot N_{y} \cdot N_{z} \\
n=n_{x} \cdot n_{y}
\end{gathered}
$$

em que

$N_{x}, N_{y}$ e $N_{z}$ correspondem ao número de células nas direções $x, y$ e $z$ do volume do problema

$n_{x}$ e $n_{y}$ correspondem ao número de subdivisões em $x$ e $y$

O tempo equivalente de cálculo por célula relaciona todas as características de um determinado computador e do programa em sua versão atual ao tempo que necessitará para executar os cálculos. Obtém-se seu valor empiricamente por meio da medida do tempo de cálculo empregado numa simulação, em um único nó, de um problema com dimensões quaisquer e com um determinado número de iterações no tempo. Estes parâmetros deverão garantir que a simulação atinja seu regime estável e também evitar erros significativos de medida de tempo devido às oscilações do Sistema Operacional. Sugere-se, por isso, que as dimensões sejam as maiores possíveis capazes de serem alocadas na memória física do computador e o número de iterações no tempo não seja menor que 100. Escolhidos os valores e medido o tempo total de processamento da simulação - lembrando-se que se trata do tempo de execução do laço FDTD - por meio da própria (4.4) encontra-se o valor de $T_{e q}$. É importante salientar que caso se façam alterações no programa ou se utilize um computador com outras características, este cálculo deverá ser refeito.

Por exemplo, realizando-se a simulação de um problema com 100 x 100 x 150 células, num computador com, entre outras características, $3 \mathrm{GHz}$ de freqüência de clock, por 100 iterações no tempo, encontra-se um tempo de execução do laço FDTD de $52 \mathrm{~s}$, o que resulta em $T_{e q}=347 \mathrm{~ns} /$ célula/iteração. Agora, supondo-se 
uma nova situação, utilizando-se este valor em conjunto com (4.4), pode-se estimar o tempo para um problema com 200 x 200 x 150 células, isto é, quatro vezes maior que a situação anterior, e por 1000 iterações, isto é, 10 vezes maior que anteriormente. Tem-se, assim, um tempo de cálculo de 2082 s, considerando-se um único computador, ou $694 \mathrm{~s}$, considerando-se três computadores com iguais características.

Já o cálculo do tempo de comunicação possui um conjunto de variáveis maior. Para cada subdivisão em $x$ ou $y$, será necessária a troca de componentes de campos, como observa-se na seção 4.7.6. Além disso, a quantidade de elementos na interface que deverão ser transferidos dependerá da direção e do número de subdivisões. O tempo ainda terá influência do tamanho, em bytes, dos elementos e da taxa média de transferência de dados da rede.

Começando-se o equacionamento pelo número de comunicações em $x\left(n_{c x}\right)$ e $y$ $\left(n_{c y}\right)$, tem-se

$$
\begin{aligned}
& n_{c x}=4\left(n_{x}-1\right) f_{d x} \\
& n_{c y}=4\left(n_{y}-1\right) f_{d y}
\end{aligned}
$$

com

$$
\begin{aligned}
& f_{d x}=\left\{\begin{array}{l}
1, \text { se "switch" } \\
n_{y}, \text { se "hub" }
\end{array}\right. \\
& f_{d y}=\left\{\begin{array}{l}
1, \text { se "switch" } \\
n_{x}, \text { se "hub" }
\end{array}\right.
\end{aligned}
$$

nas quais 4 representa a quantidade de componentes de campo envolvidas nos processos de transferência, $\left(n_{x}-1\right)$ e $\left(n_{y}-1\right)$ representam a quantidade de interfaces entre nós, de acordo com a topologia de subdivisão, e $f_{d x}$ e $f_{d y}$ são fatores que consideram o tipo de periférico "comutador" de rede utilizado. Conforme já abordado 
na seção 2.2.3, os chaveadores (switches) possuem a propriedade de conectar diversos pares de nós simultaneamente, garantindo-lhes a máxima taxa de transferência, enquanto que os hubs particionam no tempo os dados que trafegam entre todos os pares de nós. Por isso, se chaveadores forem utilizados, espera-se uma maior taxa líquida de dados no sistema da simulação como um todo. Observando-se por outro ângulo, seria equivalente a ter um menor número de comunicações em intervalos de tempo distintos. Justificam-se, assim, os valores de $f_{d x}$ e $f_{d y}$, mostrados em (4.7), os quais consideram que todas as transferências ocorrem em intervalos de tempo distintos, para o caso do hub, ou com a influência de transmissões simultâneas, para o caso do chaveador.

Em seguida, deve-se calcular o número de células envolvidas na comunicação em $x\left(n_{c c x}\right)$ e $y\left(n_{c c y}\right)$ entre os subvolumes adjacentes, o que pode ser realizado por

$$
\begin{aligned}
& n_{c c x}=\left(\frac{N_{y}}{n_{y}}+2 M_{y}\right) N_{z} \\
& n_{c c y}=\left(\frac{N_{x}}{n_{x}}+2 M_{x}\right) N_{z},
\end{aligned}
$$

em que $M_{x}$ e $M_{y}$ correspondem às margens em $x$ e $y$ de recepção dos dados, conforme o exposto na seção 4.7.6. O fator 2 aparece pelo fato de haver margens nos dois extremos do subvolume na dada direção.

Com estas informações, pode-se calcular o número de elementos que serão transferidos durante uma iteração no tempo por

$$
\begin{aligned}
& n_{e x}=n_{c x} \cdot n_{c c x} \\
& n_{e y}=n_{c y} \cdot n_{c c y} .
\end{aligned}
$$

Finalmente, o tempo de comunicação é obtido por meio de

$$
t_{c o m}\left(n_{x}, n_{y}\right)=\left(n_{e x}+n_{e y}\right) \cdot T_{e} \cdot N_{I} \cdot \frac{1}{R_{T}}
$$


em que se multiplica o número de elementos total, $n_{e x}+n_{e y}$, transferidos durante uma iteração pelo tamanho em bytes de cada elemento, $T_{e}$, e pela quantidade de iterações no tempo da simulação, fornecendo a quantidade total, em bytes, de dados transferidos não-simultaneamente no tempo. Dividindo-se, então, este valor pela taxa de transferência média da rede, $R_{T}$, encontra-se o tempo de comunicação procurado.

$T_{e}$ dependerá do compilador utilizado, do Sistema Operacional e do tipo escolhido da variável durante a codificação do programa. Para o Sistema Operacional Linux, utilizando-se o compilador gcc, seus valores, para os tipos de variáveis aplicáveis, são apresentados em (4.11), a seguir.

$$
T_{e}=\left\{\begin{array}{l}
4 \text { bytes/elem., se "float" } \\
8 \text { bytes/elem., se "double" } \\
12 \text { bytes/elem., se "long double" }
\end{array}\right.
$$

$R_{T}$, por sua vez, deverá ser obtido empiricamente, pois a taxa de transferência média no contexto da simulação é diferente da taxa de transferência máxima possível da rede, devido às influências da forma de implementação do programa, aos acréscimos de cabeçalhos nos pacotes de dados transferidos e à presença de outras comunicações que podem existir. Este procedimento é realizado uma única vez, durante a etapa de caracterização do sistema paralelizado - a não ser que haja alguma alteração no programa ou nos periféricos e que possa se refletir na taxa de transferência.

Há duas formas sugeridas para a obtenção da taxa média de transferência. Contudo, em qualquer uma delas, o volume do problema da simulação deverá possuir uma quantidade razoável de células, a fim de que a tarefa de comunicação apresente maior eficiência, ao atingir seu estado estável. Além disso, a realização de simulações com quantidades variadas de nós é aconselhada e, no caso de chaveadores serem empregados, deve-se estar atento para com as taxas líquidas obtidas, quando 
a análise for feita considerando-se o volume total de dados transferidos durante a simulação, o que pode fornecer taxas maiores que as máximas, devido à simultaneidade de transferências. Complementando-se, a quantidade de passos no tempo não deve ser muito pequena, a fim de evitar erros devido às flutuações existentes no sistema. Sugere-se 1000 passos no tempo.

A primeira técnica consiste em se acompanhar as transferências realizadas por um nó utilizando-se o programa Ethereal. Após concluída a simulação, levanta-se a estatística da taxa de transferência média, mas desconsiderando o tempo utilizado para os cálculos.

A segunda técnica consiste em medir todo o tempo utilizado para a comunicação durante o laço FDTD - o programa já possui este recurso - e, em seguida, utilizar (4.10) para estimar a taxa média.

Em ambas as técnicas, o valor a ser adotado para $R_{T}$ é a média das taxas médias obtidas.

Como exemplo, utilizando-se a segunda técnica, a simulação de um problema com dados do tipo double, 250 x 100 x 160 células, por 1001 passos no tempo, com uma topologia de subdivisão de 5 x 1 e com o uso de chaveador de 100 Mbytes/s, fornece $t_{\text {com }}=184,9$ s. Substituindo-se os valores em (4.10), encontra-se $R_{T}=$ $11,31 \cdot 10^{6}$ bytes $/ \mathrm{s}=10,79 \mathrm{Mbytes} / \mathrm{s}$. Este procedimento poderia, então, ser repetido para outras topologias de subdivisão do tipo $n_{x} \mathrm{x} 1$, alterando-se a quantidade de nós envolvidos e obtendo-se outros valores para $R_{T}$, com os quais se poderia obter a média final a ser empregada nas estimativas. Supondo-se, assim, que a média forneça $R_{T}=10,5 \mathrm{Mbytes} / \mathrm{s}$, pode-se estimar o tempo de comunicação para, por exemplo, a situação na qual o volume do problema é de 102 x 100 x 160 células, ainda com dados tipo double, com topologia de subdivisão 3 x 1, em 1001 passos no tempo, utilizando-se o mesmo chaveador, fornecendo o resultado $t_{\text {com }}=95,0 \mathrm{~s}$.

Para as estimativas apresentadas, algumas simplificações foram realizadas, desprezando-se o tempo gasto em certos detalhes da operação do programa e empre- 
gando-se valores médios para a taxa de transmissão. Isto, de fato, acarretará erros entre o valor estimado e o realmente observado. Contudo, como será demonstrado na Capítulo 5, elas ainda retratam com considerável proximidade as magnitudes dos tempos envolvidos, suficiente para a análise à qual elas serão aplicadas.

O tempo total do processamento, então, poderá ser obtido por

$$
t_{t o t}\left(n_{x}, n_{y}\right)=t_{c a l c}\left(n_{x}, n_{y}\right)+t_{c o m}\left(n_{x}, n_{y}\right)
$$

Observando-se (4.12) em conjunto com (4.4) e (4.10), percebem-se algumas importantes características, conforme descrito na seqüência.

\subsubsection{Análises da Influência das Topologias nos Tempos}

Com o objetivo de avaliar o comportamento das equações em função da quantidade de nós utilizados numa simulação, consideram-se a quantidade de subdivisões em $x$ e $y$ como variáveis e se fixam todos os demais parâmetros.

Agora, observando-se (4.4), tem-se que o tempo de cálculo decresce à razão1/n, conforme aumenta-se o número de nós $n$, fato este que justifica o paralelismo para a redução do tempo de processamento. Por outro lado, observando-se (4.10), é possível notar que, com o aumento de $n_{x}$ e (ou) $n_{y}$, o tempo de comunicação também aumenta, conforme já esperado, devido à maior quantidade de dados transferidos. Assim, se para um único nó o tempo de cálculo apresenta seu maior valor e o tempo de comunicação é nulo, para uma quantidade grande de nós o tempo de cálculo tende a ser nulo e o tempo de comunicação a ser alto, passando estes tempos pelos valores intermediários ao ir de um extremo ao outro. Portanto, o tempo total, conforme expresso em (4.12), deverá iniciar num determinado valor e, com o aumento da quantidade de nós, decrescer, por causa da diminuição do tempo de cálculo e de valores ainda baixos do tempo de comunicação, chegar a um mínimo e, depois, voltar a crescer, monotonicamente. Em particular, o ponto para o tempo 
total mínimo é um ponto interessante de ser obtido, pois ele permite realizar uma simulação com o menor tempo de processamento possível. Então, conhecendo-se este ponto antecipadamente, pode-se configurar o sistema paralelizado, para cada problema a resolver, de forma a realizar o processamento neste menor tempo. A Figura 4.17 mostra o comportamento das equações em discussão.

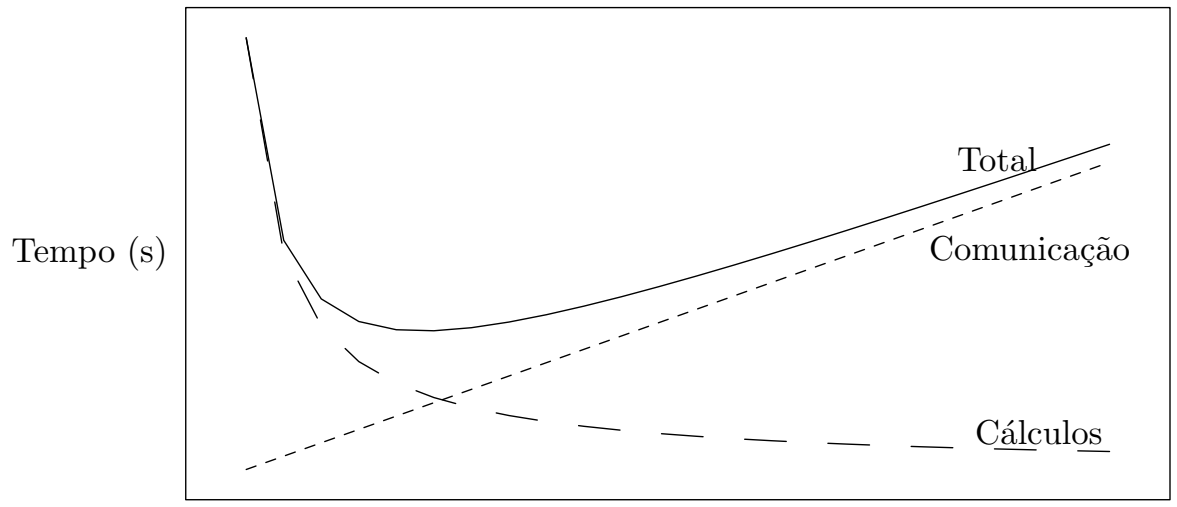

Quantidade de nós

Figura 4.17: Gráfico com as curvas do comportamento dos tempos de cálculo, comunicação e total. Nota-se, neste gráfico, claramente, um ponto de mínimo para o tempo total.

A determinação do tempo mínimo, contudo, não é imediata, devido às relações no equacionamento e aos parâmetros do problema que se alteram a cada nova situação.

Essencialmente, o ponto de mínimo é o ponto de inflexão da curva representada por (4.12), considerando-se como variáveis $n_{x}$ e $n_{y}$.

No estudo serão consideradas as topologias $n_{x} \mathrm{x} 1$ e 1 x $n_{y}$.

\section{Influência das Topologias $n_{x} \mathrm{x} 1$ e 1 x $n_{y}$}

O uso destas topologias produzirá uma análise mais simplificada. Os cálculos serão desenvolvidos para a topologia de subdivisão $n_{x}$ x 1 e, em seguida, por analogia, o resultado final é reescrito para a topologia $1 \times n_{y}$.

Definindo-se a constante

$$
K_{1}=N_{T} \cdot N_{I} \cdot T_{e q}
$$


pode-se escrever

$$
t_{\text {calc }}\left(n_{x}, n_{y}\right)=K_{1} \cdot \frac{1}{n_{x} n_{y}} .
$$

Da mesma forma, definindo-se outra constante

$$
K_{2}=T_{e} \cdot N_{I} \cdot \frac{1}{R_{T}}
$$

pode-se escrever

$$
t_{c o m}\left(n_{x}, n_{y}\right)=K_{2} \cdot\left[n_{e x}\left(n_{x}, n_{y}\right)+n_{e y}\left(n_{x}, n_{y}\right)\right]
$$

Como a topologia em interesse é a $n_{x} \mathrm{x} 1$, tem-se que $n_{y}=1$. Também, adota-se $n=n_{x}$. Agora, colocando-se estas considerações em (4.14), tem-se

$$
t_{\text {calc }}(n)=K_{1} \cdot \frac{1}{n}
$$

e em (4.16), já se realizando algumas substituições a mais conforme (4.9), (4.8) e (4.6), obtém-se

$$
t_{c o m}(n)=4(n-1) \cdot\left(N_{y}+2 M_{y}\right) N_{z} \cdot K_{2}
$$

e, mais uma vez, adotando outra constante

$$
K_{2 a}=K_{2} \cdot 4\left(N_{y}+2 M_{y}\right) N_{z}
$$

obtém-se

$$
t_{c o m}(n)=K_{2 a}(n-1)
$$

Substituindo-se (4.17) e (4.20) em (4.12) e derivando-se em relação a $n$, tem-se

$$
\frac{\mathrm{d} t_{t o t}(n)}{\mathrm{d} n}=-\frac{K_{1}}{n^{2}}+K_{2 a}
$$


Como a segunda derivada é maior que zero, igualando-se (4.21) a zero encontra-se o ponto de mínimo, o qual é

$$
n_{x p \min }=\sqrt{\frac{K_{1}}{K_{2 a}}}
$$

em que o índice $x$ lembra que se trata de número de subdivisões na direção $x$.

Substituindo-se as constantes por seus valores, como apresentado em (4.13), (4.15) e (4.19), resulta em

$$
n_{x p \min }=\frac{1}{2} \sqrt{\frac{N_{x} N_{y} T_{e q} R_{T}}{T_{e}\left(N_{y}+2 M_{y}\right)}} .
$$

Como, normalmente, $N_{y} \gg M_{y}$, tem-se que

$$
\sqrt{\frac{N_{y}}{N_{y}+2 M_{y}}} \approx 1
$$

e, por isso, pode-se simplificar (4.23) para

$$
n_{x p \min }=\frac{1}{2} \sqrt{\frac{N_{x} T_{e q} R_{T}}{T_{e}}} .
$$

Esta equação fornece, então, o número de subdivisões em $x$, sem subdivisões em $y$, que resultará no menor tempo de processamento na situação de um determinado problema e das características do sistema paralelizado.

Utilizando-se um desenvolvimento análogo, encontra-se

$$
n_{\text {ypmin }}=\frac{1}{2} \sqrt{\frac{N_{y} T_{e q} R_{T}}{T_{e}}},
$$

a qual indica o número de subdivisões em $y$, sem subdivisões em $x$, que ocasionará o processamento no menor tempo possível para a situação.

O desenvolvimento matemático, nestas topologias estudadas, é o mesmo tanto para o emprego de chaveadores quanto para o de $h u b s$, pois $f_{d x}$ ou $f_{d y}$ tem sempre 
o valor 1 quando não for multiplicado por zero, em (4.6a) e (4.6b).

Quanto ao número de subdivisões obtido por meio dessas equações, provavelmente, seu valor será fracionário. Lembrando-se que o número de subdivisões definirá a quantidade de nós a serem utilizados, este valor deve ser aproximado para algum inteiro próximo. Como o comportamento de $t_{t o t}$ é bastante suave na região próxima ao ponto de mínimo, não há a obrigatoriedade de se adotar exatamente o valor inteiro conforme o critério de arredondamento. Dependendo da situação, o inteiro seguinte - se o arredondamento for "para baixo" -, ou o anterior - se o arredondamento for "para cima" -, poderá ser empregado, sem muita alteração no tempo de processamento. Justifica-se esta afirmação ao observar-se a variação de inclinação da curva de $t_{t o t}$ nos pontos "inteiros" vizinhos ao ponto de mínimo. A escolha final se dará, então, pela quantidade de nós disponíveis, pela quantidade de memória necessária ou por alguma outra característica adicional desejada.

Por exemplo, utilizando-se um chaveador com taxa de transferência média de 10 Mbytes/s, dado um volume de 250 x 150 x 200, um tempo equivalente de célula de 347 ns/célula/iteração, com topologia de subdivisão 3 x 1, variáveis tipo double, margens com espessura de 1 célula em $x$ e $y$ e realizando-se 500 iterações no tempo, obtém-se, por (4.4), (4.10) e (4.12), um tempo de cálculo de 433,8 s, um tempo de comunicação de 92,8 s e um tempo total de 526,5 s, conforme também pode ser visto na Figura 4.18.

Agora, se a mesma quantidade de nós for utilizada, mas com uma topologia de subdivisão 1 x 3, o tempo de comunicação, cálculo e total serão, respectivamente, 433,8, 153,8 e 587,6 s. Percebe-se que o tempo de cálculo manteve-se o mesmo, pois depende apenas da quantidade de nós e não da topologia de subdivisão. O tempo de comunicação, por sua vez, aumentou, provocando também um aumento do tempo total. Isto deve-se ao fato de a quantidade de dados trocados ser diferente para as duas topologias de subdivisão citadas, já que o volume possui mais células em $x$ do que em $y$. Tendo-se em vista a escolha de uma topologia que permita a realização 


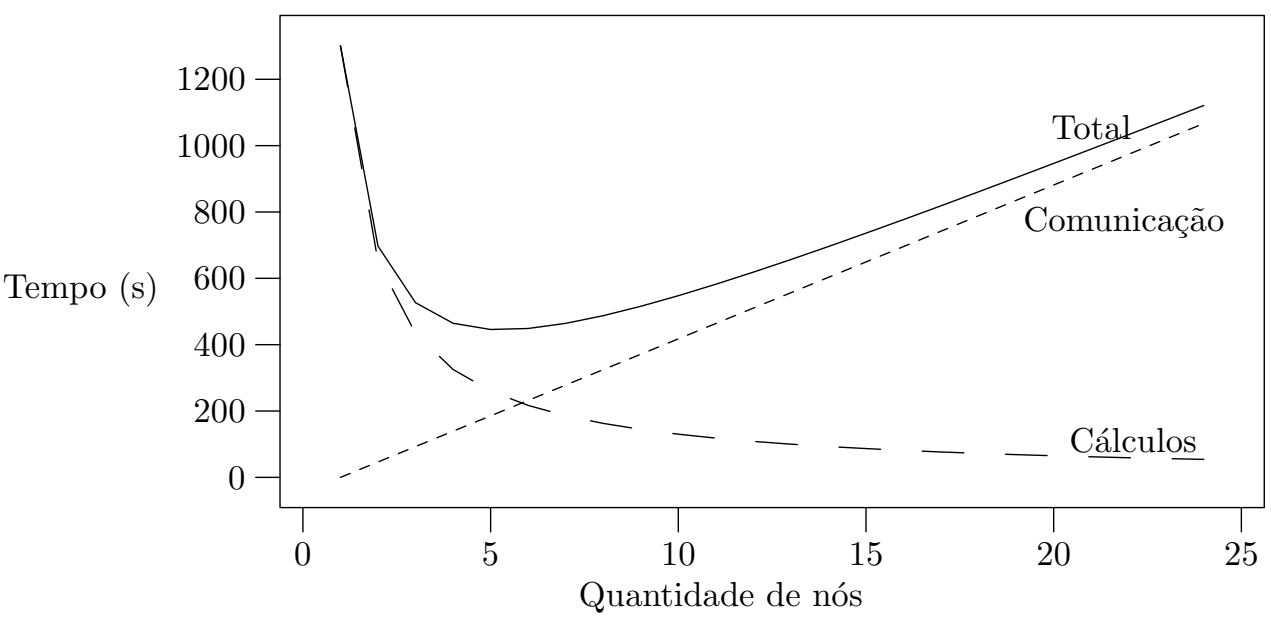

Figura 4.18: Gráfico com os tempos de cálculo, de comunicação e total correspondentes ao exemplo descrito no texto.

da simulação no menor tempo possível, aqui está um primeiro critério para sua definição: as subdivisões deverão ser realizadas na dimensão com o maior número de células, ao optar por uma das topologias $n_{x} \times 1$ ou $1 \times n_{y}$.

Ainda considerando-se uma das duas topologias em questão, a quantidade de nós ideal para o menor tempo de processamento poderá ser obtido por (4.24) ou (4.25). Realizando-se as operações, encontra-se um valor de 5,33 para $n_{x}$ e 4,13 para $n_{y}$. Como o número de subdivisões deve ser inteiro, o valor para $n_{x}$ passa a ser 5 e para $n_{y}$ passa a ser 4 . Calculando-se com estas subdivisões, encontra-se um tempo total de 445,8 s para a topologia $5 \times 1$ e de 556,0 para a topologia 1 x 4 . Nota-se que, realmente, estes valores são menores que os obtidos anteriormente, para cada topologia. É também perceptível a obtenção, novamente, de um menor tempo para a topologia $n_{x}$ x 1, conforme já exposto. As topologias alternativas que se poderiam adotar seriam a $6 \times 1$ ou $1 \times 5$, as quais forneceriam um tempo total de $448,4 \mathrm{~s}$ ou 567,9 s, sem muita alteração em relação ao mínimo encontrado, principalmente para a topologia $6 \times 1$.

Estas análises, para o caso da topologia $n_{x} \times 1$, também podem ser observadas na Figura 4.18, na qual percebe-se o ponto de mínimo da curva e a quantidade correspondente de subdivisões. 


\subsubsection{Ganho e Eficiência}

Dois parâmetros importantes a serem definidos - já comumente utilizados - é o ganho de velocidade, $G_{v}$, e a eficiência, $E_{f}$.

O ganho de velocidade refere-se a "o quanto mais rápido" um problema foi simulado. Idealmente, o tempo de comunicação deveria ser sempre nulo, o que resultaria num tempo de processamento tanto menor quanto maior o número de nós utilizados. Ou seja, utilizando-se, por exemplo, dois nós, o tempo total deveria ser a metade daquele gasto ao se empregar apenas um nó. Em outras palavras, teria-se um ganho de velocidade de 2. Com três nós, seria esperado um ganho de 3. Com quatro, 4, e assim por diante. Mas, nos casos reais, o tempo de comunicação não é nulo, ocasionando ganhos menores que os das situações ideais.

A eficiência é simplesmente a relação entre o ganho num caso real e o ganho num caso ideal, fornecendo um indicativo de quanto se aproveitou dos recursos empregados no sistema paralelizado.

Para o desenvolvimento de uma expressão adequada para as análises teóricas e, posteriormente, práticas, define-se o fator de relação

$$
f_{r}=\frac{t_{c o m}(n)}{t_{c a l c}(n)}
$$

sendo $t_{\text {com }}(n)=t_{\text {com }}\left(n_{x}, n_{y}\right)$ e $t_{c a l c}(n)=t_{c a l c}\left(n_{x}, n_{y}\right)$ e $n$ o número de nós.

O ganho é a razão entre o tempo total necessário para se resolver um problema em um único nó e o tempo total necessário para se resolver o mesmo problema utilizando-se $n$ nós. Assim,

$$
G_{v}=\frac{t_{t o t}(1)}{t_{t o t}(n)}
$$

Desenvolvendo-se,

$$
G_{v}=\frac{t_{c a l c}(1)}{t_{\text {calc }}(n)+t_{\text {com }}(n)}
$$

e realizando-se a substituição conforme (4.26), lembrando-se que $t_{\text {calc }}(n)=t_{\text {calc }}(1) / n$, 
chega-se a

$$
G_{v}=\frac{n}{1+f_{r}}
$$

Ainda, relacionando-se $G_{v}$ com o ganho máximo no caso ideal, tem-se a eficiência

$$
E_{f}=\frac{G_{v}}{n}=\frac{1}{1+f_{r}}
$$

Analisando-se (4.29) e (4.30), tem-se: para os casos ideais, $t_{\text {com }}(n)=0$ e, portanto, $G_{v}=n$ e $E_{f}=1$ (ou $100 \%$ ), como esperado. Para o caso de um único nó, $t_{c o m}(n)$ ainda é nulo, fornecendo $G_{v}=1$ e $E_{f}=1$. As eficiências de $100 \%$ indicam que o máximo ganho possível de ser obtido é obtido. Se $t_{c o m}(n)=t_{c a l c}(n), G_{v}=n / 2$ e $E_{f}=0,5$. Isto significa que a situação cujos tempos de comunicação e cálculo são iguais, o ganho será metade do máximo possível e a eficiência será de 50 \%, ou seja, os recursos computacionais seriam suficientes para resolver o problema em metade do tempo, mas a limitação imposta pelo tempo necessário de comunicação não permite atingir este desempenho. E se $t_{c o m}(n)>t_{c a l c}(n)$, o ganho será menor que a metade do máximo possível e a eficiência será menor que $50 \%$.

No exemplo citado na seção 4.8.2, têm-se o ganho e a eficiência para as topologias $3 \times 1,5 \times 1$ e 6 x 1 iguais a 2,47 e $82 \%, 2,92$ e $58 \%$ e 2,90 e $48 \%$. Percebese, nestes dados, que na topologia ótima, na qual o tempo de processamento é o menor, o ganho é máximo. Contudo, verifica-se também que um alto ganho não implica uma alta eficiência, porque se por um lado o aumento do número de nós pode diminuir o tempo de cálculo e aumentar o ganho, por outro lado o tempo de comunicação aumenta, o que faz decrescer a eficiência. Já entre as topologias $5 \times 1$ e 6 x 1, têm-se ganhos muito próximos, e os tempos totais de processamento, como salientado antes, próximos. A eficiência, por sua vez é $10 \%$ menor para a topologia $6 \times 1$, indicando que os recursos computacionais são mais sub-utilizados devido ao aumento no tempo de comunicação. Daqui, pode-se concluir um segundo critério para a escolha da topologia: uma vez encontrado o ponto de mínimo, por 
meio de (4.24) ou (4.25), e analisado o ponto adjacente de ganho aproximadamente igual, deve-se optar pela topologia que fornecer a maior eficiência. Como uma maior eficiência implica num menor tempo de comunicação, esta escolha pode ser bastante importante para diminuir o tráfego de dados em alguma rede - dependendo de sua configuração -, em especial se, simultaneamente ao processamento paralelo, outras atividades que utilizam a mesma rede estiverem sendo realizadas - entre elas, por exemplo, outro processamento paralelo.

\subsubsection{Memória Requisitada}

A quantidade de memória requisitada para cada nó para a simulação é diretamente proporcional ao volume do problema e inversamente proporcional ao número de nós envolvidos.

Ela depende das peculiaridades de implementação do programa e pode ser calculada, para o programa atual, pelo conjunto de equações a seguir

$$
\begin{aligned}
\text { mem }_{\text {princ }}= & 20 \cdot T_{e}\left(\frac{N_{x}}{n_{x}}+2 M_{x}\right)\left(\frac{N_{y}}{n_{y}}+2 M_{y}\right) N_{z} \\
\operatorname{mem}_{P M L}= & 2 \cdot T_{e}\left[N_{x} N_{y}\left(2 N_{P M L}+1\right)+\right. \\
& \left.N_{x} N_{z}\left(2 N_{P M L}+1\right)+N_{y} N_{z}\left(2 N_{P M L}+1\right)\right] \\
\text { mem }_{\text {tot }}= & \text { mem }_{\text {princ }}+\text { mem }_{P M L}
\end{aligned}
$$

em que mem $_{\text {princ }}$ refere-se à memória principal necessária, $m_{e} m_{P M L}$ refere-se à memória para alocação das matrizes tridimensionais da PML utilizadas para as integrações e mem $_{t o t}$ refere-se à memória total para a simulação do problema. Nessas equações, o fator 20, em (4.31a), corresponde a: 9 matrizes de componentes de vetores (sendo 3 para cada um dos vetores $\vec{D}, \vec{E}$ e $\vec{H}$ ), 1 matriz de obtenção de máximos, 9 matrizes de constantes matemáticas relacionadas ao meio físico e 1 matriz com a identificação do material em cada ponto; já o fator 2, em evidência em (4.31b), 
deve-se pela consideração da PML em ambos os vetores atualizados nas varreduras do método das diferenças finitas: o vetor $\vec{D}$ e o $\vec{H}$ - lembra-se que $\vec{E}$ é calculado a partir de $\vec{D}$.

Dada a quantidade de memória requisitada por um problema e a quantidade de memória disponível para cada nó, pode-se definir o número mínimo de nós a ser utilizado.

Se, acaso, algum nó, para alocar o problema, necessitar utilizar, além da sua memória física, a memória virtual, no espaço de troca do disco rígido, o tempo de processamento aumentará enormemente, devido ao tempo de acesso do disco rígido ser grande, inviabilizando, assim, a simulação. Portanto, esta é uma situação a ser evitada. 


\section{Capítulo 5}

\section{APLICAÇÕES}

As aplicações concretizam a finalidade de todos os desenvolvimentos. Assim, deve-se provar a validade matemática e física dos modelos elaborados.

Com tais objetivos, serão abordados exemplos que irão validar tanto o código isto é, o modelo computacional - quanto as estimativas matemáticas apresentadas. Por último, um exemplo de estudo para uma aplicação prática será considerado.

\subsection{Validação do Código}

A fim de validar o código, foi repetida uma simulação descrita em [6]. O problema consiste em encontrar os modos numa cavidade ressonante com ar em seu interior. Se o programa estiver correto, aplicando-se uma fonte senoidal com a freqüência da ressonância, os modos irão aparecer. As dimensões da cavidade são 8,5 x 4,5 x $26 \mathrm{~cm}$, discretizadas com $\delta=2,5 \mathrm{~mm}$. A cavidade é definida colocando-se paredes condutoras nas seis faces do volume. Estas, por sua vez, são caracterizadas especificando-se uma alta condutividade. O passo de tempo é de 4,17 ps. A freqüência de ressonância da cavidade é de 2,469 GHz. A fonte senoidal foi aplicada num plano em $z=0,5 \mathrm{~cm}$, sendo o perfil espacial das amplitudes neste plano também senoidal (isto é, nas bordas do plano, amplitude nula, ao centro do plano, amplitude 
máxima, e nas outras regiões os valores senoidais intermediários). Realizando-se a simulação num único computador por, aproximadamente, 7000 passos no tempo, obteve-se o resultado da Figura 5.1. Tal resultado é coerente com o apresentado em [6] e a obtenção dos modos valida o código. Convém notar que, devido à presença das paredes condutoras, foi necessário acrescentar mais duas células em cada dimensão, a fim de manter o volume interno da cavidade de acordo com as dimensões citadas anteriormente.

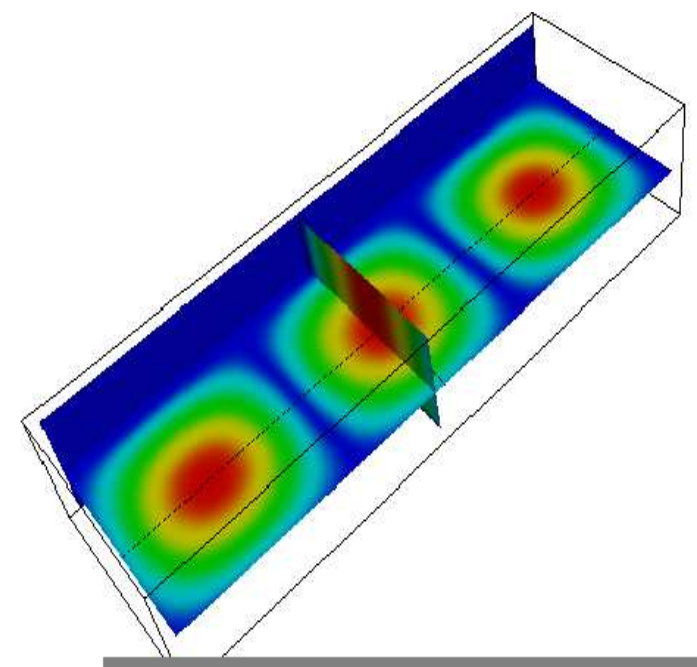

Figura 5.1: Modos resultantes numa cavidade, para a freqüência de ressonância.

\subsection{Validação das Estimativas Matemáticas e Aná- lises de Desempenho do Sistema Paralelizado}

Executando-se a simulação de um problema de tamanho computacional fixo, realizaram-se medidas dos tempos de cálculo, comunicação e total, para a topologia $n_{x} \mathrm{x} 1$. Em seguida, estes tempos foram comparados com os estimados matematicamente, conforme os desenvolvimentos apresentados na seção 4.8, a fim de validar as equações deduzidas. O ganho de velocidade e a eficiência reais também foram comparados com os estimados. 
Primeiramente, o tempo equivalente por célula, $T_{e q}$, foi encontrado. Simulandose, em um único computador, um problema com um volume de $100 \times 100 \times 80$ células, variáveis do tipo double e 1001 passos no tempo, mediu-se um tempo de cálculo de $321,8 \mathrm{~s}$. Isto resulta em $T_{e q}=402 \mathrm{~ns} /$ célula/iteração.

Em seguida, determinou-se a taxa de transferência média, $R_{T}$. Para tanto, várias simulações foram realizadas com problemas de diferentes volumes, variáveis tipo double e 1001 passos no tempo, utilizando-se chaveadores de 100 Mbits/s. Para cada simulação, encontrou-se um $R_{T}$ e, por fim, calculou-se a média do valores encontrados. Para a escolha dos volumes utilizados, cuidou-se para que não se excedesse a memória física dos nós e também para que as dimensões do volume não tivessem ordem de grandeza muito diferente entre si. Feito isto, obteve-se $R_{T}=$ 10, 01 Mbytes/s.

Na seqüência, efetuaram-se as medidas dos tempos para simulações de um problema com um volume de 100 x 100 x 160 células, por 1001 passos no tempo, utilizando-se variáveis do tipo double e interconectando-se os nós da rede com os mesmos chaveadores de $100 \mathrm{Mbits} / \mathrm{s}$. Os computadores empregados possuíam freqüência de clock de 2,2 GHz e 256 Mbytes de memória. As topologias utilizadas foram a $n_{x} \mathrm{x} 1, \operatorname{com} n_{x}=1,2, \ldots, 8$. Após as simulações, os dados reais medidos, juntamente com os estimados matematicamente e os correspondentes módulos dos erros percentuais, apresentam-se na tabela 5.1.

Convém salientar que a dimensão $x$ do volume do problema foi ligeiramente ajustada para que, ao dividi-la pela quantidade de nós, o resultado fosse sempre inteiro. Também é importante notar que os resultados de tempo "medidos" quando utilizou-se apenas um nó foram obtidos pela multiplicação por 2 da simulação de um problema com o volume de 100 x 100 x 80. Procedeu-se desta forma porque a quantidade de memória física disponível do computador era insuficiente para alocar o problema original, de volume duas vezes maior.

A Figura 5.2 mostra o comportamento das informações registradas na tabela 5.1. 
Tabela 5.1: Tempos de cálculo, comunicação e total reais medidos por meio da simulação de um problema com tamanho fixo e com quantidade de nós variáveis, segundo a topologia $n_{x} \mathrm{x} 1$. São mostrados, também, os tempos correspondentes obtidos pelas estimativas matemáticas e o erro percentual (em módulo) entre estes e os reais. Os tempos para a topologia com $n_{x}=1$ foram obtidos por extrapolação de dados, conforme descreve o texto.

\begin{tabular}{c||c|c|c||c|c|c||c|c|c}
\multicolumn{1}{l||}{} & \multicolumn{3}{c||}{ Medidos (em s) } & \multicolumn{3}{c||}{ Estimados (em s) } & \multicolumn{3}{c}{ Erros (em \%) } \\
\hline$n_{x}$ & $t_{\text {calc }}$ & $t_{\text {com }}$ & $t_{\text {tot }}$ & $t_{\text {calc }}$ & $t_{\text {com }}$ & $t_{\text {tot }}$ & $t_{\text {calc }}$ & $t_{\text {com }}$ & $t_{\text {tot }}$ \\
\hline 1 & 643,8 & 0,0 & 643,8 & 643,8 & 0,0 & 643,8 & 0,0 & - & 0,0 \\
2 & 356,4 & 64,7 & 421,1 & 321,9 & 49,8 & 371,7 & 9,7 & 23,0 & 11,7 \\
3 & 211,3 & 119,0 & 330,3 & 214,6 & 99,6 & 314,2 & 1,6 & 16,3 & 4,9 \\
4 & 154,0 & 156,3 & 310,3 & 161,0 & 149,4 & 310,4 & 4,5 & 4,4 & 0,0 \\
5 & 122,9 & 185,8 & 308,7 & 128,8 & 199,2 & 328,0 & 4,8 & 7,2 & 6,3 \\
6 & 104,0 & 218,1 & 322,1 & 107,3 & 249,0 & 356,3 & 3,2 & 14,2 & 10,6 \\
7 & 91,9 & 249,3 & 341,2 & 92,0 & 298,8 & 390,8 & 0,1 & 19,9 & 14,5 \\
8 & 81,4 & 280,0 & 361,4 & 80,5 & 348,6 & 429,1 & 1,1 & 24,5 & 18,7
\end{tabular}

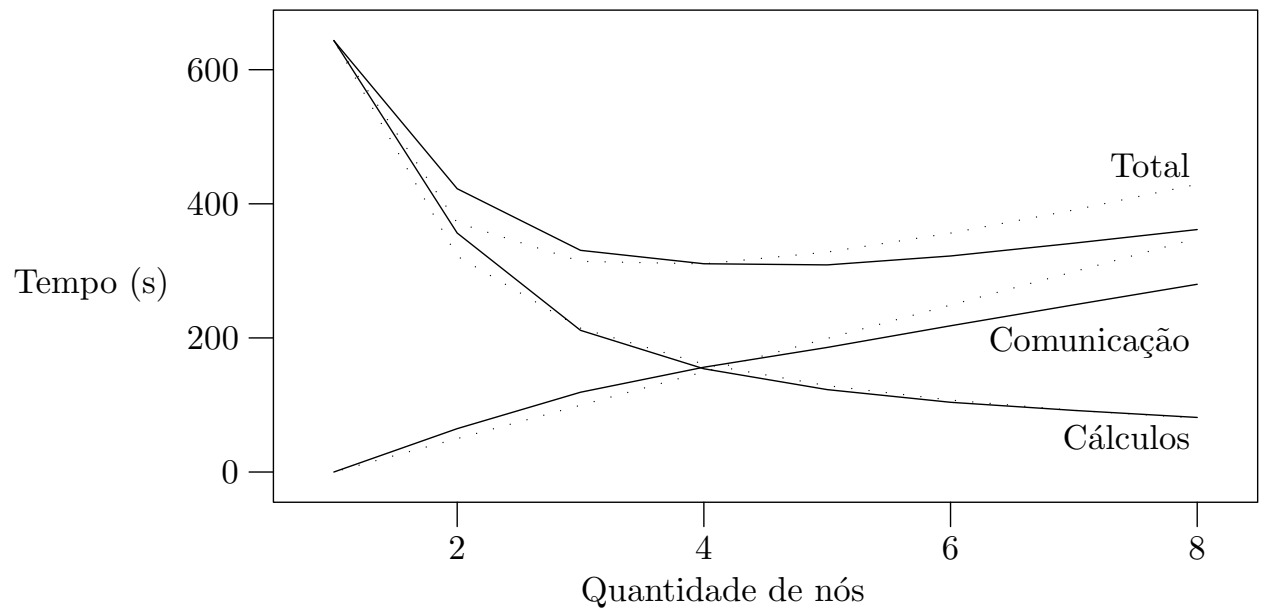

Figura 5.2: Tempos medidos e estimados relativos à tabela 5.1. As linhas "cheias" indicam os tempos medidos e as "pontilhadas", os estimados. 
Nela, percebe-se que o tempo de cálculo cai à razão de $1 / n_{x}$, conforme esperado e também estimado matematicamente. Pode-se considerar que as diferenças entre o medido e o estimado são bastante pequenas, permitindo afirmar que o equacionamento formulado fornece uma boa aproximação. A justificativa para as diferenças reside no fato do tempo equivalente por célula não ser exatamente sempre o mesmo, devido às "oscilações de processamento" que podem ocorrer.

Quanto ao tempo de comunicação, tem-se uma variação de seu valor crescente com o aumento do número de nós, conforme também esperado, devido à maior quantidade de transferências de dados necessárias. A relação entre o aumento do tempo e o número de nós é praticamente linear. Nos tempos de comunicação medidos, nota-se que para as topologias $2 \times 1$ e $3 \times 1$, a taxa de aumento do tempo com o número de nós é maior que para as demais topologias. Este efeito deve ter ocorrido por, provavelmente, otimizações intrínsecas nas transferências de dados, para as topologias de ordem maior, possíveis de ocorrerem pelo uso de chaveador. Talvez, o fato de poder existirem, da topologia $4 \times 1$ em diante, pares que realizam parte das transferências dos dados simultaneamente, explique a diminuição do aumento do tempo de comunicação. A aproximação matemática, por sua vez, apresenta-se razoável, uma vez que os erros não são muito grandes, os quais permanecem abaixo de $25 \%$. Com esta aproximação, para um primeiro trecho, compreendendo as topologias 2 x 1 e $3 \times 1$, os valores encontrados são menores que os medidos. Neste caso, as equações podem não estar prevendo alguma causa que diminua a taxa líquida de tranferência, a qual foi obtida por uma média. E para um segundo trecho, para as demais topologias, a aproximação fornece valores superiores aos medidos, com erro crescente ao se aumentar o número de nós. Portanto, o equacionamento provavelmente não considera alguma causa que provoque a diminuição do tempo de comunicação, e que pode ser a causa citada há pouco, para o caso da diminuição da taxa de aumento dos tempos medidos com o aumento do número de nós. Contudo, a estimativa apresenta-se razoável, como já afirmado. 
Em seguida, o tempo total de processamento, que é a soma do tempo de cálculo com o de comunicação, apresenta-se decrescente com o aumento do número de nós até um mínimo e, a partir deste ponto, passa a ser crescente, tendendo a acompanhar a mesma taxa de aumento do tempo de comunicação. O comportamento é semelhante tanto para o tempo total medido quanto para o tempo total estimado. Há apenas uma certa diferença decorrente das diferenças apresentadas no tempo de cálculo e comunicação. Nota-se também que o erro percentual do tempo total é inferior a $20 \%$, em contraste com o limiar de $25 \%$ do tempo de comunicação. Isto aconteceu porque houve uma compensação entre os erros do tempo de cálculo e de comunicação, de tal forma a anular uma certa parcela da diferença do tempo total.

Agora, utilizando-se a expressão (4.24) do Capítulo 4, pode-se determinar matematicamente qual a quantidade de nós que fornece o menor tempo de processamento. Aplicando-a, resulta em uma quantidade igual a 3,63 nós. Arredondando-se este valor, obtém-se 4 nós. Portanto, o mínimo deve ser observado na topologia 4 x 1. Com base nos dados da tabela 5.1, o mínimo ocorreu para a topologia 5 x 1 . Entretanto, a diferença de tempo para a topologia $4 \times 1$, ainda considerando os tempos medidos, é de apenas 1,6 s. Assim, caso esta topologia tivesse sido prevista para realizar a simulação no menor tempo possível, o resultado teria sido bastante satisfatório, conforme comentado na seção 4.8.2.

De acordo com o exposto no desenvolvimento, outra topologia que, teoricamente, poderia ser adotada para obter um tempo total próximo do seu mínimo seria a 3 x 1 . Utilizando-a, pelas estimativas matemáticas, haveria uma diferença de apenas 3,8 s em relação ao mínimo, mantendo ainda razoável a afirmação. Contudo, no caso real, para tal topologia, nota-se uma diferença de 21,6 s, a qual é uma diferença razoável. Por isso, esta topologia não seria uma boa escolha.

Ainda, do atual exemplo podem-se extrair as informações de razão entre o tempo de comunicação e cálculo $\left(f_{r}\right)$, eficiência $\left(E_{f}\right)$, e ganho de velocidade $\left(G_{v}\right)$. Tais dados são mostrados na tabela tabela 5.2 e na Figura 5.3. 
Tabela 5.2: Razão entre tempos de comunicação e cálculo, eficiência e ganho de velocidade do caso simulado e das estimativas matemáticas.

\begin{tabular}{c||c|c|c||c|c|c}
\multicolumn{1}{c||}{} & \multicolumn{3}{c||}{ Medidos } & \multicolumn{3}{c}{ Estimados } \\
\hline$n_{x}$ & $f_{r}$ & $E_{f}$ & $G_{v}$ & $f_{r}$ & $E_{f}$ & $G_{v}$ \\
\hline 1 & 0,000 & 1,000 & 1,000 & 0,000 & 1,000 & 1,000 \\
2 & 0,155 & 0,866 & 1,732 & 0,182 & 0,846 & 1,693 \\
3 & 0,464 & 0,683 & 2,049 & 0,563 & 0,640 & 1,919 \\
4 & 0,927 & 0,518 & 2,075 & 1,015 & 0,496 & 1,985 \\
5 & 1,547 & 0,393 & 1,963 & 1,512 & 0,398 & 1,991 \\
6 & 2,321 & 0,301 & 1,807 & 2,097 & 0,323 & 1,937 \\
7 & 3,248 & 0,235 & 1,648 & 2,713 & 0,269 & 1,885 \\
8 & 4,330 & 0,188 & 1,501 & 3,440 & 0,225 & 1,802
\end{tabular}

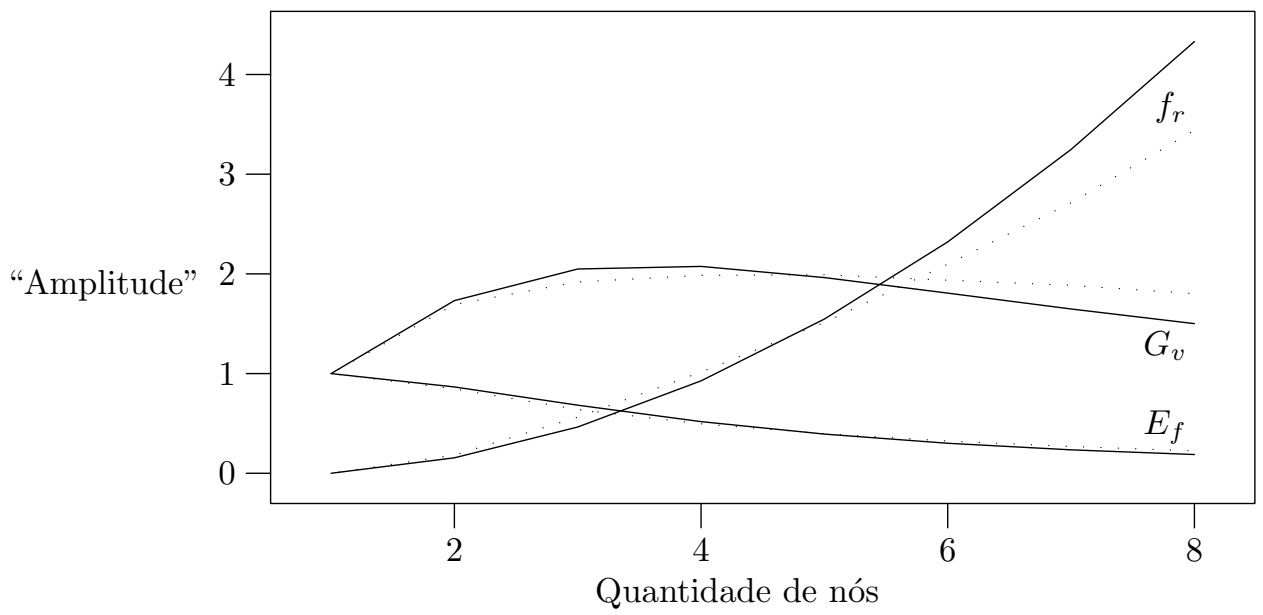

Figura 5.3: Razão entre tempos de comunicação e cálculo $(f)$, eficiência $\left(E_{f}\right)$ e ganho de velocidade $\left(G_{v}\right)$ do caso simulado e das estimativas matemáticas, conforme a tabela 5.2. As linhas "cheias" indicam os valores do caso simulado e as "pontilhadas", das estimativas matemáticas. 
Observando-se o comportamento de $f$, percebe-se que ele aumenta com o número de nós. Isto significa que a taxa de aumento do tempo de comunicação é maior que a taxa de redução do tempo de cálculo, ao aumentar o número de nós. Tal fato é o responsável por limitar a quantidade de nós para se obter o menor tempo de processamento, de forma que se mais nós do que este limite forem utilizados, o tempo total irá aumentar novamente. A diferença entre as curvas de valores medidos e de valores estimados, relaciona-se aos mesmos fatores já expostos na análise das curvas do tempo de cálculo. Por exemplo, considerando-se a segunda parte da curva, da topologia 4 x 1 em diante, a curva dos valores medidos tem taxa de aumento maior que a dos estimados, pois os tempos de comunicação dos medidos foram menores que os dos estimados. Portanto, há coerência dos resultados.

Realizando-se, em seguida, uma análise de $E_{f}$, percebe-se que ele parte de 1,0, ou $100 \%$, e decresce com o aumento do número de nós. O comportamento para ambos os valores medidos e estimados é semelhante e bastante próximo, indicando que a estimativa mostra-se bastante válida para este parâmetro. Interpretando-se, em especial, um ponto, percebe-se que quando $f_{r}=1$, isto é, quando o tempo de cálculo é igual ao tempo de comunicação, a eficiência é de 0,5, isto é, $50 \%$. Este valor significa que $50 \%$ do tempo é utilizado para as transferências de dados, enquanto que, pelos recursos computacionais disponíveis - número de nós - se poderia realizar o processamento em metade do tempo. O melhor aproveitamento dos recursos computacionais seria possível apenas se o tempo de comunicação fosse reduzido, substituindo-se os equipamentos de rede por outros com maiores taxas de transferência.

Já a curva do ganho apresenta-se crescente até um máximo e, logo após, decrescente. As diferenças entre os valores medidos e estimados, anteriormente referenciadas, refletem-se também entre estas curvas, para este parâmetro. Mas, em uma ou outra, percebe-se que para o emprego de mais alguns poucos nós, o ganho aumenta bastante. Empregando mais nós ainda, o ganho aumenta, mas com uma 
taxa bastante pequena. E, se mais alguns nós forem acrescentados, o ganho volta a diminuir. Portanto, o parâmetro, além de indicar o quanto mais rápido um problema será simulado, indica também que não há muita vantagem em se aumentar o número de nós após uma determinada quantidade, pelo fato da pouca variação no tempo total de processamento.

Passando-se a análise, neste instante, para dois casos extremos, observam-se resultados um tanto curiosos. Utilizando-se os mesmos equipamentos do exemplo anterior, mas escolhendo-se, como exemplo, duas topologias e dois volumes com características particulares, os resultados mostrados na tabela 5.3 são obtidos.

Tabela 5.3: Dois exemplos, utilizando-se a topologia $n_{x} \mathrm{x}$ 1, de casos extremos, mostrando valores das estimativas matemáticas incoerentes frente aos medidos. Foram realizados 1001 passos no tempo.

\begin{tabular}{c|c||c|c|c||c|c|c||c|c|c}
\multicolumn{2}{c||}{ Dados } & \multicolumn{3}{c||}{ Medidos (em s) } & \multicolumn{3}{c||}{ Estimados (em s) } & \multicolumn{3}{c}{ Erros (em \%) } \\
\hline$n_{x}$ & volume & $t_{\text {calc }}$ & $t_{\text {com }}$ & $t_{\text {tot }}$ & $t_{\text {calc }}$ & $t_{\text {com }}$ & $t_{\text {tot }}$ & $t_{\text {calc }}$ & $t_{\text {com }}$ & $t_{\text {tot }}$ \\
\hline 5 & $1000 \times 50 \times 80$ & 316,9 & 16,8 & 333,7 & 321,9 & 50,8 & 372,7 & 1,6 & 202,4 & 11,7 \\
6 & $1200 \times 50 \times 80$ & 328,6 & 15,2 & 343,8 & 321,9 & 63,5 & 385,4 & 2,0 & 317,8 & 12,1
\end{tabular}

Percebe-se que o tempo de cálculo estimado está bastante próximo do medido. Contudo, o tempo de comunicação tem um erro muito alto. O tempo total, não apresentou erro tão grande porque o tempo de cálculo predomina sobre o de comunicação.

A hipótese para justificar tais ocorrências baseia-se na forma de como deve ser realizada a comunicação entre os nós. Um nó, ao transferir dados para outro, deve aguardar uma resposta deste outro confirmando ou não o recebimento. Por isso, quando realizaram-se as simulações com um certo volume com as arestas com a mesma ordem de grandeza, como no exemplo inicial, a alta quantidade de dados a serem transferidos de um nó a outro deve ter requisitado que estes dados fossem particionados, de forma que o bloco total dos dados fosse transmitido em duas ou mais vezes. Uma vez que, no programa, as comunicações são iniciadas quase ao mesmo tempo, então os nós iniciam entre si as transferências de dados, quase ao 
mesmo tempo também. Durante as transmissões, um nó esperará de outro uma resposta de confirmação do recebimento. E assim, enquanto um nó transmite dados, não poderá transmitir a confirmação e, enquanto transmite a confirmação, não pode transmitir dados - a comunicação, provavelmente, deve ser do tipo full duplex, o que possibilita o envio e a recepção de dados simultaneamente; mas isto não soluciona a questão colocada. Portanto, este comportamento fará com que haja uma espécie de encadeamento entre os nós, de forma como que apenas um par de nós comunicase a cada instante. Por isso, há o coeficiente $\left(n_{x}-1\right)$ ou $\left(n_{y}-1\right)$ nas expressões apresentadas na seção 4.8. Já no caso das situações mostradas na tabela 5.3, tem-se um volume de dados razoavelmente grande, mas suas arestas não são da mesma ordem. Conseqüentemente, a quantidade de dados que serão transferidos será bastante reduzida. Portanto, não haverá múltiplos blocos a serem enviados de um nó a outro. E, assim, uma única resposta por parte de um nó receptor ao nó transmissor será suficiente para encerrar a transmissão entre eles. Suspeita-se que uma quantidade inferior a 128 kbytes de dados a serem transmitidos seja o limite para tal comportamento. Por fim, com as causas descritas, tem-se o efeito de que todos os nós comunicar-se-ão ao mesmo tempo. Como resultado, o tempo de comunicação será o tempo equivalente à transferência de dados entre um único par de nós. Isto faz, então, o termo $\left(n_{x}-1\right)$ ou $\left(n_{y}-1\right)$ ser reduzido a 1 . Utilizado-se, agora, esta conclusão, chega-se aos resultados mostrados na tabela 5.4.

Tabela 5.4: Os mesmos exemplos da tabela 5.3, mas agora com os tempos de comunicação corrigidos conforme o descritivo.

\begin{tabular}{c|c||c|c|c||c|c|c||c|c|c}
\multicolumn{2}{c||}{ Dados } & \multicolumn{3}{c||}{ Medidos $(\mathrm{em} \mathrm{s})$} & \multicolumn{3}{c||}{ Estimados $(\mathrm{em} \mathrm{s})$} & \multicolumn{3}{c}{ Erros (em \%) } \\
\hline$n_{x}$ & volume & $t_{\text {calc }}$ & $t_{\text {com }}$ & $t_{\text {tot }}$ & $t_{\text {calc }}$ & $t_{\text {com }}$ & $t_{\text {tot }}$ & $t_{\text {calc }}$ & $t_{\text {com }}$ & $t_{\text {tot }}$ \\
\hline 5 & $1000 \times 50 \times 80$ & 316,9 & 16,8 & 333,7 & 321,9 & 12,7 & 334,6 & 1,6 & 24,4 & 0,3 \\
6 & $1200 \times 50 \times 80$ & 328,6 & 15,2 & 343,8 & 321,9 & 12,7 & 334,6 & 2,0 & 16,4 & 2,7
\end{tabular}

Verifica-se, assim que os tempos de comunicação ficaram bem mais próximos dos valores medidos, o que indica haver certa coerência nas afirmações expostas. Ainda 
no caso, os tempos de comunicação medidos devem ter sido um pouco maiores que os estimados por causa dos dados de confirmação enviados pelos nós receptores e que não foram considerados na estimativa. E o tempo total, como conseqüência, apresentou um erro, entre os valores medidos e estimados, ainda menor.

Portanto, com tais colocações, tem-se que, com o uso de chaveadores como elementos de interconexão de uma rede, há a possibilidade de comunicações simultâneas entre vários pares de nós, desde que um não tenha que esperar a liberação do outro.

Este efeito passa, então, a ser observado num volume regular, isto é, com dimensões das suas arestas com a mesma ordem entre si, quando se utilizam as topologias $n_{x} \mathrm{x} n_{y}, \operatorname{com} n_{x}$ e $n_{y}$ maiores que a unidade. Por exemplo, numa topologia $4 \times 2$, há duas linhas de nós com quatro nós cada uma. Em cada linha, devido à quantidade de dados a serem transmitidos ser relativamente grande - pensando-se num volume regular e com considerável quantidade de células - numa mesma linha haverá o cascateamento entre os nós quando houver comunicações "na direção horizontal", isto é, em $x$. Contudo, neste tipo de comunicação não há troca de dados entre os nós de linhas diferentes. Por isso, a transferência de dados entre os nós de uma linha ocorrerá simultaneamente com a da outra linha. Portanto, o tempo de comunicação necessário dá-se como se houve uma única linha com quatro nós. Esta mesma análise é análoga para qualquer topologia, não restringindo-se a duas linhas. Também de forma semelhante, se houver a comunicação entre os nós "na direção vertical", isto é, em $y$, não haverá troca de dados entre os nós de diferentes colunas. Portanto, os quatro pares de nós que assim se formam, irão realizar as transferências simultaneamente. Como resultado, do ponto de vista do tempo de comunicação, tem-se o equivalente à transferência de dados entre os nós de único par de nós. Mais uma vez, esta análise não se restringe a esta topologia. Justifica-se, com estes argumento, o fator 1 que aparece na determinação de $f_{d x}$ e $f_{d y}$, em (4.7), na seção 4.8, para o caso de se utilizar chaveadores.

Considerando-se algumas topologias do tipo $n_{x} \mathrm{x} n_{y}$, foram levantados os dados 
da tabela 5.5. As características da simulação são: volume de 100 x 100 x 160 células, 1001 passos no tempo, variáveis do tipo double, emprego de chaveadores de $100 \mathrm{Mbits} / \mathrm{s}$, tempo equivalente de célula de 402 ns/célula/iteração e taxa de transferência média de 10,01 Mbytes/s.

Tabela 5.5: Tempos de cálculo, comunicação e total reais medidos por meio da simulação de um problema com tamanho fixo e com quantidade de nós variáveis, segundo a topologia $n_{x} \mathrm{x} n_{y}$. São mostrados também os tempos correspondentes obtidos pelas estimativas matemáticas e o erro percentual entre estes e os reais.

\begin{tabular}{c|c||c|c|c||c|c|c||c|c|c}
\multicolumn{3}{c||}{ Dados } & \multicolumn{3}{c||}{ Medidos (em s) } & \multicolumn{3}{c||}{ Estimados (em s) } & \multicolumn{3}{c}{ Erros (em \%) } \\
\hline$n_{x}$ & $n_{y}$ & $t_{\text {calc }}$ & $t_{\text {com }}$ & $t_{\text {tot }}$ & $t_{\text {calc }}$ & $t_{\text {com }}$ & $t_{\text {tot }}$ & $t_{\text {calc }}$ & $t_{\text {com }}$ & $t_{\text {tot }}$ \\
\hline 2 & 2 & 155,1 & 68,2 & 223,3 & 161,0 & 50,8 & 211,8 & 3,8 & 25,5 & 5,2 \\
3 & 2 & 105,5 & 70,9 & 176,4 & 107,3 & 68,0 & 175,3 & 1,7 & 4,1 & 0,6 \\
4 & 2 & 77,9 & 87,9 & 165,8 & 80,5 & 89,4 & 169,9 & 3,3 & 1,7 & 2,5
\end{tabular}

Os resultados apresentados mostram considerável proximidade entre os valores medidos e os estimados, validando, portanto, as afirmações expostas e o equacionamento desenvolvido na seção 4.8 .

No caso do uso de hubs, entretanto, em nenhuma topologia haverá a possibilidade de comunicações simultâneas de pares de nós. Assim, tomando-se o mesmo exemplo de uma topologia 4 x 2, para comunicações "na horizontal", o tempo de comunicação será equivalente ao necessário para os nós da primeira linha realizarem as transferências, cada par por vez, somado ao tempo necessário para os nós da segunda linha, também cada par por vez. Isto resulta, portanto, num fator igual ao número de linhas que multiplica o tempo necessário para cada linha. Analogamente, numa comunicação "na vertical", o mesmo ocorrerá, aparecendo um fator igual ao número de colunas. E esta análise é válida para qualquer topologia. Desta forma, justifica-se o fator $n_{x}$ ou $n_{y}$ que aparece na determinação de $f_{d x}$ e $f_{d y}$, para o caso do emprego de hubs.

Nos testes, não foram exploradas as várias topologias com o emprego de hubs, pois os disponíveis possuíam taxa de transferência muito baixa e preferiu-se prio- 
rizar o uso dos chaveadores, num primeiro momento. Contudo, será mostrado o resultado para uma simulação com seu emprego, podendo-se perceber, ao menos, a influência significativa da taxa de transferência. Realizou-se, então, uma simulação com os computadores interconectados por hub, com taxa de transferência nominal de $10 \mathrm{Mbits} / \mathrm{s}(1,2 \mathrm{Mbytes} / \mathrm{s})$ e com taxa média de $290 \mathrm{kbytes} / \mathrm{s}$, por 301 passos no tempo, considerando-se um volume de 100 x 100 x 60 células, sendo o tempo equivalente por célula de 402 ns/célula/iteração. Os resultados mostrados na tabela 5.6 são para as topologias 1 x 1 e 2 x 1 .

Tabela 5.6: Tempos medidos, estimados e os erros percentuais correspondentes para a simulação de um problema num sistema paralelizado utilizando-se dois computadores interconectados por $h u b$ de baixa velocidade.

\begin{tabular}{c||c|c|c||c|c|c||c|c|c}
\multicolumn{1}{c||}{ Dado } & \multicolumn{3}{c||}{ Medidos (em s) } & \multicolumn{3}{c||}{ Estimados (em s) } & \multicolumn{3}{c}{ Erros (em \%) } \\
\hline$n_{x}$ & $t_{\text {calc }}$ & $t_{\text {com }}$ & $t_{\text {tot }}$ & $t_{\text {calc }}$ & $t_{\text {com }}$ & $t_{\text {tot }}$ & $t_{\text {calc }}$ & $t_{\text {com }}$ & $t_{\text {tot }}$ \\
\hline 1 & 73,8 & 0,0 & 72,6 & 72,6 & 0,0 & 72,6 & 1,6 & - & 1,6 \\
2 & 34,4 & 189,9 & 224,3 & 36,3 & 198,5 & 234,8 & 5,4 & 4,5 & 4,7
\end{tabular}

Novamente, os resultados medidos e estimados mostram-se bastante próximos. Nota-se, contudo, que o tempo total de processamento do sistema paralelizado é maior do que o tempo total sem paralelização. Isto deve-se por causa do alto tempo de comunicação, decorrente do uso de um $h u b$ de baixa velocidade. A vantagem que se pode obter para um sistema paralelizado com estas características será apenas a viabilização da simulação de um determinado problema que requisite mais memória que a disponível num único computador. Este fato será exemplificado na seqüência.

A quantidade de memória a ser utilizada pelo programa também tem sua estimativa matemática, conforme (4.31) apresentado na seção 4.8 do Capítulo 4. Por exemplo, para um problema com um volume de 100 x 100 x 160 células, a quantidade de memória total necessária é de 254 Mbytes.

Analisando-se com um pouco mais de detalhes o uso da memória, se este problema com o volume citado for simulado num computador com apenas 256 Mbytes de memória física, certamente não haverá memória física suficiente disponível para 
alocar todas as matrizes, lembrando-se que o Sistema Operacional reserva uma certa quantidade para a operação de todo o sistema. Assim, o espaço de troca em disco será utilizado, como se fosse uma memória virtual. Contudo, como o tempo de acesso a disco é muito mais elevado que o acesso à memória física, tem-se o resultado de um longo tempo de processamento para a simulação. Neste caso, o uso do paralelismo, mesmo numa rede com taxa de transferência baixa, pode viabilizar a simulação. Como comparativo das situações neste contexto, apresentam-se os dados da tabela 5.7.

Tabela 5.7: Comparativos entre várias situações para a simulação de um problema com quantidade de dados que não pode ser alocada totalmente na memória física de um único computador. O computador utilizado possui 256 Mbytes de memória física e o volume considerado é de 100 x 100 x 160 células, necessitando de 254 Mbytes de memória. As situações são: (a) ideal, caso houvesse memória física suficiente para um único nó alocar o problema; (b) real, para um passo no tempo, nas condições atuais, para um nó; (c) real, idem a (b), mas para 1001 passos no tempo - resultado obtido por extrapolação; (d) real, com uso de hub com baixa taxa de transferência; (e) real, com uso de chaveador com média taxa de transferência.

\begin{tabular}{l|c|c|c}
\multicolumn{1}{c|}{ Situação } & Topologia & $N_{I}$ & $t_{\text {tot }}$ (s) \\
\hline (a) Ideal & $1 \times 1$ & 1001 & 643,6 \\
(b) Real & $1 \times 1$ & 1 & 187,8 \\
(c) Real & $1 \times 1$ & 1001 & 187987,8 \\
(d) Real com $h u b$ & $2 \times 1$ & 1001 & 2082,3 \\
(e) Real com chaveador & $2 \times 1$ & 1001 & 421,1
\end{tabular}

Na tabela, para o caso da situação (a), o tempo total de 643,6 s seria obtido caso um único computador possuísse memória física suficiente para alocar o problema e realizando-se 1001 iterações no tempo. Na situação (b), tem-se o tempo de 187,8 s, que foi realmente encontrado para as características atuais do computador, ao realizar-se apenas uma iteração no tempo. Extrapolando-se este resultado, obtém-se o valor da situação (c), o qual corresponde a 2 dias e 4 horas. Percebe-se, assim, que a simulação se tornaria inviável. Utilizando-se, em seguida, dois computadores interligados por $h u b$ de baixa velocidade - com taxa nominal de $10 \mathrm{Mbits} / \mathrm{s}$ -, o tempo obtido seria de 2082,3 s, ou aproximadamente 35 minutos, o que tornaria a simulação viável, embora o tempo total seja maior que o da situação (a) - a qual 
é uma referência. Por último, utilizando-se um chaveador de média velocidade com taxa de $100 \mathrm{Mbits} / \mathrm{s}^{-}$, obtém-se um tempo quase cinco vezes menor. Portanto, conforme afirmado anteriormente, num sistema paralelizado, os equipamentos de rede, podem, a princípio, não permitir a redução do tempo total de processamento, para algum problema possível de ser alocado na memória de um único computador. Contudo, para problemas maiores, impossíveis de serem alocados na memória física de um único computador, os equipamentos, ao menos, tornariam viável a simulação de tais problemas.

Por fim, embora os valores de tempo estimados matematicamente apresentem um certo erro quando comparados com os medidos, é possível concluir que as estimativas matemáticas são válidas, devido à coerência e à proximidade dos resultados. Assim, tem-se um método para prever os tempos de cálculo, comunicação e total de uma simulação em função do número de nós, além de também se poder estimar a quantidade total de memória necessária. Ainda, utilizando-se tais ferramentas matemáticas, criam-se condições de se encontrar a topologia que fornecerá o menor tempo de simulação ou a topologia que poderá viabilizar a simulação de um determinado problema.

\subsection{Nota sobre a Funcionalidade do Paralelismo}

Os problemas, quando simulados no sistema paralelizado, utilizando nós virtuais ou reais, apresentaram os corretos resultados, conforme esperado, o que garantiu que as técnicas de transferências de dados foram adequadamente implementadas. Isto tornou, portanto, o sistema paralelizado funcional e aplicável à solução de problemas da área do eletromagnetismo. 


\subsection{Ensaio para o Estudo de uma Aplicação Prá- tica - Descargas Atmosféricas em Regiões com Edifícios}

O estudo das descargas atmosféricas próximas a regiões com edifícios é um assunto de bastante interesse, porque permitirá analisar a influência dos prédios sobre a distribuição do campo eletromagnético e, a partir dos resultados, extrair algumas conclusões de ordem prática. Por exemplo, será possível prever as tensões induzidas numa linha de distribuição de energia elétrica de acordo com a sua localização em relação aos prédios.

Neste ensaio, será considerada uma região física total de 500 x 1600 x 1600 m, com a presença de 12 prédios sobre um solo real, iluminada pelo campo eletromagnético decorrente de uma descarga atmosférica.

O objetivo deste ensaio, neste momento, será o de mostrar a aplicabilidade da ferramenta desenvolvida a um caso próximo a um caso real. Portanto, simplificações no modelamento da situação serão realizadas. Com trabalho mais específico sobre o assunto, tornar-se-ia possível uma representação ainda mais próxima dos fenômenos físicos envolvidos em tal problema. O programa, por si, apresenta as condições necessárias para a implementação de tal representação.

Os dados do problema simulado são, então, os seguintes:

- Os prédios possuem alturas de 10,20 e $40 \mathrm{~m}$, permissividade elétrica $4,0 \epsilon_{0} \mathrm{e}$ condutividade $1,0 \mathrm{~S} / \mathrm{m}$;

- o solo possui uma espessura de $100 \mathrm{~m}$, permissividade $2,8 \epsilon_{0}$ e condutividade $10^{-3} \mathrm{~S} / \mathrm{m}$

- os passos no tempo e no espaço são de, respectivamente, 16,7 ns e 10 m;

- a fonte será uma rampa até 1,67 $\mu$ s, isto é, por 100 passos no tempo, quando 
atinge o valor o máximo, mantendo-o constante em seguida; a forma da fonte plana, posicionada próxima aos prédios, como mostrado na Figura 5.4; o campo aplicado será um campo elétrico vertical;

- consideração de "região aberta" para o volume analisado, com a utilização da PML.

A geometria do problema enunciado é mostrada na Figura 5.4.

Nota-se que, com tais dados, tem-se um volume computacional de 50 x 160 x 160 células, o que irá requisitar por volta de 206 Mbytes de memória. Considerandose o uso de computadores com 256 Mbytes de memória física total, conclui-se que um único não será suficiente para alocar o problema, lembrando-se que o Sistema Operacional não libera para o programa toda a memória física instalada. Portanto, há a necessidade de, ao menos, dois computadores deste tipo. Também, desejando-se que a execução ocorra num menor tempo de processamento e adotando-se a topologia $n_{x} \times 1$, três computadores deverão ser empregados.

Se a simulação deste problema fosse realizada num único computador, por 200 passos no tempo, o tempo total necessário de processamento seria de, aproximadamente, 5000 s! Isto porque, pelo fato de não haver memória física suficiente disponível, seria utilizado o espaço de troca em disco, cujo acesso é bastante lento. Por outro lado, utilizando-se, por exemplo, 4 computadores, obteve-se um tempo total de simulação, que inclui o tempo de cálculo e o de comunicação, de apenas 42 s. Depois, foram necessários mais $90 \mathrm{~s}$ para a concatenação dos resultados num único computador, fornecendo um tempo final do processo de 132 s. Assim, percebe-se, mais uma vez, a vantagem do uso do paralelismo.

Como resultado da simulação, tem-se disponível a distribuição do campo elétrico vertical, mostrada na Figura 5.5, para o instante de tempo de 1,67 $\mu$ s e a $10 \mathrm{~m}$ de altura do solo.

Analisando-se a imagem da figura, começa-se a verificar o efeito da blindagem 


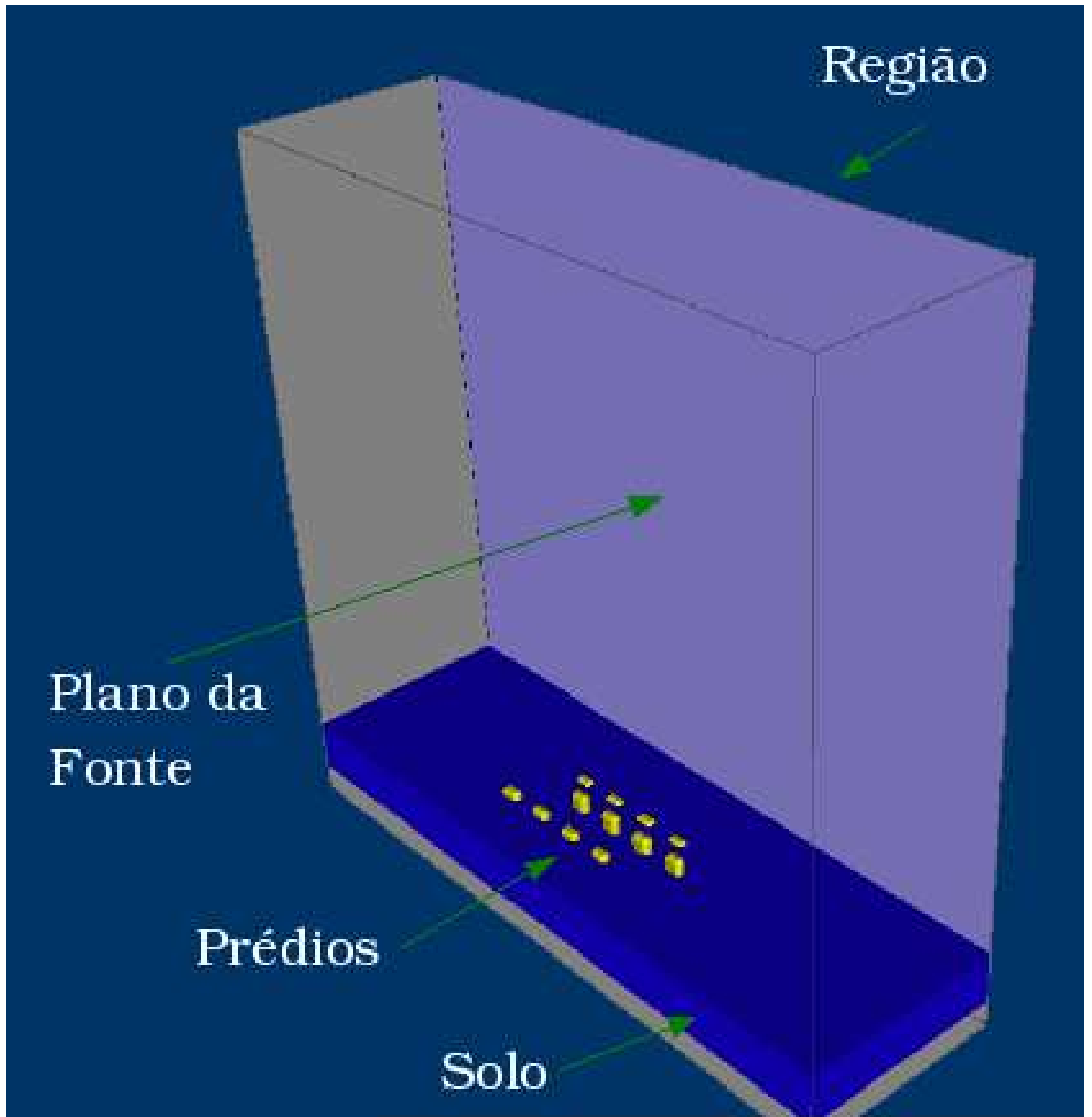

Figura 5.4: Geometria do problema para a simulação de uma situação próxima a um caso real de descarga atmosférica em regiões com edifícios. Nela, tem-se indicado o plano de aplicação da fonte, o solo e os prédios. O espaço aberto será considerado pela presença da PML, não desenhada nesta figura. 


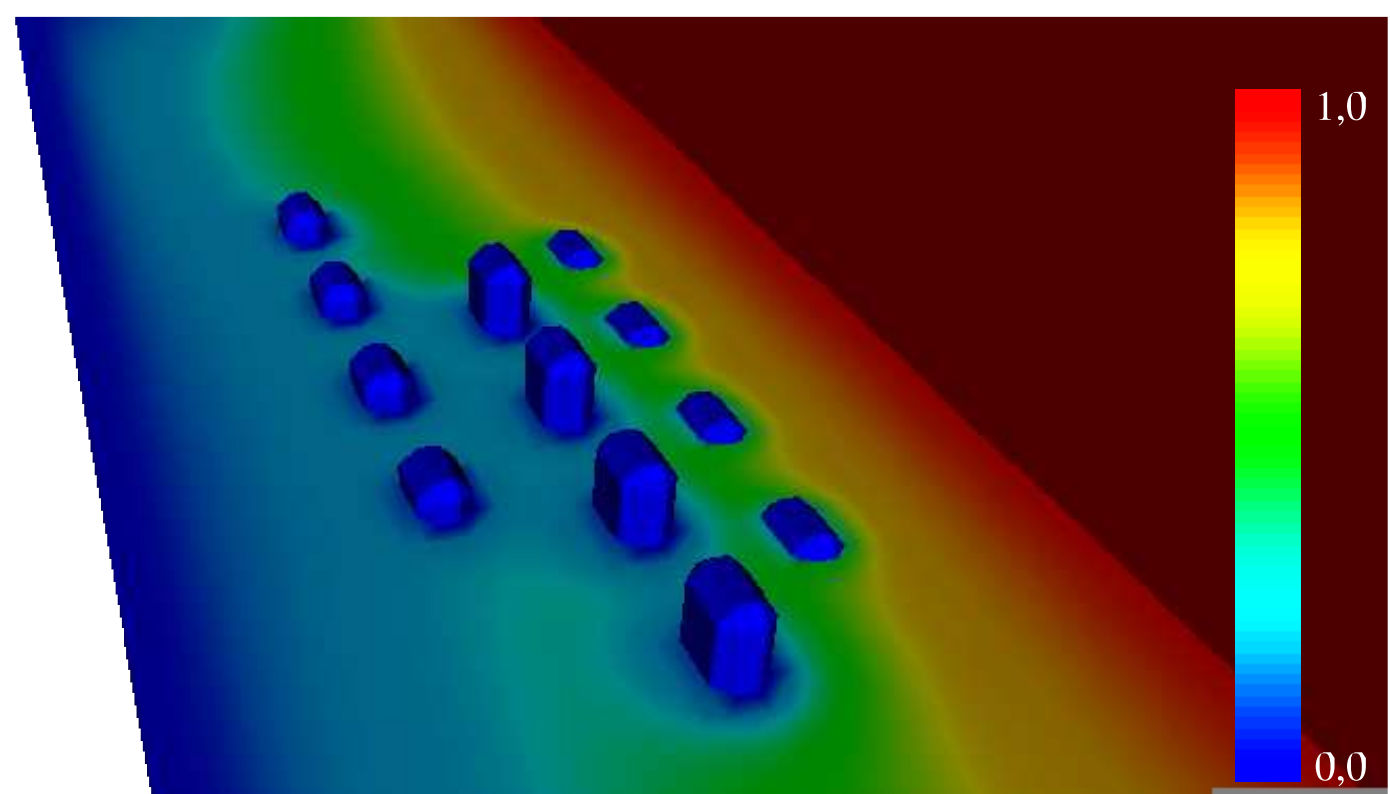

Figura 5.5: Distribuição do campo elétrico vertical no instante de tempo $1,67 \mu$ s a $10 \mathrm{~m}$ acima do solo. A barra de cores indica as intensidades relativas do campo elétrico.

oferecida pelos prédios ao se observar a distorção na propagação do campo na região dos prédios mais próximos da fonte. As cores da figura indicam a intensidade relativa do campo elétrico, sendo o vermelho os campos mais intensos e o azul, os menos intensos.

Continuando-se, após mais alguns instantes de tempo, tem-se a nova distribuição do campo mostrada na Figura 5.6. Nesta situação, os campos mais intensos encontram-se aos arredores dos prédios, permanecendo, na região entre eles, um campo com menor intensidade.

Por fim, para o instante de tempo igual a $2,51 \mu \mathrm{s}$, os campos aos arredores dos prédios são um pouco mais intensos e, na região entre eles, continuam-se os campos menos intensos, conforme mostra a Figura 5.7.

Portanto, uma conclusão possível de chegar com tal análise, é que se uma linha de transmissão for colocada entre os prédios e tendo-se a ocorrência de uma descarga atmosférica, a tensão induzida nela será menor do que se ela estivesse em qualquer outro local, pois o campo elétrico é menos intenso. Mesmo se a descarga ocorrer em 


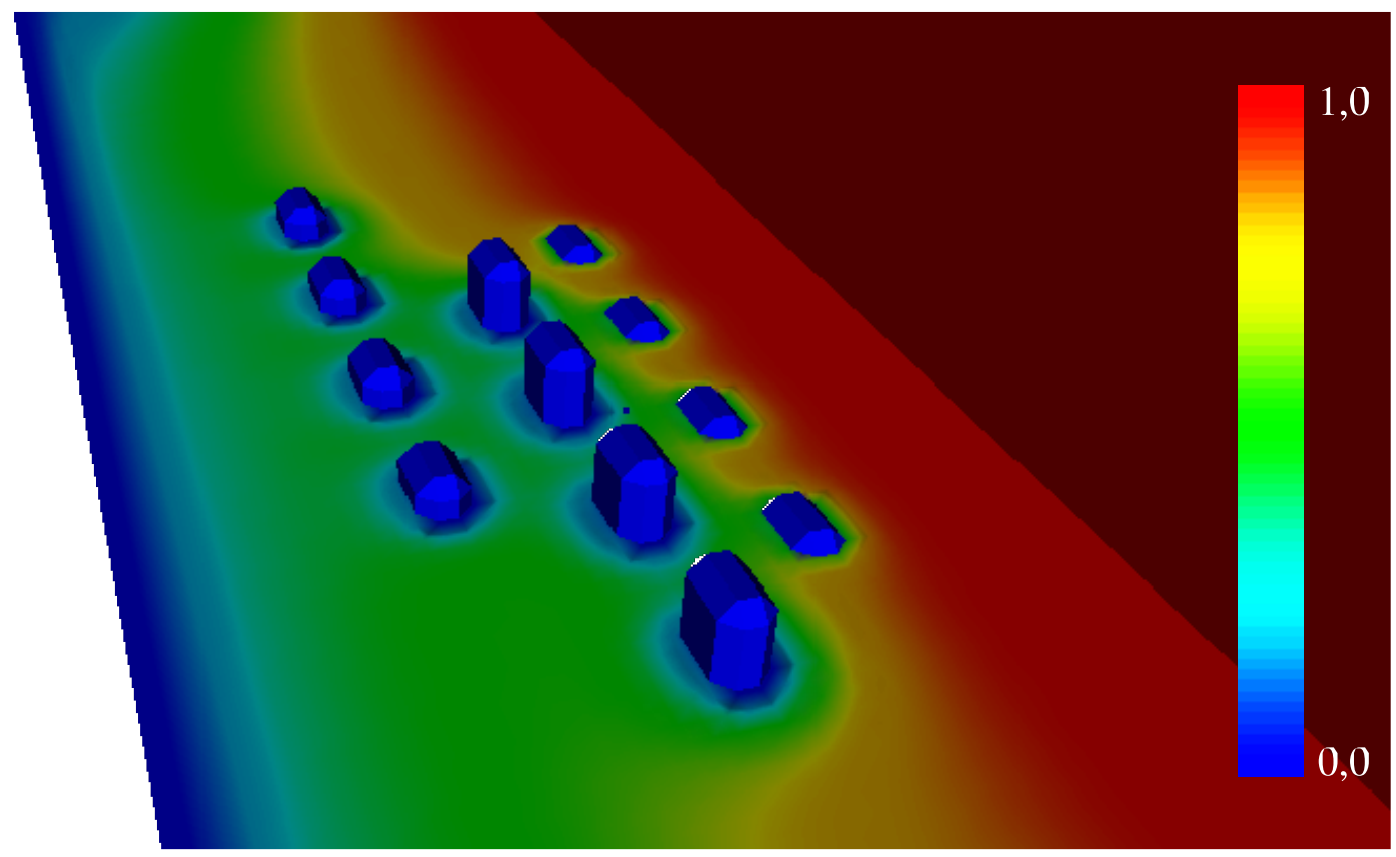

Figura 5.6: Distribuição do campo elétrico vertical no instante de tempo 2,00 $\mu$ s a $10 \mathrm{~m}$ acima do solo. Nota-se a presença de campos mais intensos nos arredores da região dos edifícios e a de campos menos intensos na região entre eles. A barra de cores indica as intensidades relativas do campo elétrico.

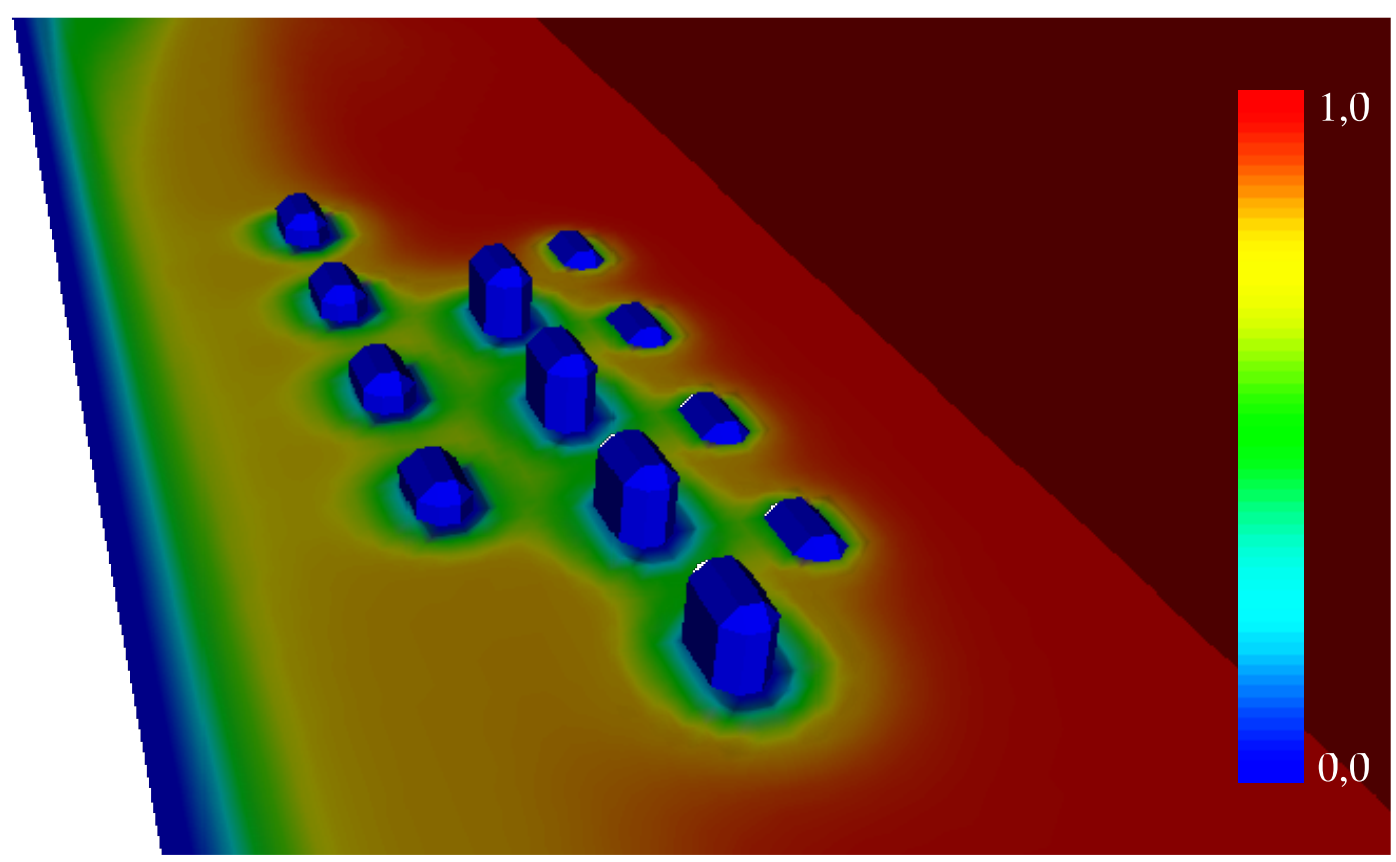

Figura 5.7: Distribuição do campo elétrico vertical no instante de tempo 2,51 $\mu$ s a $10 \mathrm{~m}$ acima do solo. Nota-se que a presença de campos mais intensos aos arredores da região dos edifícios permanece, assim como a de campos menos intensos na região entre eles. A barra de cores indica as intensidades relativas do campo elétrico. 
posições diferentes da mostrada no exemplo, esta conclusão permanece igual, desde que a linha esteja situada no "centro" da região com edifícios.

É possível também observar, em gráfico, a variação do campo elétrico ao longo do espaço, conforme ilustra-se na Figura 5.8. Nesta figura, percebem-se intensidades menores de campo elétrico na região que é circundada pelos edifícios.

\section{nEy entre os prédios}

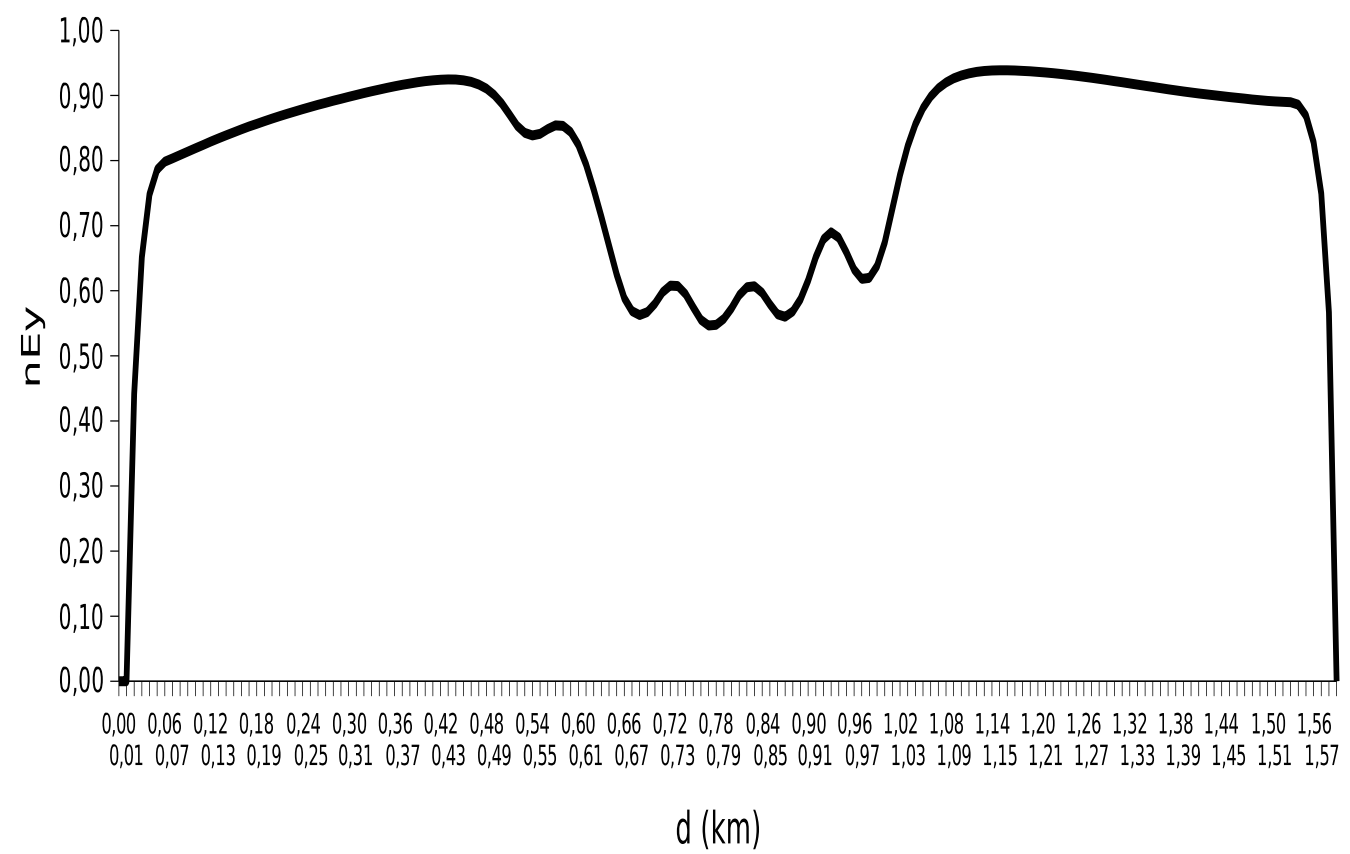

Figura 5.8: Variação ao longo do espaço do campo elétrico. O campo elétrico traçado corresponde a uma linha horizontal que passa entre os prédios, na direção de maior dimensão. A notação nEy indica que a intensidade do campo elétrico mostrada está normalizada em relação à máxima intensidade aplicada pela fonte.A distância $d$ é medida a partir da borda plana esquerda do volume. Cada traço representa $10 \mathrm{~m}$ no eixo $d$.

A variação do campo elétrico em alguns pontos do espaço ao longo do tempo também pode ser observada num gráfico. Por exemplo, na Figura 5.9 mostra-se tal variação para pontos situados num plano a $10 \mathrm{~m}$ de altura. Neste plano, suas localizações são: na faixa de aplicação da fonte, na frente dos edifícios, entre os edifícios e atrás dos edifícios. Percebe-se, novamente, que o campo elétrico no ponto entre os edifícios atinge uma amplitude menor que os demais pontos.

A mesma espécie de gráfico pode ser observada na Figura 5.10, mas agora a $30 \mathrm{~m}$ 


\section{nEy em vários pontos a $10 \mathrm{~m}$ de altura}

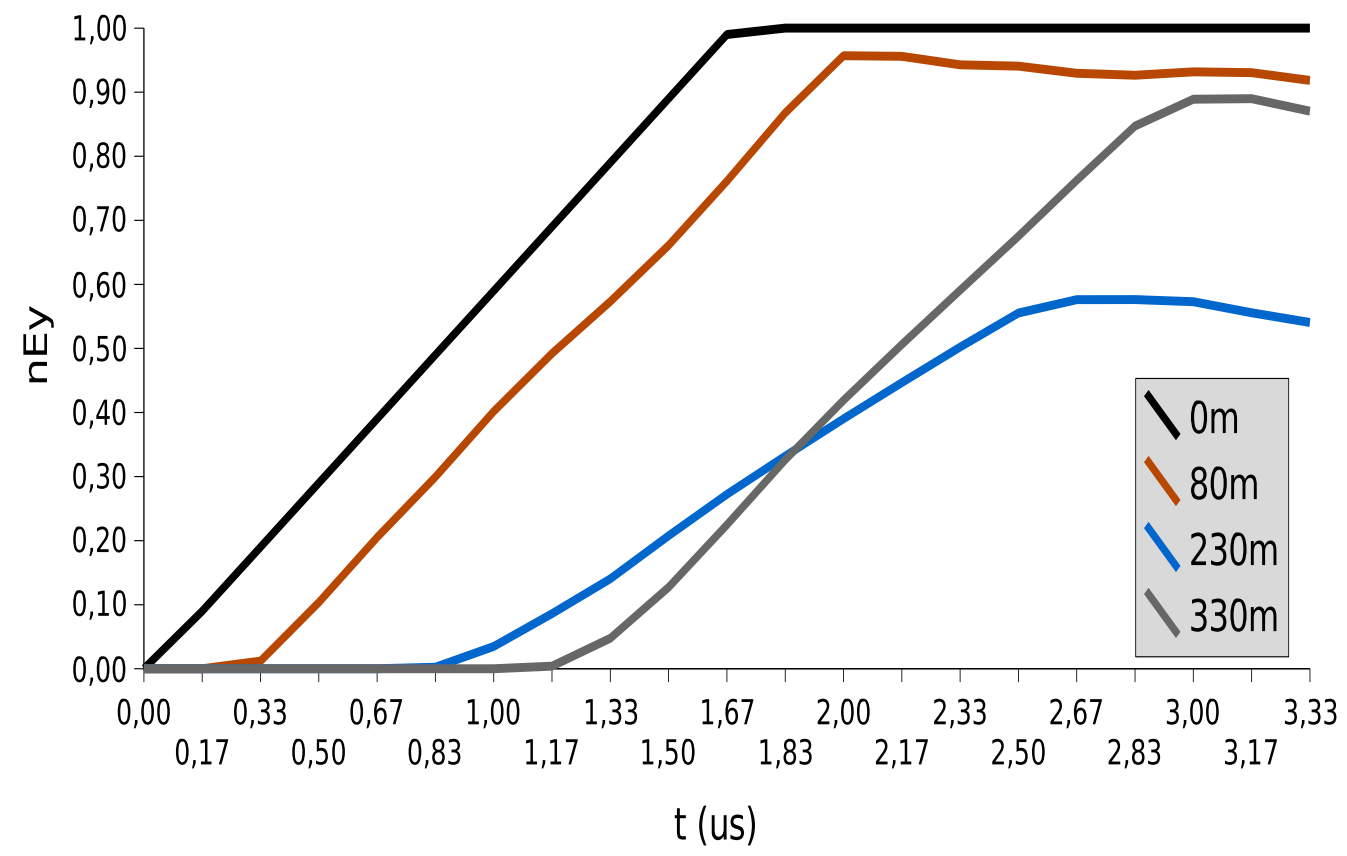

Figura 5.9: Variação do campo elétrico ao longo do tempo em quatro pontos distintos, num plano a $10 \mathrm{~m}$ de altura. Na legenda, a distância de $0 \mathrm{~m}$ corresponde à posição da fonte e as distâncias maiores, a posições mais afastadas da fonte. Assim, tem-se, respectivamente, pontos que se situam em frente aos edifícios, entre eles e atrás deles. A notação nEy indica que a intensidade do campo elétrico mostrada está normalizada em relação à máxima intensidade aplicada pela fonte. 
de altura. É notável a menor amplitude do campo elétrico no ponto circundado por edifícios, após os transitórios iniciais. Contudo, esta amplitude é maior que a correspondente na altura de $10 \mathrm{~m}$, como mostrado na Figura 5.9. Tal resultado apresenta-se coerente devido à menor influência dos edifícios em pontos a $30 \mathrm{~m}$ do solo, quando comparada às suas influências em pontos a $10 \mathrm{~m}$ do solo.

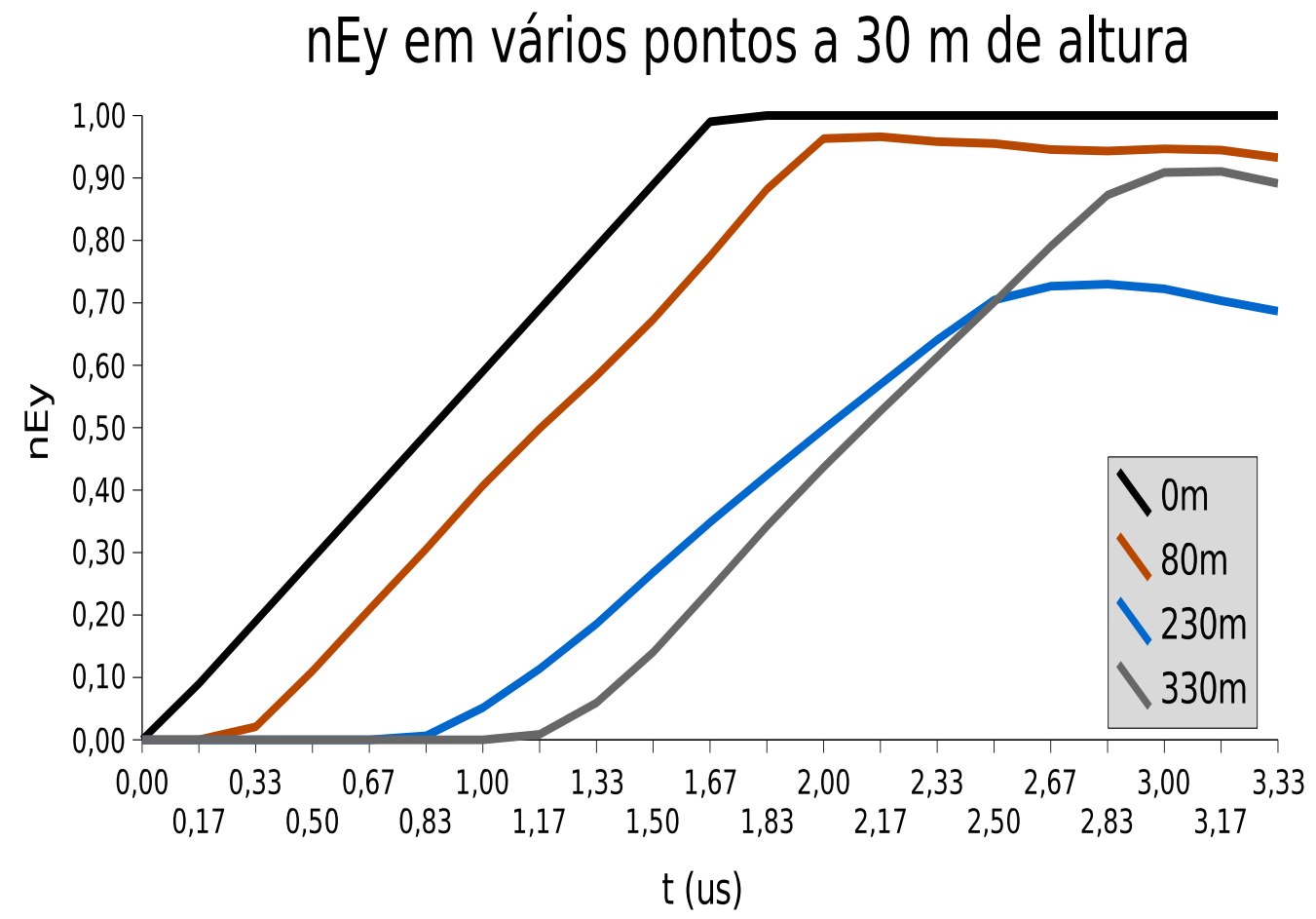

Figura 5.10: Variação do campo elétrico ao longo do tempo em quatro pontos distintos, num plano a $30 \mathrm{~m}$ de altura. Na legenda, a distância de $0 \mathrm{~m}$ corresponde à posição da fonte e as distâncias maiores, a posições mais afastadas da fonte. Assim, tem-se, respectivamente, pontos que se situam em frente aos edifícios, entre eles e atrás deles. A notação nEy indica que a intensidade do campo elétrico mostrada está normalizada em relação à máxima intensidade aplicada pela fonte.

Por fim, o exemplo apresentado mostra a aplicabilidade da ferramenta para a análise de problemas de eletromagnetismo, conforme os objetivos e as propostas iniciais. 


\section{Capítulo 6}

\section{CONCLUSÕES}

O código paralelizado desenvolvido mostrou-se válido pela reprodução de resultados já conhecidos.

Isso significa que as técnicas empregadas para a transmissão e a recepção dos dados são válidas e foram implementadas adequadamente. Também, as técnicas alternativas para a aplicação da fonte mostraram-se eficazes e eficientes, pela otimização do código e pela flexibilidade oferecida. Igualmente, a implementação diferenciada da PML resultou em um código mais reduzido e consistente, o que, entre outras vantagens, facilitou a paralelização dos laços de diferenças finitas.

Como um todo, as características procuradas para a implementação do programa também foram, em sua grande parte, alcançadas, com o emprego das boas práticas de programação. Uma das pendências presentes, importante para a aplicabilidade do programa, é a facilitação da entrada da geometria do problema, a qual, atualmente, é realizada via código de programação.

A proposta de desenvolvimento e operação utilizando programas e ambientes Linux gratuitos foi adequadamente atendida.

Os testes paralelizados em nós reais executaram-se em uma rede de computadores já previamente existente, satisfazendo as premissas inicialmente propostas.

A redução do tempo total de processamento e aumento da memória disponível, 
que são as principais vantagens do processamento paralelo, foram satisfatoriamente obtidas.

Percebeu-se, contudo, que a redução do tempo de processamento só é possível ao se utilizar periféricos de rede com, ao menos, uma taxa média de transferência de dados, por volta de $100 \mathrm{Mbits} / \mathrm{s}$. Por outro lado, notou-se também que, mesmo utilizando um periférico de rede com taxa de transferência baixa, podem-se obter vantagens. Tal fato ocorre nas situações em que a memória física disponível de um computador é inferior à requisitada pelo problema e, ao utilizar o paralelismo, temse uma maior quantidade de memória que pode ser alocada ao mesmo problema. Caso não se utilizasse o paralelismo, a memória virtual seria utilizada e resultaria num tempo de processamento extremamente grande. Assim, apesar do tempo de processamento do caso paralelizado com periférico de baixa taxa de transferência ser maior do que seria na hipótese de um único computador possuir a quantidade suficiente de memória, o tempo de processamento resultante ainda é bastante inferior àquele que se faria uso da memória virtual para a simulação.

A quantidade de memória disponível, por sua vez, aumentou com o paralelismo, porque foi utilizado um sistema com memória distribuída.

A liberdade de escolha da quantidade de nós e da topologia de subdivisão do problema entre os nós foi implementada com êxito e permitiu realizar o estudo do sistema paralelizado em função do número de nós.

A aproximação matemática para a estimativa dos tempos de cálculo e comunicação apresentou-se como uma ferramenta útil, apresentando erros toleráveis em relação aos tempos correspondentes medidos, tanto para as topologias $n_{x} \mathrm{x} 1$ e 1 x $n_{y}$ quanto para as topologias $n_{x} \mathrm{x} n_{y}$. O uso desta ferramenta para a determinação do número de nós a serem utilizados num processamento de forma a obter o menor tempo total possível na simulação também foi aprovado.

Os resultados do estudo sobre a aplicação prática, para a demonstração da aplicação da ferramenta na análise de problemas de eletromagnetismo, apresentaram-se 
qualitativamente coerentes com os esperados. Conclui-se, então, que a ferramenta é aplicável ao fim desejado.

Como continuidade ao trabalho, pretende-se, gradativamente, realizar complementações no programa, como a maior facilidade de especificação da geometria por um usuário, estender o código para a obtenção de outras grandezas físicas a partir dos campos eletromagnéticos encontrados, realizar aplicações da ferramenta em casos práticos diversos e, conforme conveniente, disponibilizar a ferramenta para que outros possam também utilizá-la.

Por fim, e em resumo, o processamento paralelo de métodos numéricos apresentase como uma ferramenta que procura agregar os recursos tecnológicos computacionais "distribuídos" disponíveis para aumentar as potencialidades de simulação de problemas que necessitam de considerável refinamento, devido à alta quantidade de detalhes presente, em especial aqueles da área de eletromagnetismo, por sua natural complexidade. 


\section{Referências Bibliográficas}

[1] K. S. Yee, "Numerical Solution of Initial Boundary Value Problems Involving Maxwell's Equations in Isotropic Media," IEEE Transactions on Antennas and Propagation, vol. vol. AP-14, no. 3, pp. 302-307, may 1966.

[2] D. M. Sullivan, Electromagnetic Simulation Using the FDTD Method. New York: IEEE Press Series on RF and Microwave Technology, 2000.

[3] M. N. O. Sadiku, Numerical Techniques in Electromagnetics, 2nd ed. Boca Raton: CRC Press, 2001.

[4] A. Taflove and S. C. Hagness, Computation Electrodynamics; the finitedifference time-domain method, 2nd ed. Norwood: Artech House, Inc, 2000.

[5] C. Wu, K. Wu, Z. Bi, and J. Litva, "Accurate Characterization of Planar Printed Antennas Using Finite-Difference Time-Domain Method," IEEE Transactions on Antennas and Propagation, vol. vol. 40, pp. 526-534, May 1992, issue 5.

[6] A. C. Pavão, "Cavidades carregadas - estudo da pertubação dos campos eletromagnéticos," Ph.D. dissertation, Escola Politécnica da Universidade de São Paulo, 2004.

[7] G. D. Kondylis, F. Falaviis, G. J. Pottie, and T. Itoh, "A Memory-Efficient Formulation of the Finite-Difference Time-Domain Method for the Solution of Maxwell Equations," IEEE Transactions on Microwave Theory and Techniques, vol. vol. 49, no. 7, pp. 1310-1320, July 2001. 
[8] Y. S. Rickard and W. P. H. N. K. Georgieva, "Application and Optimization of PML ABC for the 3D Wave Equation in the Time Domain," IEEE Transactions on Antennas and Propagation, vol. vol. 51, no. 2, pp. 286-295, February 2003.

[9] W. P. Pala, A. Taflove, M. J. Piket, and R. M. Joseph, "Parallel finite-difference time-domain calculations," IEEE International Conference on Computation in Electromagnetics, pp. 83-85, 1991.

[10] T. Sterling, D. Becker, M. Warren, T. Cwik, J. Slamon, and B. Nitzberg, "An assessment of Beowulf-class computing for NASA requirements: initial findings from the first NASA workshop on Beowulf-class clustered computing," IEEE Aerospace Conference. Proceedings., pp. 367-381, March 1998.

[11] P. H. Carns, W. B. Ligon, S. P. Mcmillan, and R. B. Ross, "An evaluation of message passing implementations on Beowulf workstations," IEEE Aerospace Conference. Proceedings., pp. 41-54, March 1999.

[12] D. P. Rodohan and S. R. Saunders, "Parallel Implementation of the Finite Difference Time Domain (FDTD) Method," IEEE Second International Conference on Computation in Electromagnetics, pp. 367-370, 1994.

[13] D. P. Rodohan, S. R. Saunders, and R. J. Glover, "A Distributed Implementation of the Finite Difference Time-Domain (FDTD) Method," IEEE International Journal of Numerical Modelling: Electronic Networks, Devices and Fields, vol. vol. 8, pp. 283-291, 1995.

[14] G. A. Schiavone, I. Codreanu, R. Palaniappan, and P. Wahid, "FDTD Speedups Obtained in Distributed Computing on a Linux Workstation Cluster," IEEE Antennas and Propagation Society International Symposium, vol. vol. 3, pp. 1336-1339, july 2000.

[15] J. Forenc and A. Skorek, "Analysis of High Frequency Electromagnetic Wave 
Propagation Using Parallel MIMD Computer and Cluster System," International Conference on Parallel Computing in Electrical Engineering. PARELEC 2000. Proceedings., pp. 176-180, august 2000.

[16] M. Sypniewski, J. Rudnicki, and M. C. Marcysiak, "Investigation of Multithread FDTD Schemes for Faster Analysis on Multiprocessor PCs," IEEE Antennas and Propagation Society International Symposium, vol. vol. 1, pp. 252-255, July 2000.

[17] N. Tadaka, T. Ito, K. Motojima, M. Ideo, T. Sato, and S. Kozaki, "The highspeed computation on a distribuited personal computer network by our distributed FDTD method," Microwave Conference, pp. 273-276, December 2000.

[18] E. N. Szynkiewicz and A. Sikora, "Algorithms for Distribuited Simulation Comparative Study," IEEE Proceedings of the International Conference on Parallel Computing in Electrical Engineering (PARALEC'02), pp. 261-266, September 2002.

[19] B. Butrylo, C. Vollaire, and L. Nicolas, "Parallel implementation of the vector finite element and finite difference time domain methods," IEEE Proceedings of the International Conference on Parallel Computing in Electrical Engineering (PARELEC'02), 2002.

[20] C. Guiffaut and K. Mahdjoubi, "A Parallel FDTD Algorithm Using the MPI Library," IEEE Antennas and Propagation Magazine, vol. 43, no. 2, pp. 94-103, April 2001.

[21] H. Rogier, D. Zutter, and F. Olyslager, "A parallel implementation of the hybrid FDTD-BIE technique," IEEE Antennas and Propagation Society International Symposium, pp. 224-227, july 2000.

[22] L. Yin, X. Yin, and W. Hong, "Domain Decomposition Method for the Solution 
of Electromagnetic Field Penetration Problems," IEEE Antennas and Propagation Society International Symposium, vol. vol. 1, pp. 42-45, July 2000.

[23] D. Yang, C. Liao, L. Jen, and J. Xiong, "A parallel FDTD algorithm based on domain decomposition method using the MPI library," Proceedings of the Fourth International Conference on Parallel and Distributed Computing, pp. 730-733, August 2003.

[24] C. Trinitis, M. Eberl, and W. Karl, "Numerical Calculation of Electromagnetic Problems on an SCI Based PC Cluster," International Conference on Parallel Computing in Electrical Engineering, 2000. PARELEC 2000. Proceedings., pp. 166-170, August 2000.

[25] C. T. Kelley, D. L. Woolard, P. Zhao, M. Kerr, and M. I. Lasater, "ParallelPlatform Based Numerical Simulation of Instabilities in Nanoscale Tunneling Devices," IEEE-NANO 2002. Proceedings of the 2002 2nd IEEE Conference on Nanotechnology, pp. 417-420, August 2002.

[26] T. Watanabe, H. Asai, T. Sasaki, and K. Araki, "Parallel-distributed FDTDbased full-wave simulator for large-scale printed wiring boards," Electrical Performance of Electronic Packaging, pp. 287-290, October 2002.

[27] M. P. Trevizan and J. M. Janiszewski, "An efficient use of the FDTD method with parallel processing for accurate analysis of electromagnetic fields," $M O$ MAG 2006, August 2006.

[28] W. Yuan and E. Li, "Analysis of signal propagation in high-speed differential signal lines with full-wave time-domain technique," IEEE International Symposium on Electromagnetic Compatibility, vol. vol. 2, pp. 1004-1009, 2002.

[29] T. T. Le and J. Rejeb, "Performance of parallel logic event simulation on PC- 
cluster," 7th Symposium on Parallel Architectures, Algotithms and Networks. Proceedings., pp. 434-438, May 2004.

[30] P. P. M. So, C. Eswarappa, and W. J. R. Hoeffer, "Parallel and Distributed TLM Computation with Signal Processing for Electromagnetic Field Modelling," International Journal of Numerical Modelling: Electronic Networks, Devices and Fields, vol. vol. 8, pp. 169-185, November 1995.

[31] W. Walendziuk, A. Jordan, and A. Skorek, "Visualization of the parallel finitedifference time-domain method computation results," IEEE International Conference on Parallel Computing in Electrical Engineering. PARALEC 2004, pp. 152-155, 2004.

[32] J. Mache, “An assessment of Gigabit Ethernet as cluster interconnect," 1st IEEE Computer Society International Workshop on Cluster Computing, pp. 36-42, December 1999.

[33] F. L. Teixeira, "Time-domain computational electromagnetics: FDTD and FETD methods," MOMAG 2006 - Short Course, August 2006.

[34] The GNU C Library, 1994, accessible in http://wwwwbs.cs.tu-berlin.de/user-taipan/kraxel/gnuinfo/libc/Top.html.

[35] Howto: set up ssh keys, Paul Keck, 2001, accessible in http://www.arches.uga.edu/ pkeck/ssh/.

[36] LAM/MPI Parallel Computing, Lam-Mpi.org, 2006, accessible in http://www.lam-mpi.org.

[37] IBM Parallel Environment for AIX 5L - MPI Subroutine Reference, IBM Corporation, 2005, downloadable from http://www.nersc.gov/vendor_docs/ibm/pdf/am107002.pdf. 